\title{
Dynamic Processes on Gold-Based Catalysts Followed by Environmental Microscopies
}

\author{
Eric Genty ${ }^{1, *}$, Luc Jacobs ${ }^{1}$, Thierry Visart de Bocarmé ${ }^{1,2, *}$ and Cédric Barroo ${ }^{1,2}$ \\ 1 Chemical Physics of Materials and Catalysis, Université libre de Bruxelles, CP243, 1050 Brussels, Belgium; \\ lucjacob@ulb.ac.be (L.J.); cbarroo@ulb.ac.be (C.B.) \\ 2 Interdisciplinary Center for Nonlinear Phenomena and Complex Systems (CENOLI), Université libre de \\ Bruxelles, 1050 Brussels, Belgium \\ * Correspondence: eric.genty@ulb.ac.be (E.G.); tvisart@ulb.ac.be (T.V.d.B.); Tel.: +32-2-650-5711 (E.G.); \\ +32-2-650-5724 (T.V.d.B.)
}

Academic Editors: Leonarda F. Liotta and Salvatore Scirè

Received: 30 March 2017; Accepted: 20 April 2017; Published: 1 May 2017

\begin{abstract}
Since the early discovery of the catalytic activity of gold at low temperature, there has been a growing interest in $\mathrm{Au}$ and $\mathrm{Au}$-based catalysis for a new class of applications. The complexity of the catalysts currently used ranges from single crystal to 3D structured materials. To improve the efficiency of such catalysts, a better understanding of the catalytic process is required, from both the kinetic and material viewpoints. The understanding of such processes can be achieved using environmental imaging techniques allowing the observation of catalytic processes under reaction conditions, so as to study the systems in conditions as close as possible to industrial conditions. This review focuses on the description of catalytic processes occurring on Au-based catalysts with selected in situ imaging techniques, i.e., PEEM/LEEM, FIM/FEM and E-TEM, allowing a wide range of pressure and material complexity to be covered. These techniques, among others, are applied to unravel the presence of spatiotemporal behaviours, study mass transport and phase separation, determine activation energies of elementary steps, observe the morphological changes of supported nanoparticles, and finally correlate the surface composition with the catalytic reactivity.
\end{abstract}

Keywords: gold catalysis; Au-based catalysts; environmental microscopies; in situ microscopies; surface science; FEM; FIM; PEEM; LEEM; E-TEM

\section{Introduction}

In the current technology era, an increasing amount of restrictions is imposed on industrial applications, e.g., fine chemical industry and automotive industry, to safeguard the environment. Moreover, the development of novel, economically cheap and green processes in the chemical industry requires the use of catalytic materials. According to the current estimations, the major part of chemical processes uses a catalytic substance in at least one of the production steps ( $90 \%$ of the processes). Among these, the dominant part uses heterogeneous catalytic materials (solid catalysts principally), while the homogeneous catalysts and biocatalysts are used in only $20 \%$ of the catalytic processes. One important and challenging role of any catalyst is to increase the selectivity towards the desired products. This is achieved by providing an alternative reaction pathway, of lower activation energy, for the reaction towards the desired products. In the specific case of heterogeneous catalysis, the materials used can be divided into two types: the noble-metal based catalysts (Rh, $\mathrm{Pd}, \mathrm{Pt}, \mathrm{Ru}, \mathrm{Au} . .$.$) supported$ on oxides $\left(\mathrm{Al}_{2} \mathrm{O}_{3}, \mathrm{ZrO}_{2}, \mathrm{CeO}_{2}, \mathrm{SiO}_{2}, \mathrm{TiO}_{2} \ldots\right)$ or zeolites [1-8]; and the metal-oxide catalysts [9-18]. Regarding the first class of catalytic materials, the deposition method of the active species, principally in case of noble metals, allows highly dispersed nanoparticles (NPs) to be obtained $[19,20]$ resulting in an important number of active sites available for catalytic reactions. These catalysts include mainly 
platinum, palladium and rhodium supported on oxide supports and play key roles in many important chemical processes. For instance, platinum-based catalysts are useful in hydro-treatment and complete oxidation processes, whereas palladium and rhodium are crucial components in the abatement of automotive emissions [20-23]. Indeed, the coexistence of these three noble metals in the catalytic converters corresponds to the optimum of catalytic activity at low temperature for the NOx selective catalytic reduction and $\mathrm{CO}$ and hydrocarbon oxidation reactions. One of the main problems during this process concerns the emissions of pollutants when the system has not reached its working temperature, also called cold start period. The majority of the emissions are produced after the starting of the vehicle engine when the temperature in the exhaust system is lower than $425 \mathrm{~K}$. For the catalytic oxidation of carbon monoxide, the Pd or Pt-based catalysts do not bring a total conversion at this temperature $[24,25]$. Understanding how the catalyst works in order to improve its catalytic activity at low temperature is thus of great importance. At the end of the 1980s, Haruta and co-workers showed an outstanding catalytic activity for the CO oxidation at low temperature $(200 \mathrm{~K})$ with the use of highly dispersed gold nanoparticles on reducible support. The deposition of nanoparticles with diameters of 2 to $5 \mathrm{~nm}$ on reducible support such as $\mathrm{Fe}_{2} \mathrm{O}_{3}, \mathrm{Co}_{3} \mathrm{O}_{4}$, and $\mathrm{NiO}$ exhibits the highest reactivity [26-29]. Together with the research performed by the Hutchings group on the hydro-chlorination of acetylene, Haruta's discovery triggered a great scientific interest for catalysis by gold [30-32]. This is shown in Figure 1 representing the growing trend in term of publications per year involving gold-based catalytic materials and the use of environmental microscopies.

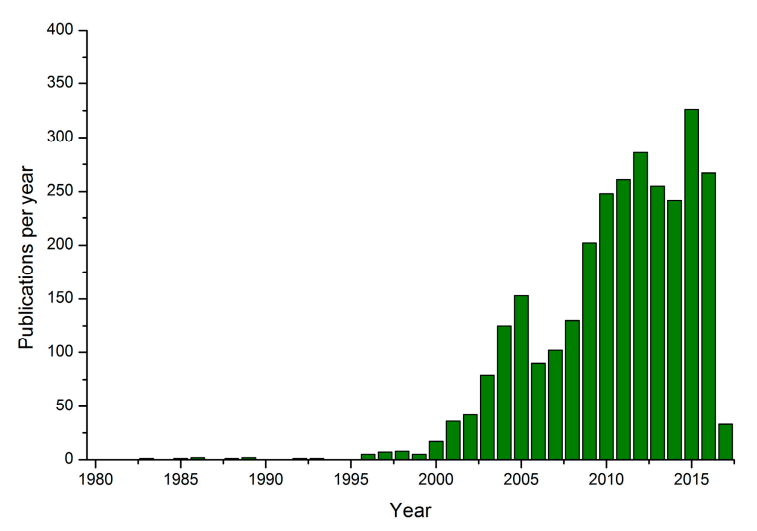

Figure 1. Increasing number of published papers from 1980 to 2017 in the Scopus Scholar database using "gold-based catalysts" and "environmental microscopy" as search keywords (March 2017).

Regarding the evolution of the number of studies using gold-based catalysts, the major part of the scientific publications concern the methods used for the deposition of gold nanoparticles with very narrow and well-defined sizes [33-47]. Besides conflicting papers on the influence of the support materials, the effect of the size on the reactivity of gold catalysts for environmental reactions is well established. The small size of gold nanoparticles induces a modification of the electronic structure of these nanoparticles. In addition to this, a decreased size of the particles increases the dispersion, and accordingly the number of edges and kinks on the metallic particles: such highly uncoordinated surface sites could correspond to the preferential adsorption sites, and their increasing number could then be responsible for the increasing reactivity of the catalytic materials. During the last decade, the research on catalytic materials with gold mainly focuses on the development of bimetallic gold-based catalysts [48-52]. Indeed, the use of bimetallic catalysts allows, to some extent, the size sensitivity of gold catalysts to be diminished. Moreover, the metal particles composed of two metallic components can be used to obtain different and improved catalytic properties as compared to the monometallic catalysts. These new properties are principally due to the synergistic effects between the two metals. Moreover, the catalytic reactivity of the bimetallic particles can be influenced by their structure, the atoms of the nanoparticles can be organised as solid solutions or core-shell 
structures [51,53-55]. Furthermore, the studies are also focused on the development of synthesis methodologies for the size of the gold nanoparticles deposited on catalytic supports or stabilized in solution [56-59]. The functionalisation of the nanoparticles in solution are mainly used for solid-liquid heterogeneous catalysis [60-62]. Others studies are reported on the immobilisation of enzyme on the gold nanoparticles by the stabilisation of these NPs with $\pi$-conjugated dithiol ligands for biocatalytic applications [63-67].

In order to understand the influence of parameters such as the size, the chemical composition or the crystallographic structure of the nanoparticles on the reactivity, the use of environmental microscopy techniques brings outstanding new viewpoints on this catalysis. The development and use of environmental microscopies enables the influence of different atmospheres on the behaviour of the catalytic phase to be analysed. The variety of these techniques makes possible the observation of either the evolution of the active phase or the evolution of the catalytic material at different scales (from $\mathrm{nm}$ to $\mathrm{mm}$ ) and under reaction pressures ranging from $10^{-6}$ to $10^{5} \mathrm{~Pa}$. This review is divided in two parts. The first one concerns the description of the principal environmental microscopies commonly used to study catalytic systems. The second part of this review presents the selected case studies of gold or gold-based catalysts with these environmental microscopy techniques. The main techniques used in these studies and presented in this contribution are Photoemission Electron Microscopy (PEEM), Low-Energy Electron Microscopy (LEEM), Field Ion Microscopy/Field Emission Microscopy (FIM/FEM) and Environmental Transmission Electron Microscopy (E-TEM).

\section{Environmental Microscopies}

Since the early developments of Ultra-High Vacuum (UHV) techniques, many research groups studied model surfaces following the so-called "surface science approach" [68-73]. In this way, the surface structure and their chemical composition can be routinely analysed with high-resolution, providing a better insight into fundamental surface chemistry phenomena. The control and the systematic study of the parameters related to the substrate (crystallographic orientation, density of surface defects, size effect...) is of great importance to get a better understanding of the elementary steps of surface reactions [74]. However, a fundamental problem arises considering the extrapolation of the obtained results towards studies with the applied formulation of catalysts used in industrial conditions. This issue of different working conditions i.e., low pressures and well characterised model surfaces as compared to high pressures and complex formulation of catalysts, is known as the "pressure and materials gap" [75]. Bridging the materials gap can be achieved by using samples with increasing complexity, as illustrated in Figure 2. It then becomes possible to work with samples that approach closely the complexity of industrial catalysts in terms of size, structure and presence of support.

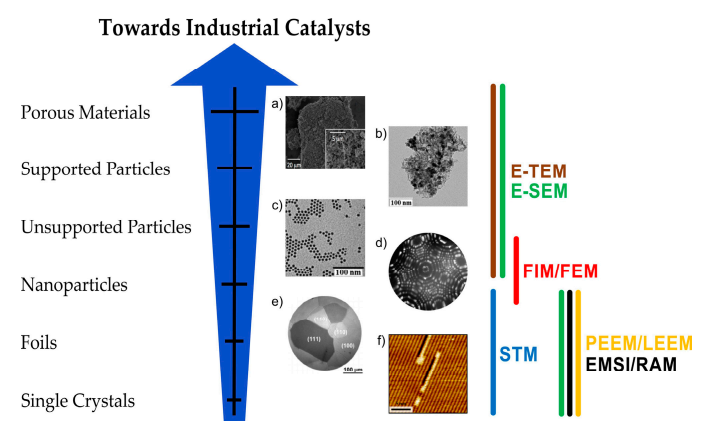

Figure 2. Schematic representation of catalysts samples of increasing complexity studied by different environmental microscopy techniques allowing the materials gap to be bridged. (a) Reproduced from [76]. Copyright 2015, MDPI; (b) and (c) Adapted with permission from [77]. Copyright 2016, American Chemical Society; (d) Reprinted from [78]. Copyright 2015, Springer; (e) Adapted with permission from [79,80]. Copyright 2013, American Chemical Society; (f) Reproduced from [80]. Copyright 2016, Macmillan Publishers Ltd. 
In the mid 50s, the importance of studying catalysts in their catalytically active state has already been underlined. Classical microscopy and spectroscopy techniques operate under UHV conditions because of the working principle of the techniques, but also to avoid misinterpretations of the collected data due to the presence of residual gases [81]. During the past decades, major breakthroughs were achieved in the development of surface sensitive analysis techniques working at higher pressures, thereby largely reducing the pressure gap [82], without excessive loss on the lateral resolution [81]. The combination of these techniques with in situ measurements makes them relevant and essential in the field of catalysis.

To study the catalytic systems in details, different samples with a large variety of morphological features, sizes and shapes can be used, as described in Figure 2. Therefore, the use of adapted analysis techniques becomes necessary. The techniques or combination of techniques must be able to resolve structural properties at different levels. As an example, for the analysis of single nanoparticles, atomic resolution is necessary, whereas for studies on foils, the catalytic behaviour can be studied at the mesoscale where the difference in reactivity between crystallographic planes of a few tens of $\mu \mathrm{m}$ may be sufficient. To further explain this idea, Table 1 gathers the basic principles, capabilities and main applications in catalysis of environmental microscopy techniques, e.g., FIM/FEM (Field Ion Microscopy/Field Emission Microscopy), PEEM/LEEM (Photoemission Electron Microscopy/Low-Energy Electron Microscopy), E-SEM (Environmental Scanning Electron Microscopy), E-TEM (Environmental Transmission Electron Microscopy), EMSI/RAM (Ellipso-Microscopy for Surface Imaging and Reflection Anisotropy Microscopy) and STM (Scanning Tunnelling Microscopy). Figure 3 represents the approximate pressure domain of applicability and the size of the resolvable features in the presence of a reactive gas phase.

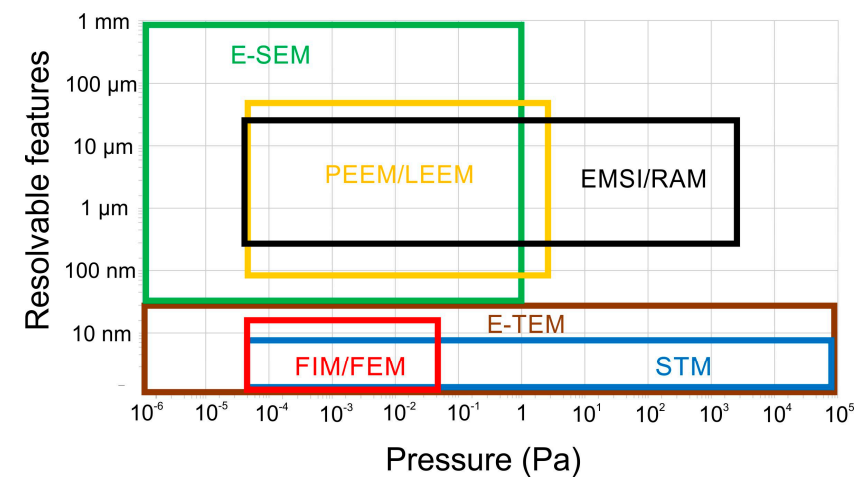

Figure 3. Application domains of different environmental microscopy techniques in terms of resolvable features and gas pressure permitted in the system under reaction conditions (see Table 1 for a detailed description of the techniques).

\subsection{Environmental Microscopies in Catalysis}

In the catalysis field, research mainly focuses on two different aspects: from the catalytic reaction point of view and from the catalyst point of view. The first one aims to resolve the mechanism of reaction by determining the presence of intermediate species, kinetic parameters, or the presence of specific dynamics in the system [83]. The second one focuses on the catalytic materials and their evolution during the reaction, for example the presence of surface reconstructions, segregations, sintering... [84,85]. These problems are difficult to tackle with classical microscopies working under UHV conditions, where the samples are typically characterised before and after reaction. Therefore, the presence of transient reconstruction or transient dynamics cannot be probed under UHV conditions. To some extent, environmental microscopies bring solutions as the sample imaging occurs in the presence of a reactive atmosphere. Either the chamber of the microscope is designed for in situ experiments, or special sample holders are adapted to allow in situ characterisations within a conventional microscope [86]. 
Table 1. General description of the main relevant environmental microscopy techniques used for catalysis applications, together with their advantages, inconvenient, and domains of applications in catalysis.

\begin{tabular}{|c|c|c|c|c|c|}
\hline Techniques & Description & Advantage & Inconvenient & Applications in Catalysis & References \\
\hline $\begin{array}{l}\text { Field Ion Microscopy } \\
\text { (FIM) }\end{array}$ & $\begin{array}{l}\text { - Field ionisation of imaging gas } \\
\text { - Resolution: } 2 \AA \\
\text { - Pressure: up to } 10^{-2} \mathrm{~Pa} \\
\text { - Samples: prepared as tips modelling a } \\
\text { single nanoparticle (15-100 nm diameter) }\end{array}$ & $\begin{array}{l}\text { - Direct imaging } \\
\text { - Atomic resolution } \\
\text { - Possible coupling with } \\
\text { mass spectrometry }\end{array}$ & $\begin{array}{l}\text { - Limited to conductive samples } \\
\text { - Presence of an electric field } \\
\text { - Limited pressure }\end{array}$ & $\begin{array}{l}\text { - Surface structure and reconstruction } \\
\text { - Spatial and temporal } \\
\text { reaction dynamics } \\
\text { - Structure/reactivity influence } \\
\text { - Diffusion/front propagation }\end{array}$ & [87-93] \\
\hline $\begin{array}{l}\text { Field Emission } \\
\text { Microscopy (FEM) }\end{array}$ & $\begin{array}{l}\text { - Field emission of surface electrons } \\
\text { - Resolution: } 15 \AA \\
\text { - Pressure: up to } 10^{-2} \mathrm{~Pa} \\
\text { - Samples: prepared as tips modelling a } \\
\text { single nanoparticle }\end{array}$ & $\begin{array}{l}\text { - Direct imaging } \\
\text { - Possible coupling with } \\
\text { mass spectrometry } \\
\text { - Great variety of gases }\end{array}$ & $\begin{array}{l}\text { - Limited to conductive samples } \\
\text { - Presence of an electric field } \\
\text { - Limited pressure }\end{array}$ & $\begin{array}{l}\text { - Spatial and temporal } \\
\text { reaction dynamics } \\
\text { - Structure/reactivity influence } \\
\text { - Diffusion/front propagation } \\
\text { - Local activity } \\
\text { - Non-linear behaviour }\end{array}$ & [94-98] \\
\hline $\begin{array}{l}\text { Photoemission electron } \\
\text { microscopy (PEEM) }\end{array}$ & $\begin{array}{l}\text { - Photoemission of surface electrons } \\
\text { - Resolution: } 50 \mathrm{~nm} \\
\text { - Pressure: up to } 10^{-1} \mathrm{~Pa} \\
\text { - Samples: single crystals, foils, } \\
\text { micro composites }\end{array}$ & $\begin{array}{l}\text { - Direct imaging } \\
\text { - Non-destructive } \\
\text { - Possible coupling with } \\
\text { mass spectrometry }\end{array}$ & - Limited to flat samples & $\begin{array}{l}\text { - Spatial and temporal } \\
\text { reaction dynamics } \\
\text { - Diffusion and front propagation } \\
\text { - Structure and reactivity dependence } \\
\text { - Determination of active sites }\end{array}$ & {$[89,99-104]$} \\
\hline $\begin{array}{l}\text { Low energy electron } \\
\text { microscopy (LEEM) }\end{array}$ & $\begin{array}{l}\text { - Reflection of backscattered low } \\
\text { energy electrons } \\
\text { - Resolution: } 2-10 \mathrm{~nm} \\
\text { - Pressure: up to } 10^{-2} \mathrm{~Pa} \\
\text { - Samples: single crystals, foils, } \\
\text { micro composites }\end{array}$ & $\begin{array}{l}\text { - Tuneable probing depth } \\
\text { - Combination with LEED } \\
\text { (Low Energy } \\
\text { Electron Diffraction) }\end{array}$ & $\begin{array}{l}\text { - Limited to flat samples } \\
\text { - Limited pressure }\end{array}$ & $\begin{array}{l}\text { - Surface structure and reconstruction } \\
\text { - Film growth } \\
\text { - Phase transitions } \\
\text { - Reaction dynamics } \\
\text { - Front propagation }\end{array}$ & {$[102,105-111]$} \\
\hline $\begin{array}{l}\text { Environmental scanning } \\
\text { electron microscopy } \\
\text { (E-SEM) }\end{array}$ & $\begin{array}{l}\text { - Detection of secondary and } \\
\text { backscattered electrons } \\
\text { - Resolution: } 5 \mathrm{~nm} \\
\text { - Pressure: up to } 1000 \mathrm{~Pa} \\
\text { - Samples: porous materials, } \\
\text { supported nanoparticles }\end{array}$ & $\begin{array}{l}\text { - Variable pressure (VP-SEM) } \\
\text { - Operational at } \\
\text { high pressures }\end{array}$ & $\begin{array}{l}\text { - Conductive samples } \\
\text { - Time resolution } \\
\text { (scanning method) } \\
\text { - Nature of gases }\end{array}$ & $\begin{array}{l}\text { - Surface structure } \\
\text { - Surface composition } \\
\text { - Local activity }\end{array}$ & {$[74,112]$} \\
\hline $\begin{array}{l}\text { Environmental } \\
\text { transmission electron } \\
\text { microscopy (E-TEM) }\end{array}$ & $\begin{array}{l}\text { - Detection of transmitted electrons } \\
\text { - Resolution: } 2 \AA \\
\text { - Pressure: up to } 10^{5} \mathrm{~Pa} \\
\text { - Samples: porous materials, supported } \\
\text { nanoparticles, unsupported nanoparticles }\end{array}$ & $\begin{array}{l}\text { - Direct imaging } \\
\text { - Reaction cells } \\
\text { - Combination with } \\
\text { diffraction and spectroscopy }\end{array}$ & $\begin{array}{l}\text { - Thickness of samples } \\
\text { - Beam damage } \\
\text { - Data treatment }\end{array}$ & $\begin{array}{l}\text { - Surface structure and reconstruction } \\
\text { - Growth studies of } \\
\text { nanostructured materials } \\
\text { - Chemical composition changes } \\
\text { - Atomic diffusion }\end{array}$ & [113-120] \\
\hline
\end{tabular}


Table 1. Cont

\begin{tabular}{|c|c|c|c|c|c|}
\hline Techniques & Description & Advantage & Inconvenient & Applications in Catalysis & References \\
\hline $\begin{array}{l}\text { Ellipsomicroscopy for } \\
\text { surface imaging (EMSI) }\end{array}$ & $\begin{array}{l}\text { - Variations of the surface } \\
\text { ellipsometric parameters } \\
\text { - Resolution: } 20 \mu \mathrm{m} \\
\text { - Pressure: up to } 10^{-1} \mathrm{~Pa} \\
\text { - Samples: single crystals, foils }\end{array}$ & $\begin{array}{l}\text { - Wide range of pressures } \\
\text { (UHV to ambient) }\end{array}$ & $\begin{array}{l}\text { - Light source } \\
\text { - Height sensitivity }\end{array}$ & $\begin{array}{l}\text { - Thickness of adsorbate layers, } \\
\text { - Chemical composition } \\
\text { - Surface structure } \\
\text { - Diffusion } \\
\text { - Spatial and temporal } \\
\text { reaction dynamics }\end{array}$ & {$[69,71,103,121]$} \\
\hline $\begin{array}{l}\text { Reflection anisotropy } \\
\text { microscopy (RAM) }\end{array}$ & $\begin{array}{l}\text { - Local variations of anisotropy } \\
\text { - Resolution: } 10 \mu \mathrm{m} \\
\text { - Pressure: up to } 10^{-2} \mathrm{~Pa} \\
\text { - Samples: single crystals, foils }\end{array}$ & $\begin{array}{l}\text { - Wide range of pressures } \\
\text { (UHV to ambient) }\end{array}$ & - Light source & $\begin{array}{l}\text { - Surface reconstructions } \\
\text { - Surface adsorption and } \\
\text { adsorption energies } \\
\text { - Diffusion } \\
\text { - Spatial and temporal } \\
\text { reaction dynamics }\end{array}$ & {$[69,103,121,122]$} \\
\hline $\begin{array}{l}\text { Scanning tunnelling } \\
\text { microscopy (STM) }\end{array}$ & $\begin{array}{l}\text { - Measurement of the tunnelling current } \\
\text { - Resolution: } 2 \AA \\
\text { - Pressure: up to } 10^{5} \mathrm{~Pa} \\
\text { - Samples: single crystals, } \\
\text { foils, nanoparticles }\end{array}$ & $\begin{array}{l}\text { - Atomic resolution } \\
\text { - Direct real space imaging } \\
\text { - Large surface analysed } \\
\text { - No pressure limit }\end{array}$ & $\begin{array}{l}\text { - Time resolution } \\
\text { (scanning method) } \\
\text { - Electric field }\end{array}$ & $\begin{array}{l}\text { - Atomic diffusion } \\
\text { - Surface structure } \\
\text { - Spatial reaction dynamics } \\
\text { - Determination of active sites }\end{array}$ & {$[70,73,123-128]$} \\
\hline
\end{tabular}




\subsection{Basic Principles of Relevant Techniques}

As stated in the introduction, this review will focus on the analysis of catalytic behaviours on three main family of techniques: Field Ion Microscopy/Field Emission Microscopy (FIM/FEM) to study the catalytic behaviour on a single nanoparticle, Photoemission Electron Microscopy/Low-Energy Electron Microscopy (PEEM/LEEM) to investigate catalytic processes on flat samples, and Environmental Transmission Electron Microscopy (E-TEM) allowing the analysis of unsupported, supported and self-supported catalysts. These techniques are described in more details in this section, together with striking examples on their possibilities.

\subsubsection{Field Emission Microscopy FEM/Field Ion Microscopy FIM}

Field emission techniques such as Field Emission Microscopy (FEM) and Field Ion Microscopy (FIM) are used to study samples prepared as sharp tips. The extremity of the tip-sample is a highly curved surface, which is a good model of a catalytic nanoparticle with a diameter of 20-100 nm [98,129]. Pure gold samples are routinely prepared by electrochemical etching of a gold wire using $\mathrm{KCN}$ solutions, but also in $\mathrm{CaCl}_{2}, \mathrm{NaCl}, \mathrm{KCl}$, and $\mathrm{H}_{2} \mathrm{SO}_{4}+\mathrm{HNO}_{3}$ solutions [130-134]. Alternatively, inert metallic tips such as tungsten can be prepared and then covered with a few atomic layers of $\mathrm{Au}$ by vacuum evaporation or laser deposition [135-137]. In the case of alloys, the samples are prepared either by electrochemical etching of the alloy wire [138], or by evaporation of the two metals followed by annealing to ensure the homogenisation of the alloy-layer [139].

Field emission techniques are not widely used these days as surface science techniques for catalysis applications, probably because of the scarcity of these instruments. However, the unique features of these techniques allow in situ catalytic studies in the presence of a reactive atmosphere as well as characterisation under high vacuum conditions, for pressures ranging from residual ones to $10^{-2} \mathrm{~Pa}$ and for cryogenic temperatures $(\approx 50 \mathrm{~K})$ to $\approx 900 \mathrm{~K}$. In FIM mode, the application of an electric field between the sample and the detector screen induces the process of field ionisation of an imaging gas. The ions are accelerated by the field towards the detector screen where image formation occurs. The micrographs provide the crystallographic surface structure of the sample, with an atomic lateral resolution, as seen in Figure 4a [140]. Atoms of the imaging gas are ionised over the most protruding atoms of the surface (kink and step sites). With this, a magnification of $10^{6}$ is typically obtained. The FIM images show an excellent agreement with a ball-model of a model hemisphere (Figure 4b). Morphological changes such as facetting or missing-row reconstructions can easily be imaged during their formation [98].

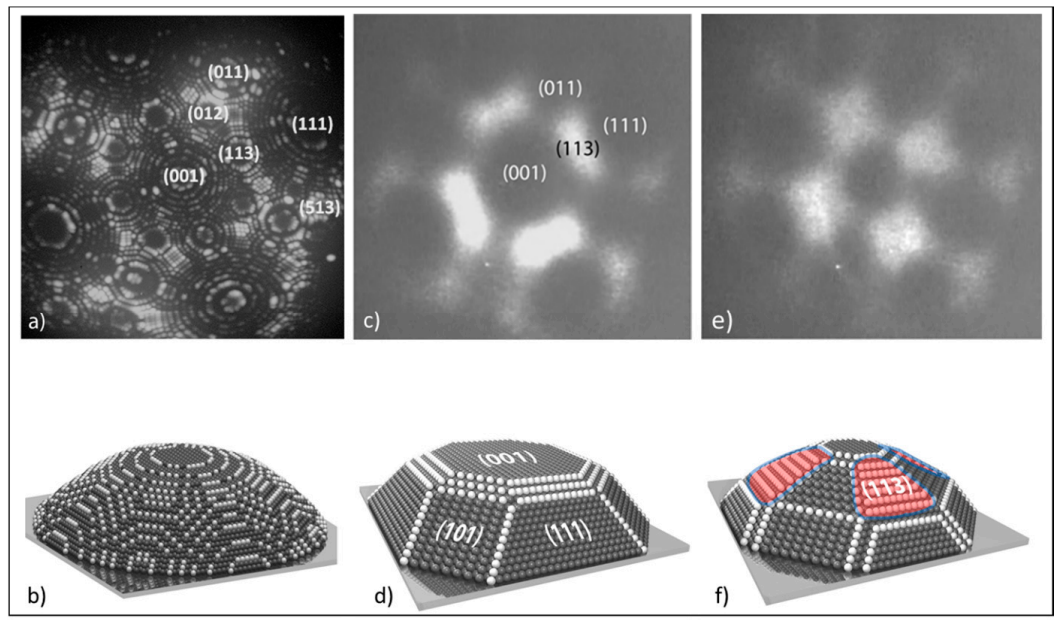

Figure 4. Analysis of surface reconstruction by FIM/FEM: (a) FIM micrograph of a Ni crystal tip and the corresponding Miller index annotations. The magnification corresponds to $\sim 10^{6}$ on a detector screen of 3 inches diameter. Conditions of acquisition: $T=61 \mathrm{~K}, F=3.5 \mathrm{~V} / \AA$; $(\mathbf{b})$ corresponding ball 
model where withe balls represent kink and step sites; (c) FEM micrograph of the same crystal under hydrogen atmosphere. Conditions of acquisition: $T=873 \mathrm{~K}, P_{\mathrm{H}_{2}}=1 \times 10^{-4} \mathrm{~Pa}$ illustrating the facetting process; (d) corresponding ball model of the facetted structure; (e) FEM micrograph of the crystal under $\mathrm{C}_{2} \mathrm{H}_{2}$ atmosphere. Conditions of acquisition: $T=873 \mathrm{~K}, P_{\text {tot }}=2.5 \times 10^{-4} \mathrm{~Pa}$; (f) schematic representation of the growth of the open (113)-facets. Adapted with permission from [140]. Copyright 2009, American Chemical Society.

In FEM mode, a negative polarisation of the sample as compared to the screen-detector initiates the emission of surface electrons, as can be observed in Figure 4c,e. The field emission depends on the work function of the crystallographic orientation of the facets. In Figure $4 c-f$, the work function variations and changes in morphology of the sample after the formation of extended facets can be followed during the early stages of C-nanotube formation on a Ni tip-sample. Since the work function depends on the presence of adsorbates, variations of the work function due to adsorption, dissociation or desorption of different chemical species lead to variations of the brightness pattern, allowing the presence of adsorbates to be followed, and therefore, the presence of specific dynamics at the surface [141].

Although field emission techniques have barely changed since their invention in the 1950s, they represent a powerful tool in surface science and heterogeneous catalysis. The unique possibility to image reaction dynamics make them a fruitful technique towards the understanding of fundamental phenomena occurring at the surface of catalytic particles. For example, processes such as nonlinear behaviour, surface explosions [142] or oscillations [143-146], but also reconstructions, morphology-reactivity relationship and diffusion [147] can be studied with these techniques. Moreover, these techniques can be coupled with mass spectrometry and are known as Pulsed Field Desorption Mass Spectrometry (PFDMS), or sometimes referred as the 1-Dimensional Atom Probe (1DAP) [140,148]. The general idea is to apply electric field pulses to the tip, with a specific frequency, so as to initiate field desorption of surface species. Desorbed species are analysed by time-of-flight mass spectrometry. By varying the pulsed frequency, it is possible to follow the evolution of chemical species during the progress of the reaction and to determine kinetic parameters. A similar concept is the base of the 3-Dimensional Atom Probe/Atom Probe Tomography (3DAP/APT) principle [149,150]. The main idea here is not to analyse the single layer of adsorbates, but rather the distribution and the nature of atoms within the sample [151]. The system is equipped with a position sensitive detector, allowing a tomographic reconstruction of the sample, to be obtained with atomic resolution in the $z$-direction, together with the chemical identification of the ions. Analysis of the surface segregation of catalytic nanoparticles following exposure to reactive gases $[85,88]$ is thus possible. It has to be noted that this technique requires UHV conditions. We also mention that the FEM/FIM instrument can be coupled with spectroscopy (Field Ion Appearance Energy Spectroscopy [152]).

\subsubsection{Photoemission Electron Microscopy PEEM/Low Energy Electron Microscopy LEEM}

Photoemission Electron Microscopy (PEEM) is based on the illumination of a sample with UV-light, and detection of the resulting photo-emitted electrons. The contrast arises from the local differences in the yield of electron-emission, which in turn depends on the local work function. As in the case of FEM, the local work function depends on the presence of adsorbed species. Qualitative measurements of adsorption and dissociation phenomena are thus possible [143,153]. Low Energy Electron Microscopy (LEEM) is based on the emission of electrons when the sample is exposed to a flux of low energy electrons. The impinging electrons give rise to the emission of backscattered electrons from the analysed surface allowing for real space imaging of the surface structure. By using the back focal plan as objective lens, it is easy to switch to diffraction mode and obtain diffraction patterns with the technique known as Low Energy Electron Diffraction (LEED). The contrast arises mostly from structural differences [105,154,155]. 
LEEM and PEEM are powerful tools to analyse numerous physical phenomena such as growth dynamics, the study of magnetic domains or adsorption processes, but they are not able to perform chemical characterisation. Because of the relatively low maximum pressures and resolution under in situ conditions, the use of PEEM as a surface science technique for catalysis applications is limited to a few studies such as the determination of diffusion coefficients, and some reactions on composite surfaces to study the synergy between heterogeneous domains [156]. Another well-known example is the formation of spatiotemporal patterns during the $\mathrm{CO}$ oxidation on Pt surfaces, as can be observed in Figure 5. Propagation fronts corresponding to different surface compositions are clearly discernible during in situ imaging. Indeed, the contrast is obtained via changes in the work function, which depends on the nature of the adsorbates. The work function is different in the presence of $\mathrm{O}$ (ads) or $\mathrm{CO}$ (ads), and the transitions from one domain of stability to another can be observed via the propagation of waves [157].
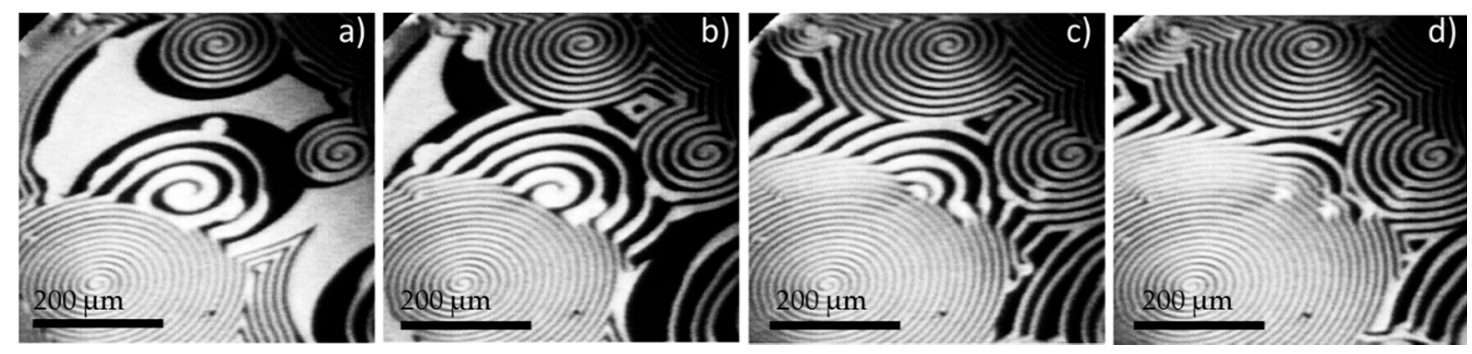

Figure 5. PEEM study of surface reaction and spatiotemporal patterns formation: Temporal evolution of diffusion patterns during the oxidation of $\mathrm{CO}$ on Pt surface. Conditions of acquisition: $\mathrm{T}=448 \mathrm{~K}$, $P_{\mathrm{O}_{2}}=4 \times 10^{-4} \mathrm{~Pa}, P_{\mathrm{CO}}=4.3 \times 10^{-3} \mathrm{~Pa}$. Reprinted from [158]. Copyright 1993, AIP Publishing.

One of the limitations of the PEEM is the lack of chemical information during imaging. However, by exploiting the synchrotron radiation, XPEEM (X-ray Photoemission Electron Microscopy) has been developed to image surfaces with chemical sensitivity. It is then possible to study the evolution of the surface composition during the ongoing processes [106,159]. PEEM can be combined with mass spectrometry to follow the global gas-phase composition during the catalytic reaction [160]. This permits catalytic activities of different catalytic materials to be compared with different crystallographic orientations [161]. Further improvements of the technique include the combination of PEEM with LEEM which add the structure sensitivity and diffraction to the capabilities of the PEEM instrument, and is known as SPELEEM (Spectroscopic Photoemission and Low-Energy Electron Microscope) [155,162-164]. The availability of XPEEM in synchrotron facilities increased the interest of this technique and derivate for catalysis applications.

Also, the samples used by PEEM techniques are single crystals, foils or composite surfaces. The deposition of homogeneous layers can be performed by evaporation, and the preparation of composite surfaces is done via lithography techniques.

\subsubsection{Environmental Transmission Electron Microscopy E-TEM}

Transmission Electron Microscopy (TEM) is widely used in the catalysis community to determine the structure, morphology and, with complimentary techniques, the chemical composition of materials used in catalysis $[82,165]$. Traditional TEM microscopes can be modified to respond to the latest demands in materials science and catalysis [82,165]. A critical step towards the development of microscopes operational at high pressures is the need to have high pressures of reactive gases around the sample and high vacuum conditions in the rest of the apparatus. For this, a specific design of the microscope can be used, or alternatively, specific sample holders that can be easily adapted on the non-environmental TEM are available $[166,167]$. This comes from the fact that it is strictly necessary to confine the gas atmosphere in the vicinity of the sample in order to avoid a reduction of the mean free 
path of the electrons altering of the results. The use of E-TEM allows studying materials with high resolution and in temperature and pressure conditions close to those used in applied formulations of catalysts. The resolution of the technique decreases with the temperature of the sample, but Au-based catalysts present the advantage of being active at relatively low temperature, enabling the study of catalysts under reactive environment without significant loss of spatial resolution. This allows transient phenomena to be imaged that may be of great importance to understand the catalytic processes.

In E-TEM mode, high energy transmitted electrons are detected after interacting with very thin samples to produce images in direct space [84]. E-TEM allows to follow changes of the catalyst, e.g., structure, size, sintering... [168], and complementary analyses can be performed by diffraction-or spectroscopic techniques-Energy Dispersive X-ray (EDX) and Electron Energy Loss Spectroscopy (EELS). EDX can give information about changes of the chemical composition of the sample due to phenomena like surface segregation [169], while EELS is used to determine the chemical composition of the system, as well as surface bonding properties [84,170,171]. Both EDX and EELS can achieve atomic resolution analysis with the new generations of TEM and under specific conditions. A relatively wide variety of samples can be analysed by TEM: supported or unsupported particles, powders, structured materials... [28,76] which makes this tool useful for catalysis studies. An example of the capabilities of the E-TEM are the morphological changes occurring on a nanoparticle of $\mathrm{Cu}$ (from $\mathrm{Cu} / \mathrm{ZnO}$ catalyst) under $\mathrm{H}_{2}$ and $\mathrm{H}_{2}+\mathrm{O}_{2}$ environments, as is presented in Figure 6 . Other processes such as particle growth due to sintering [86], as well as nanotube growth can also be followed. The parallel characterisation of the catalyst surface as well as the reactive gas phase under working conditions, allows conclusions to be drawn on the structure reactivity relationship of catalytic systems $[84,172]$.

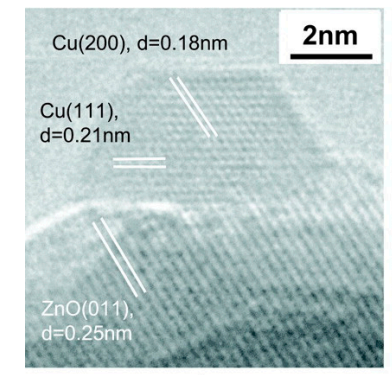

A

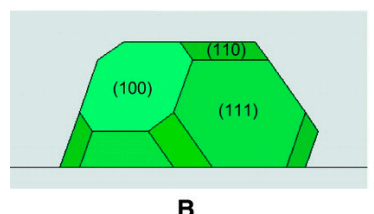

B

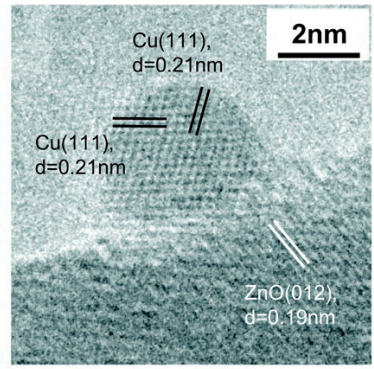

C

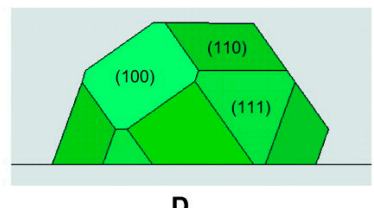

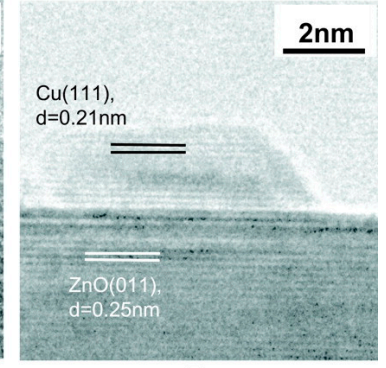

E

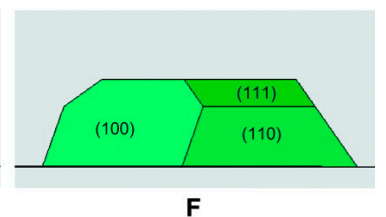

Figure 6. E-TEM analysis of catalyst reconstruction under reactive conditions: (A,C,E) Micrographs of $\mathrm{Cu}$ nanoparticles deposited on $\mathrm{ZnO}$ captured with in situ TEM analysis, $(\mathbf{B}, \mathbf{D}, \mathbf{F})$ together with their corresponding Wulff constructions illustrating the reactive gas phase induced shape transformations of the $\mathrm{Cu}$ nanoparticles. Conditions of acquisition: $T=493 \mathrm{~K},(\mathrm{~A}) P_{\mathrm{H}_{2}}=150 \mathrm{~Pa}$; (C) $P_{\text {tot }}=150 \mathrm{~Pa}$ with $P_{\mathrm{H}_{2}} / P_{\mathrm{O}_{2}}=3.1 ;(\mathrm{E}), P_{t o t}=500 \mathrm{~Pa}$ with $P_{\mathrm{H}_{2}} / P_{\mathrm{O}_{2}}=19.1$. Reprinted from [173]. Copyright 2002, AAAS.

\section{Case Studies}

This section is dedicated to an in-depth analysis of Au and Au-based catalytic systems imaged by PEEM/LEEM, FIM/FEM and E-TEM instruments. The combination of those three techniques covers a wide range of catalytic materials of increasing complexity, from single crystals to structured materials. Most of these studies are also combined with spectrometry/spectroscopy techniques to get a better insight of the systems, and are thus also discussed as a complement of the microscopic part of the studies. The remaining of this section is divided as follows: The first part is dedicated to the 
study of processes on single crystals by PEEM/LEEM. CO oxidation on Au-covered $\mathrm{Pt}$ is analysed by PEEM to highlight the presence of spatiotemporal behaviours; meanwhile the $\mathrm{O}_{2}+\mathrm{H}_{2}$ reaction is probed on Au- and $\mathrm{Au}+\mathrm{Pd}$-covered Rh by LEEM and XPEEM to study the mass transport occurring under reactive environment. The second part corresponds to the study of processes on a single grain of catalyst by FEM/FIM. This includes the FIM imaging of $\mathrm{CO} / \mathrm{O}_{2}$ interaction and water gas shift reaction on $\mathrm{Au}$ tips; the experimental determination of activation energies on the $\mathrm{H}_{2} \mathrm{O} / \mathrm{Au}$ system by FEM; and the study of NO adsorption and reduction on Au-Pd alloys by FEM, correlated with the Pd segregation studied by atom probe. The third part focuses on the study of processes on supported and self-supported catalysts by E-TEM. This comprises the study of dynamic behaviours occurring during $\mathrm{CO}$ oxidation on supported Au nanoparticles, i.e., the coalescence of nanoparticles, the morphological changes of both the catalyst and the support, as well as their correlation with the catalytic activity. The study of catalytic oxidations on nanoporous gold samples will also be addressed. Finally, the main conclusions are drawn.

\subsection{Study of Processes on Single Crystals by PEEM/LEEM}

The selected examples presented in this section will describe the presence of non-linear spatiotemporal behaviours on Au-covered Pt surfaces, as well as the observation of mass transport and phase separation on Au-covered Rh surfaces. Finally, the spectromicroscopy of a model water-gas shift catalyst is presented.

3.1.1. Processes on Au-Covered Pt Single Crystals: Influence of Au on the Presence of Kinetic Instabilities on $\mathrm{Pt}(110)$

The PEEM technique is particularly suited to study, at the mesoscale, how the reactivity of surfaces may be affected by the presence of adjacent areas with different reaction properties. CO oxidation over platinum surfaces has been extensively studied in in the past $[121,158,174-177]$ and consists of a solid base to study how the dynamics can be affected. For example, during $\mathrm{CO}$ oxidation on $\mathrm{Pt}(110)$, at a fixed temperature and oxygen $\left(\mathrm{O}_{2}\right)$ pressure, if the $\mathrm{CO}$ pressure is continuously increased, different dynamics are observed: a stable state covered by $\mathrm{O}(\mathrm{ads})$ species, an excitable state, and a stable state covered by $\mathrm{CO}(\mathrm{ads})$ species. The main feature of the excitable regime consists of the propagation of reaction-diffusion fronts, the presence of spiral waves and solitary waves [158]. The properties of these patterns are governed by parameters such as the sticking coefficient of both $\mathrm{O}_{2}$ and $\mathrm{CO}$, or the diffusion coefficients. The examples presented below will show how the spatiotemporal patterns occurring during $\mathrm{CO}$ oxidation are affected by the presence of $\mathrm{Au}$ at the surface at different coverages. The presence of gold is supposed to continuously affect the kinetic parameters; meanwhile the mesoscale homogeneity of the medium remains unaltered.

On bare $\mathrm{Pt}(110), \mathrm{CO}$ is oxidised to $\mathrm{CO}_{2}$, which is directly released in the gas phase. A reversible surface transformation $1 \times 1 \rightleftarrows 1 \times 2$ is driven by the $\mathrm{CO}$ coverage. The $\mathrm{O}_{2}$ sticking coefficient is higher on the $1 \times 1$ surface than on the $1 \times 2$ reconstructed surface, which is in turn responsible for the occurrence of kinetic instabilities for given values of the control parameters, i.e., temperature, $\mathrm{O}_{2}$ and $\mathrm{CO}$ pressures. These instabilities can be observed via the changes of the work function: $\phi$ is increased in the presence of $\mathrm{CO}(\mathrm{ads})$, and increased even more in the presence of $\mathrm{O}(\mathrm{ads})$ : O-covered regions thus appear dark and CO-covered regions appear grey.

The presence of deposited $\mathrm{Au}$ on $\mathrm{Pt}(110)$ surface affects the behaviour of CO oxidation [178-180]. Indeed, gold atoms cause a uniform modification of the kinetic parameters. The presence of Au locally inhibits the adsorption of $\mathrm{CO}$ by acting as a site blocker (but does not change its sticking coefficient); and inhibits the dissociative adsorption of $\mathrm{O}_{2}$, since it requires several neighbour Pt atoms for the dissociation to occur. According to the authors, the presence of Au does not affect the properties of neighbouring Pt atoms. For an Au-coverage of $0.05 \mathrm{ML}$ (monolayer), at the mesoscale, the gold atoms are uniformly distributed at the surface of $\mathrm{Pt}(110)$, and the properties of the spatiotemporal patterns are modified under reaction conditions. The main modifications are: (1) the excitable regime 
is reached at lower CO pressure; (2) the velocity of the front propagation is reduced, and (3) the density of nucleation centres for the formation of waves increases. This can be observed in Figure 7 corresponding to a sample with an Au-covered domain (left part) and a bare Pt domain (right part) at a fixed temperature and $\mathrm{O}_{2}$ pressure. In Figure $7 \mathrm{a}$, at low $\mathrm{CO}$ pressure, both domains are O-covered, represented by dark regions in the PEEM image. When the $\mathrm{CO}$ pressure is gradually increased, one can observe-in Figure $7 \mathrm{~b}, \mathrm{c}$ - the formation of $\mathrm{CO}$ domains of higher brightness on the Au-covered surface, but not on the bare Pt. In Figure 7d, spirals are formed on the Au-covered domains, and the emergence of $\mathrm{CO}$ domains on the $\mathrm{Pt}$ side is observed. The Figure 7e corresponds to a parametric region where both Au-covered and bare $\mathrm{Pt}$ are in a reactive state, but presenting different wavelengths. Finally, in Figure 7f, the Au-covered region is fully CO-covered, but $\mathrm{O}$-waves are still present on the $\mathrm{Pt}$ region.
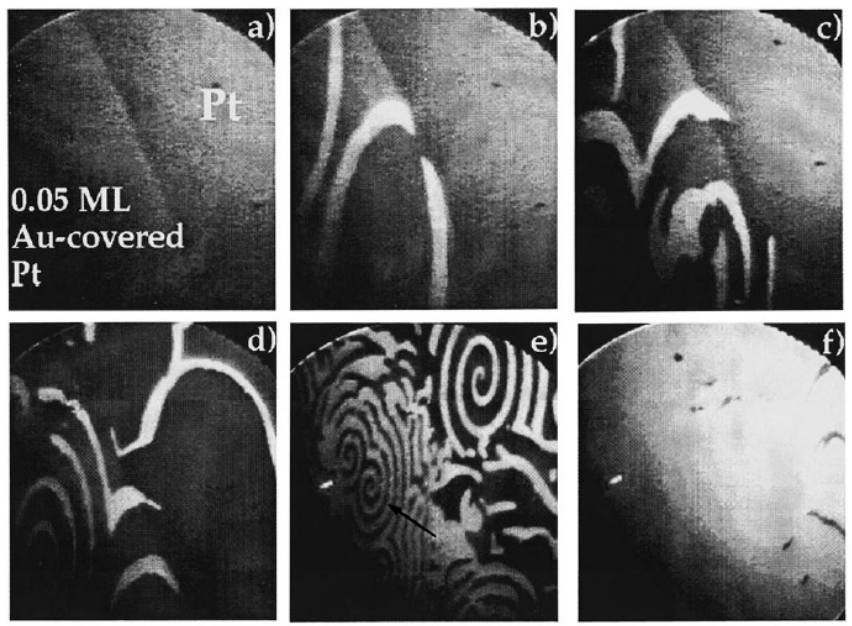

$\overleftrightarrow{100 \mu \mathrm{m}}$

Figure 7. Study of different reactive behaviours in the presence and absence of Au: PEEM snapshots during the $\mathrm{CO}$ oxidation on $0.05 \mathrm{ML}$ Au-covered $\mathrm{Pt}(110)$ adjacent to a bare $\mathrm{Pt}(110)$ area. Conditions of acquisition: $T=460 \mathrm{~K}, P_{\mathrm{O}_{2}}=4 \times 10^{-2} \mathrm{~Pa}$. The pressure is increased from (a) $P_{\mathrm{CO}}=1.0 \times 10^{-3} \mathrm{~Pa}$ : two regions in the $\mathrm{O}$-covered stable states; (b) $P_{\mathrm{CO}}=1.7 \times 10^{-3} \mathrm{~Pa}$ : formation of $\mathrm{CO}$ (ads) domains on the Au-covered side; (c) $P_{C O}=1.9 \times 10^{-3} \mathrm{~Pa}$ : formation of $\mathrm{CO}$ fronts nucleating by diffusion across the boundary; (d) $P_{C O}=3.0 \times 10^{-3} \mathrm{~Pa}$ : formation of spirals on the Au-covered domain and formation of fronts on the Pt domain; (e) $P_{C O}=4.65 \times 10^{-3}$ Pa: spiral patterns on both domains; (f) $P_{\mathrm{CO}}=5.0 \times 10^{-3} \mathrm{~Pa}$ : Au-covered domain fully covered by $\mathrm{CO}$ (ads) and presence of $\mathrm{O}$ (ads) waves on the Pt domain. Reprinted from [179], Copyright 1995, AIP Publishing.

As discussed, the presence of Au decreases the sticking probability of $\mathrm{O}_{2}$ at the surface and blocks, to a lesser extent, $\mathrm{CO}$ adsorption. Since the transition from the monostable O-covered region to an excitable regime is balanced by the coverage of $\mathrm{O}(\mathrm{ads})$ and $\mathrm{CO}(\mathrm{ads})$, the critical balance will be reached for a lower $\mathrm{CO}$ pressure, explaining the presence of different dynamics on Au-covered and bare Pt in Figure $7 \mathrm{~b}, \mathrm{c}$. The same explanation stands for the transition from excitable to monostable CO-covered presented in Figure $7 \mathrm{f}$ at higher $\mathrm{CO}$ pressure. Au atoms on Pt represent an obstacle for $\mathrm{CO}$ migration, with the direct effect of decreasing the $\mathrm{CO}$ diffusion coefficient. Therefore, the velocity of the front propagation is lower: $2.2 \mu \mathrm{m} / \mathrm{s}$ in the [110] direction on the Au-covered Pt as compared to $2.8 \mu \mathrm{m} / \mathrm{s}$ on bare Pt. This effect has been studied at different temperatures and shows the same trend of reduced velocity, as can be seen in Figure 8 .

There is a gradual decrease of the available area for gas adsorption while the Au coverage is increased, which further affects the local dynamics. The pressure range to observe patterns in excitable state becomes narrower with increasing Au coverage. For example, at a coverage of $0.3 \mathrm{ML}$, both $\mathrm{O}_{2}$ and $\mathrm{CO}$ adsorption is still possible, but the direct transition from O-covered to CO-covered is observed 
without any pattern formation. The effect of the presence of gold and the inhibition of reconstruction have to be accounted for in the full description of the catalytic system $[121,179,181]$. It can be concluded that surface inhomogeneities at the atomic scale affect the kinetic parameters averaged over mesoscopic length scale on which the surface still appears homogeneous [180].

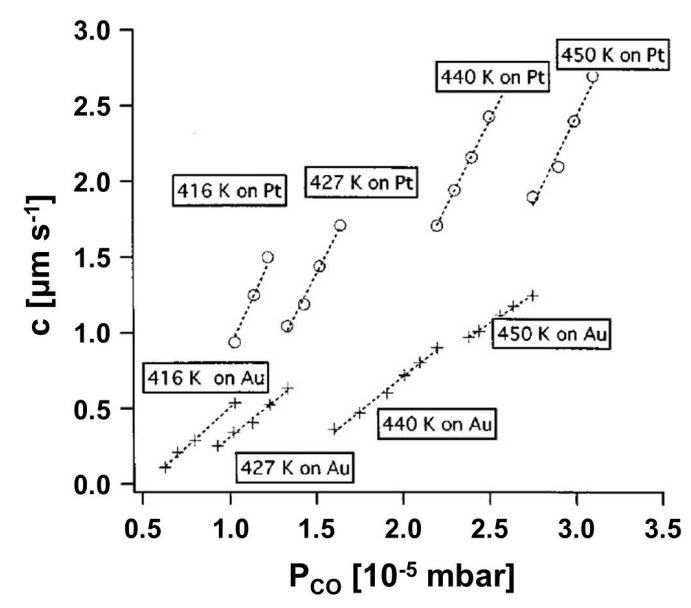

Figure 8. How the presence of $\mathrm{Au}$ atoms affects the kinetic parameters during $\mathrm{CO}$ oxidation on Pt: Propagation speeds for CO fronts on bare and 0.05 ML Au-covered $\mathrm{Pt}(110)$ as a function of CO pressure with a base oxygen pressure of $P_{\mathrm{O}_{2}}=4 \times 10^{-2} \mathrm{~Pa}$, at temperatures for conditions of dynamic bistability. This graph highlights the decrease of the $\mathrm{CO}$ diffusion coefficient due to the blocking effect of Au. Reprinted from [179], with the permission of AIP Publishing.

Another interesting effect observed in Figure 7c is the behaviour at the boundary. As a function of the pressure ratio, Au-covered and bare Pt domains present different regimes of stability and CO-waves produced in the Au-covered domain (1) cannot cross the border (the "forbidden area"); (2) can cross the border but are rapidly extinguished because of the $\mathrm{O}$ (ads) effect; or (3) can cross the border. The probability for the CO wave to cross the boundary obviously increases with higher $\mathrm{CO}$ pressures. It was noticed that there is a preferred creation of spirals at this boundary, which might be due to the higher density of defect sites acting as centres for nucleation.

\subsubsection{Processes on Au-Covered Rh Single Crystals}

The above described example mainly focused on the study from the viewpoint of the catalytic reaction. However, the catalytic system is in constant evolution and the catalyst may also undergo structural and compositional changes during the reaction. This can be probed by LEEM and XPEEM techniques as is it described below in the case of Au-covered Rh surfaces.

\section{Reaction-Induced Patterning of $\mathrm{Au} / \mathrm{Rh}(110)$ Surfaces}

In this work, Au was deposited on O-precovered $\mathrm{Rh}(110)$ surfaces [153,182], and then the $\mathrm{H}_{2}+\mathrm{O}_{2}$ reaction was monitored by LEEM. Characterisation of the sample proved that the $\mathrm{Au}$, with a coverage of $0.5 \mathrm{ML}$, is initially evenly distributed onto the Rh surface. The reaction between $\mathrm{H}_{2}$ and $\mathrm{O}_{2}$ on $\mathrm{Rh}$ forms water which desorbs immediately under the reaction conditions $(T=550 \mathrm{~K})$. Gold is chemically inert for the reaction and is thus used for its site-blocking effect. Starting from a homogeneously oxidised Au-covered surface, hydrogen is introduced in the chamber so as to ignite the formation of a reduction front. At this point, both $\mathrm{O}_{2}$ and $\mathrm{H}_{2}$ pressures are stabilised. Micro-XPS was used to obtain a quantitative chemical information of $\mathrm{Au}$ and $\mathrm{O}$ distribution, and the contrast variations observed in LEEM were in accordance with the Au $4 \mathrm{f}$ chemical maps. Therefore, LEEM was used to observe both the initiation of front propagation and the evolution of the surface under reaction conditions, as can be 
seen in Figure 9a where bright regions correspond to the reduced surface, dark regions to the oxidised surface, and grey regions to the initial surface.
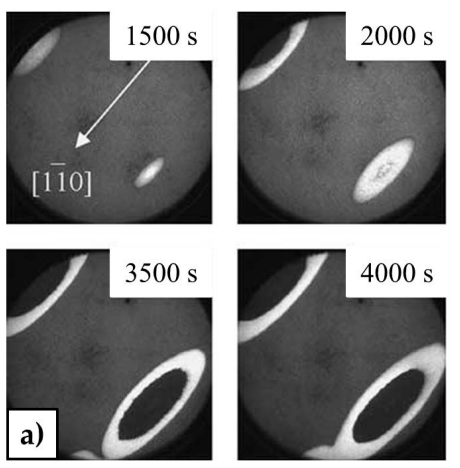
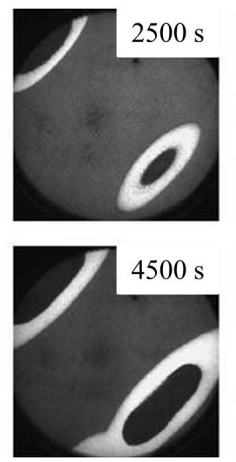
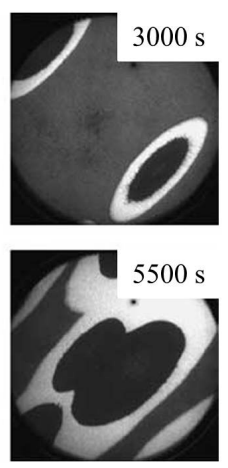
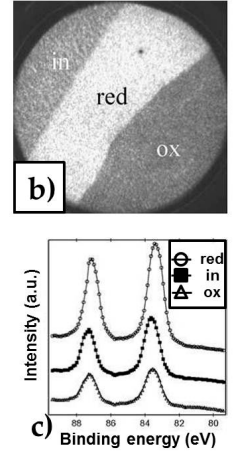

Figure 9. LEEM and micro-XPS study of front propagation and mass transport: (a) LEEM images under $\mathrm{O}_{2}+\mathrm{H}_{2}$ reaction illustrating the ignition and propagation of reduction/oxidation fronts. Field of view $=20 \mu \mathrm{m}$. Conditions of acquisition: $T=550 \mathrm{~K}, P_{\mathrm{O}_{2}}=2.8 \times 10^{-5} \mathrm{~Pa}, P_{\mathrm{H}_{2}}=3.3 \times 10^{-5} \mathrm{~Pa}$; (b) $\mathrm{Au} 4 \mathrm{f}_{7 / 2}$ map acquired during front propagation illustrating the lateral inhomogeneity induced by the reduction/oxidation front; (c) Au $4 \mathrm{f}$ spectra measured in the different regions presented in (b). Reprinted from [153]. Copyright 2004, Elsevier.

When hydrogen is introduced in the chamber, the nucleation and growth of elliptical fronts can be observed (Figure 9a). This anisotropic behaviour is supposed to find its origin in the anisotropic diffusion of adsorbate species on the substrate [183]. These bright regions correspond to the surface reduced by the first reaction front. The dark regions correspond to the propagation of oxidation fronts, generated at the centre of the reduction fronts. During the $\mathrm{O}_{2}+\mathrm{H}_{2}$ reaction on bare $\mathrm{Rh}(110)$, only reduction fronts are observed, and reaction fronts initiate a transition from an inactive ' $\mathrm{O}$-saturated' phase, to an active almost 'O-free' surface [183,184]. In the case of Au-covered Rh, micro-XPS analysis revealed that the reduced area is Au-enriched and O-free, and the oxidised area is Au-depleted (Figure 9b,c). In the reduced area, the accumulation of Au grows continuously as the front progresses, up to a value of $\approx 0.9 \mathrm{ML}$ corresponding to the maximum coverage for that system. After some time, the reaction front slows down and a quasi-stationary state can be observed (Figure 9a at $5500 \mathrm{~s}$ ). This patterned surface, consisting of Au-depleted and Au-enriched regions is preserved in an oxidising environment, proving that the mobility of $\mathrm{Au}$ on oxidised surfaces is relatively low. However, the patterned surface is rapidly destroyed in a reducing environment, a sign of the high mobility of Au on oxygen-free surfaces. The Au mass transfer process observed in this system can be explained by the presence of an energetically favourable configuration: the reorganisation of the catalyst surface into "Au-poor/O-rich" and "Au-rich/O-poor" phases. We can assume that optimisation of the energy of the system is obtained if Au-adatoms bond directly to the Rh surface, inducing a rearrangement of the oxygen layer. The presence of an active gas may promote surface diffusion of metal adatoms, and this work proves that the propagation of reduction/oxidation fronts destroys the lateral homogeneity of the Au adlayer, which results in the development of a patterned surface composed of Au-depleted and Au-enriched regions.

The initial surface composition is important in the development of such patterned structures. For example, if $\mathrm{Au}$ is deposited on a clean $\mathrm{Rh}(110)$ surface [105] as compared to a O-precovered $\mathrm{Rh}(110)$ surface, the Au mass transport starts with the ignition of oxidation fronts, and bright domains merge to larger islands, eventually forming segregated phases (Figure 10). The aggregation of Au into the bright islands is confirmed by XPEEM. 


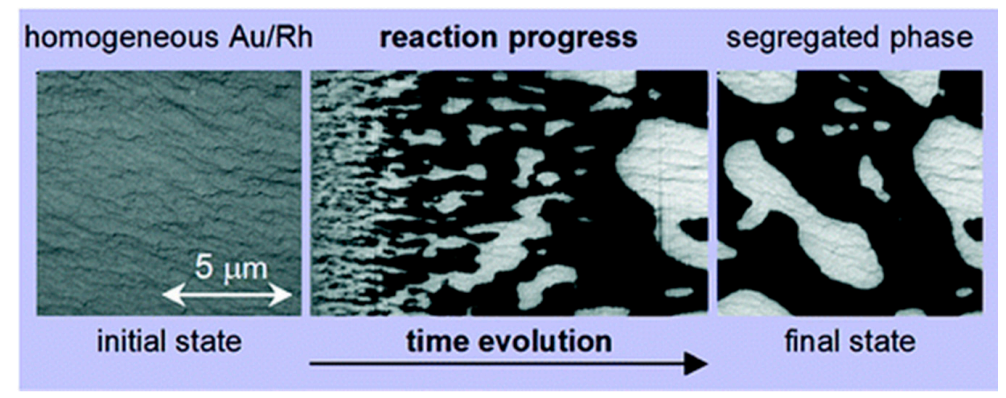

Figure 10. LEEM imaging of the formation of a segregated phase due to the gold mass transport observed under reaction conditions. Reprinted with permission from [182]. Copyright 2005, American Chemical Society.

The presence of a segregated phase is accompanied with a different reactivity. Indeed, reduction fronts are solely ignited in the Au-poor regions. The fronts then expand up to the Au-rich regions where they propagate further, but with a slower velocity. The two phases can thus be seen as independent microreactors. This proves that complex interfaces can develop, with different reactivity, even though the species responsible are chemically inert.

\section{Chemically Frozen Phase Separation}

One step further into the complexity of phase separation on catalytically active surfaces is the use of a mixed-layer of adatoms. For this, $\mathrm{Au}$ and $\mathrm{Pd}$ were deposited onto $\mathrm{Rh}(110)$ surfaces $[162,164,185,186]$ and studied under $\mathrm{H}_{2}+\mathrm{O}_{2}$ reaction conditions at different temperatures. It has been found that the water formation reaction triggered the presence of stationary 2D metallic and oxygen structures. In this case, because of the formation enthalpy of binary alloys ( $\mathrm{Au}-\mathrm{Rh}, \mathrm{Au}-\mathrm{Pd}$ and $\mathrm{Au}-\mathrm{Pd}$ ), which is only negative for Au-Pd [187], and oxygen adatoms are more strongly bonded on bare $\mathrm{Rh}$, the patterned structure is composed of mixed $\mathrm{Au}-\mathrm{Pd}$ and $\mathrm{O}$ islands. This can be seen on the XPEEM images in Figure 11a. It should be mentioned that O-covered regions may still contain very small amounts of metal adatoms depending on the reaction conditions. This lamellar structure results from chemically frozen spinodal decomposition, and is energetically favourable, but kinetically hindered in the absence of reaction. Once formed, such structures can be preserved if the temperature is quenched down to $300 \mathrm{~K}$ and the reaction is interrupted, proving the structure to be stationary rather than transient.

a)
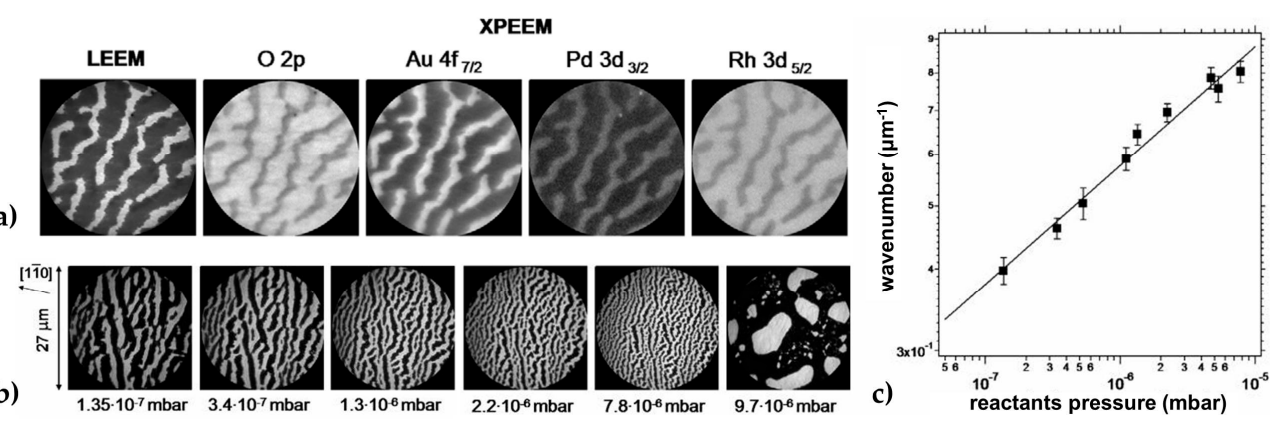

Figure 11. Chemically-frozen phase separation studied by LEEM and XPEEM: (a) LEEM and elemental XPEEM of the lamellar structures corresponding to separated Au-Pd and $\mathrm{O}$ islands. Conditions of acquisition: $T=820 \mathrm{~K}, P=5.3 \times 10^{-5} \mathrm{~Pa}, P_{\mathrm{H}_{2}} / P_{\mathrm{O}_{2}}=0.5, \Theta_{A u+P d}=0.5 \mathrm{ML} ;(\mathbf{b})$ LEEM images of stationary structures produced under different gas pressures. Conditions of acquisition: $T=820 \mathrm{~K}$, $P_{\mathrm{H}_{2}} / P_{\mathrm{O}_{2}}=0.8, \Theta_{A u+P d}=0.75 \mathrm{ML}$; (c) Plot of the structure wavenumber (in the [1]0] direction) as a function of the pressure of the reactants. Adapted with permission from [185]. Copyright 2006, American Chemical Society. 
The more important feature of such lamellar structures is that they are adaptive, which means that they can be created, preserved and reversibly modified by tuning the reaction conditions (either the gas pressure or the temperature). An example is presented in Figure 11b, where the wavelength of the structure is modified by increasing the pressure of the reactants while the pressure ratio remains the same. This wavelength, calculated along a specific direction, obeys a power law over two orders of magnitude in the pressure of the reactants (Figure 11c). Since the wavelength depends on the reaction conditions, the reaction rate could be finely adjusted by using variations of the pressure or temperature as a tool to control the wavelength, and therefore design specific microstructures at the surface of the catalyst. This also corresponds to an experimental proof of the growth of spatial modes of modifiers microsctructures in the presence of a surface chemical reaction $[188,189]$.

\subsubsection{Spectromicroscopy of Au-Supported Nanoparticles}

One noticeable study performed on Au-based systems is the spectromicroscopy of Au-supported nanoparticles [190]. As described above, the use of SPELEEM instrument adds the structure sensitivity to the capabilities of the PEEM. Recent work [190] has been performed on gold nanoparticles supported on $\mathrm{CeO}_{2-x}(111)$ crystallites, themselves deposited on a $\mathrm{Rh}(111)$ substrate. This material can be used as a model catalyst for the water-gas shift reaction. $\mathrm{Au} / \mathrm{CeO}_{2}$ systems have been, and still are, widely used for catalytic applications such as the water gas shift reaction, $\mathrm{CO}$ and volatile organic compounds (VOCs) oxidation, and $\mathrm{NO}_{2}$ reduction [33,191-194]. Therefore, the understanding of the redox behaviour of the gold/ceria system remains a crucial step in the fundamental understanding of its catalytic activity.
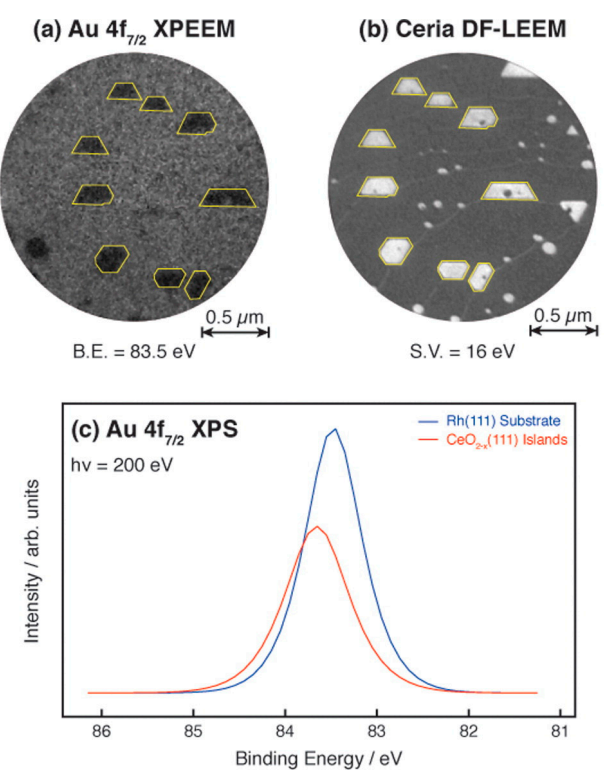

(d) Au 4f $f_{7 / 2}$ XPEEM
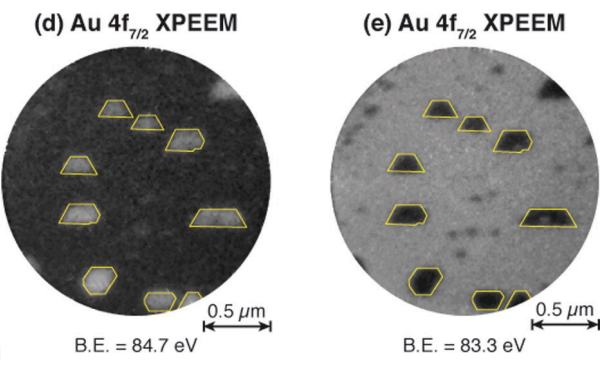

Reduce film
(pump out $\mathrm{O}_{2}$ )

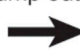

Figure 12. Spectromicroscopy of Au nanoparticles: XPEEM, LEEM and XPS analysis of Au nanoparticles deposited on $\mathrm{CeO}_{1.67} / \mathrm{Rh}(111)$ showing the effect of beam-induced reduction of the ceria. Ceria islands can be discerned in XPEEM and LEEM images. The resolution of the technique allows observing the presence of $\mathrm{Au}$ on both the ceria and the Rh support. $(\mathbf{a}-\mathbf{c})$ analysis under $P_{\mathrm{O}_{2}}=5 \times 10^{-5} \mathrm{~Pa} ;(\mathbf{d}-\mathbf{f})$ analysis under UHV conditions. Reprinted with permission from [190]. Copyright 2014, American Chemical Society.

Because the resolution of XPEEM and LEEM techniques is limited to a few tens of nanometres, Au particles cannot be resolved, but spectroscopic information can still be obtained. For example, it was shown that as the coverage of gold increased, the ceria was reduced, which is consistent with charge transfer from the gold particles to the oxide support. The effect of the presence of an oxygen atmosphere and the beam-induced reduction of the sample was also successfully investigated. 
To examine this effect, $\mathrm{Au} 4 \mathrm{f}$ region is probed and a shift to higher binding energy is observed for $\mathrm{Au}$ particles located on ceria as compared to those on Rh. The use of LEEM imaging can be correlated to XPEEM imaging of gold to discern the ceria structures, as can be seen in Figure 12. By using energy-filtered XPEEM, it is possible to distinguish the Au signal originating from the ceria crystallites, or from the Rh support. This study shows promising results for the future of PEEM and derivate techniques for catalytic applications.

\subsubsection{Perspectives}

In the past and current research, Au-based samples were not widely studied by PEEM/LEEM techniques. Only a few systems were imaged: pure Au [105], Au-Si [105,156,195], as well as $\mathrm{Au}-\mathrm{Mo}$ [105]. However, with the increasing interest in Au-based alloys for catalytic applications, model samples were produced to study the presence of specific dynamics, interfacial phenomena, the possible presence of subsurface species, as well as phase separation processes.

\subsection{Study of Processes on a Single Grain of Catalyst by FEM/FIM}

The different examples presented in this section will show (1) how the coupling between FIM and mass spectrometry allows the mechanism of reactions to be resolved, (2) how FEM can be used to determine activation energy for adsorption/desorption/diffusion processes, and (3) how the coupling of FIM with a position-sensitive detector allows the surface composition to be correlated with the reactivity.

\subsubsection{Processes on Au Tips}

Propagation Waves during $\mathrm{CO} / \mathrm{O}_{2}$ Interaction

Gold catalysts are known to be active for the low temperature CO oxidation [27,47], and it was thus straightforward to study this system by field emission techniques. One of the advantages of this technique is to allow the study of catalytic reactions in the absence of any influence of the oxidic support, which is of great importance for the fundamental understanding of the catalytic system. In addition to this, the behaviours observed are influenced by the presence of a steady electric field which could mimic conditions encountered in studies over $\mathrm{Au}^{\delta+} /$ metal-oxide catalysts [196]. In Figure 13a, we can observe a typical Au sample prepared and imaged by field ion microscopy. The study of $\mathrm{CO} / \mathrm{O}_{2}$ system was performed on such samples [197]. The authors mainly observed the presence of a propagating wave during the imaging of the gold nanoparticle in the presence of $\mathrm{CO}+\mathrm{O}_{2}$ gas mixtures at $300 \mathrm{~K}$. It has to be noted that FIM work during $\mathrm{CO}$ oxidation on Pt field emitter tips proved that oxygen is used as an imaging gas [198]. Since FIM imaging lacks chemical analysis, further studies coupling the FIM with mass spectrometry [148] were performed for different systems of increasing complexity: $\mathrm{CO} / \mathrm{Au}$ [199], $\mathrm{O}_{2} / \mathrm{Au}$ [200] and finally $\mathrm{CO}+\mathrm{O}_{2} / \mathrm{Au}$ [201].

The study of CO adsorption on Au tips [199] suggests the formation of gold mono- and di-carbonyls, as shown in Figure 13b representing the mass spectra obtained during CO adsorption at room temperature. Gold carbonyls are indeed observed, in the presence of high electrostatic field, as $\mathrm{AuCO}^{+}, \mathrm{AuCO}^{2+}$ and $\mathrm{Au}(\mathrm{CO})_{2}{ }^{+}$species. The mass spectra have been acquired over a region of approximately 400 atomic Au sites with a relatively high density of kinks, as shown in Figure 13a (black circle i.e., the probed area). The formation of carbonyls appears to be field-dependent, in agreement with the field-dependence of $\mathrm{CO}$ bonding energy to $\mathrm{Au}(111)$ [202], and DFT calculations concluded that the local field-induced surface charge accumulating on gold atoms stabilises the carbonyls on highly facetted gold nanostructures. It is suggested that in the absence of an external field, the local charges can be present at kinks and steps sites of small clusters, explaining the size-dependent reactivity of Au clusters [29,203]. 


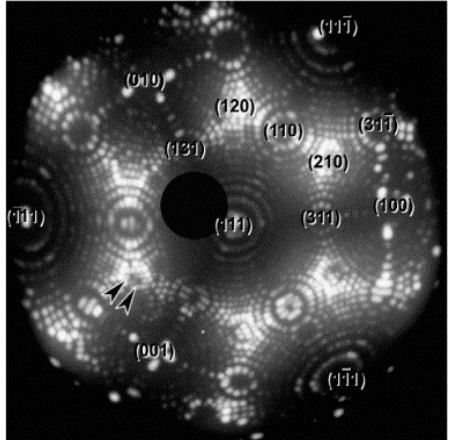

(a)

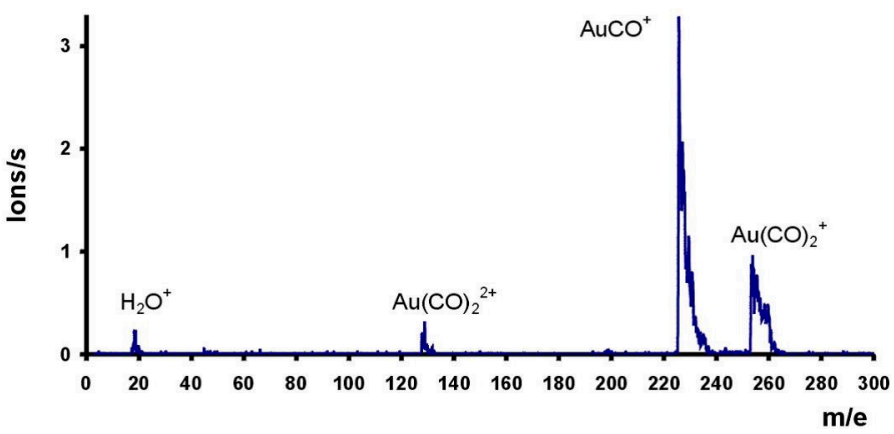

(b)

Figure 13. Analysis of a single Au nanoparticle by FIM and 1DAP: (a) Field Ion Microscopy (FIM) image of a (111)-oriented Au sample where the atomic resolution can be observed on steps and kinks and inside flat planes of small sizes. The dark circle corresponds to a typical region of analysis for studies by mass spectrometry. The magnification in FIM corresponds to $\sim 10^{6}$ on a detector screen of 3 inches diameter. Conditions of acquisition: $T=50 \mathrm{~K}, P_{N e}=10^{-3} \mathrm{~Pa}$. Reprinted from [204], Copyright 2006, Elsevier; (b) Mass spectra of an Au sample during interaction with CO in the presence of an external electric field. Mono- and di-carbonyls are formed on the sample. The region of analysis corresponds to $\approx 400$ atomic Au sites. Conditions of acquisition: $T=300 \mathrm{~K}, P_{C O}=10^{-3} \mathrm{~Pa}$, steady field $F_{R}=2.1 \mathrm{~V} / \AA$, pulsed field $F_{P}=1.1 \mathrm{~V} / \AA$, frequency of the field pulses $f=1.67 \mathrm{kHz}$. Reprinted from [199]. Copyright 2003, AIP Publishing.

The next step towards the understanding of the observed propagation wave is the study of the $\mathrm{O}_{2} / \mathrm{Au}$ system [200]. Previous work showed that the dissociative oxygen chemisorption on pure gold model nanoparticle is caused by the presence of surface impurities [205-207]. On Au tips, surface impurities are supposed to be absent due to the cleaning process following the sample preparation. Experiments by PFDMS showed that the adsorption of molecular and atomic oxygen on $\mathrm{Au}$ tips does not occur at pressures lower than $10^{-2} \mathrm{~Pa}$ in the temperature range 300-350 K. The dissociation of oxygen cannot be forced by applying an electric field up to $60 \mathrm{~V} / \AA$. $\mathrm{AuO}_{2}{ }^{+}$species are observed in the mass spectra when the applied field is close to the onset of Au field-evaporation, which means that once formed, field evaporated $\mathrm{Au}^{+}$ions undergo complexation by $\mathrm{O}_{2}$ in the very vicinity of the "take-off" location. The scenario is reinforced by the enhanced impingement rate of oxygen molecules in the presence of a strong inhomogeneous electric field. $\mathrm{O}_{2}{ }^{+}$species are also present in the PFDMS analysis, but their presence is independent of the temperature, reaction time and probed region. The presence of $\mathrm{O}_{2}{ }^{+}$thus reflects gas phase ionisation of oxygen close to the tip rather than molecular adsorption. These results are in agreement with DFT models proving that no $\mathrm{O}_{2}$ dissociation will occur in the presence of an external electric field [208]. The size of the Au tip samples is of several tens of nanometres diameter and notoriously not active in catalysis for $\mathrm{CO}$ oxidation.

As stated, the interaction of $\mathrm{CO}$ and $\mathrm{O}_{2}$ on an $\mathrm{Au}$ sample at room temperature induces the presence of a propagation wave, as it can be seen in Figure 14. Oxygen is first introduced in the reaction chamber, followed by $\mathrm{CO}$, and the surface is imaged with a field of $1.2-1.5 \mathrm{~V} / \AA$. The initiation of the wave occurs close to the central pole, where the field is the highest, and then propagates away from the nucleation region down to the shank of the tip [201]. It has been shown that the application of an external field induces the presence of gold-carbonyls [199] but does not induce the adsorption/dissociation of oxygen species [200]. It is thus rather unlikely that the propagation wave corresponds to $\mathrm{CO}$ oxidation. 

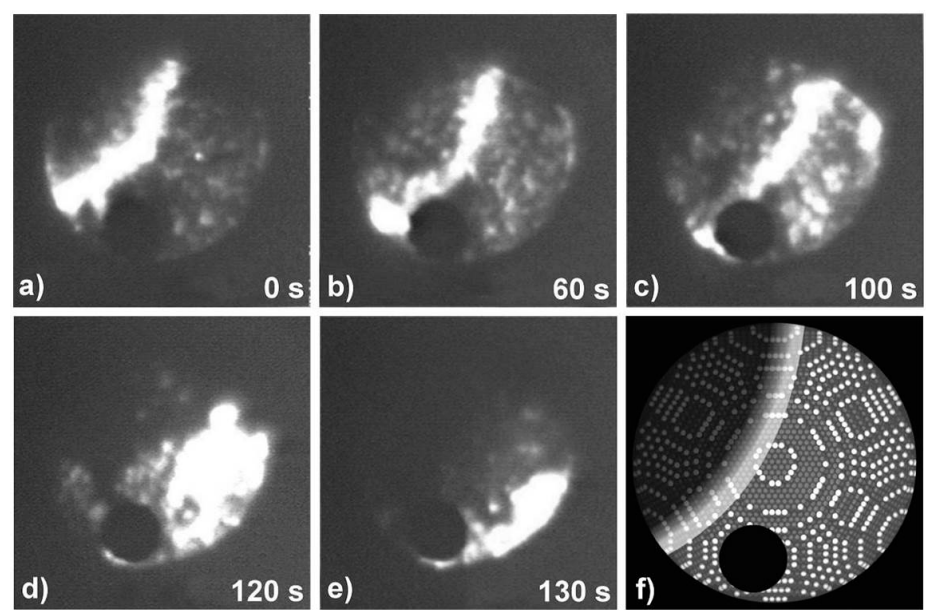

Figure 14. Imaging a chemical wave under reaction conditions by FIM: (a-e) Series of snapshots during the interaction $\mathrm{CO} / \mathrm{O}_{2}$ on an Au tip imaged by FIM during the ongoing process. A chemical wave is observed with its initiation at the apex part of the tip and propagation to the shank of the tip. The magnification in FIM corresponds to $\sim 10^{6}$ on a detector screen of 3 inches diameter. Conditions of acquisition: $T=300 \mathrm{~K}, P_{C O}=4 \times 10^{-5} \mathrm{~Pa}, P_{\mathrm{O}_{2}}=10^{-2} \mathrm{~Pa}$, imaging field $=1.4 \mathrm{~V} / \AA$; (f) Guide to the eye of the wave superimposed with a ball model of the sample. The black region corresponds to the regions probed by mass spectrometry (see Figure 15). Reproduced from [196]. Copyright 2007, John Wiley \& Sons, Ltd.

To support this hypothesis, PFDMS was used to probe the chemical nature of the adsorbates during the occurrence of the wave propagation, as depicted in Figure 14f. The resulting mass spectrometry analysis is presented in Figure 15. The absence of $\mathrm{CO}_{2}$ species in the mass spectra suggests that $\mathrm{CO}$ oxidation does not occur. As discussed above, the $\mathrm{CO}$ is chemisorbed on gold and $\mathrm{Au}$-carbonyls are formed in the presence of an external field: $\mathrm{AuCO}^{+}, \mathrm{AuCO}^{2+}, \mathrm{Au}(\mathrm{CO})_{2}{ }^{+}$and $\mathrm{Au}(\mathrm{CO})_{2}{ }^{2+}$. The propagation wave is thus mainly composed of gold-carbonyls undergoing field evaporation in a wave. The mechanism for this wave propagation is as follows: $\mathrm{CO}$ is chemisorbed at the edge site of a terrace because of the local field enhancement weakening the $\mathrm{Au}-\mathrm{Au}$ bond. The formed Au-carbonyl, denoted Au-CO, is now free to migrate in an inhomogeneous field. Due to the Au-CO dipole, the carbonyl species will be pushed towards the edge of the second layer terrace. The process of detachment/migration is then repeated, and the region where Au-CO desorption occurs, migrates as a wave, from the apex where the field is higher down to the shank of the tip where the electric field intensity drops. This decreasing electric field slows down the propagation, as observed experimentally and theoretically [209]. Regarding the oxygen species, since their quantities adsorbed on the surface are insignificant or even completely absent, the $\mathrm{O}^{+}$and $\mathrm{O}_{2}{ }^{+}$species observed come from field ionisation in the gas phase, and oxygen species only have a spectator role and act as the imaging gas.

As a conclusion, oxygen does not lead to field-induced oxidation of $\mathrm{CO}$, but the propagation corresponds to the Au-carbonyl wave made visible with oxygen as imaging gas. Simulations [209] were in good agreement with the experiments and showed the absence of oxygen dissociation, the absence of $\mathrm{CO}$ oxidation, and the wave propagation of carbonyls to a distance close to the radius of the sample. The study also notes that $\mathrm{CO}$ oxidation would be possible with a negative electric field (thus in FEM mode) for pressure in the range of $10^{4} \mathrm{~Pa}$, not accessible in a field emission microscope. 


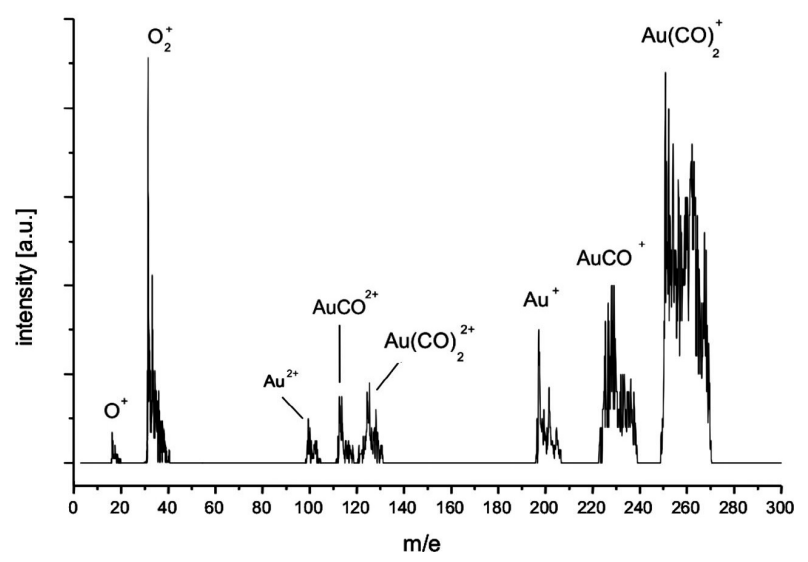

Figure 15. Chemical probing of the carbonyls-wave by PFDMS: Mass spectrum acquired on an Au tip during the wave propagation (see Figure 14) and highlighting the presence of an Au-carbonyls wave and oxygen as imaging gas The region of analysis corresponds to $\approx 300$ atomic Au sites. Conditions of acquisition: $T=300 \mathrm{~K}, P_{\mathrm{CO}}=2 \times 10^{-5} \mathrm{~Pa}, P_{\mathrm{O}_{2}}=10^{-2} \mathrm{~Pa}$, steady field $F_{R}=1.2 \mathrm{~V} / \AA$, pulsed field $F_{P}=2.5 \mathrm{~V} / \AA$, frequency of the field pulses $f=10 \mathrm{~Hz}$. Reprinted from [201], Copyright 2006, AIP Publishing.

\section{Water Gas Shift Reaction (WGSR)}

The water gas-shift reaction is of importance for the both the conversion of $\mathrm{CO}$ gas and the production of hydrogen:

$$
\mathrm{CO}(\mathrm{g})+\mathrm{H}_{2} \mathrm{O}(\mathrm{g}) \rightarrow \mathrm{CO}_{2}(\mathrm{~g})+\mathrm{H}_{2}(\mathrm{~g})
$$

Previous works suggested synergistic effects between $\mathrm{Au}$ nanoparticles and their support: the dissociative adsorption of $\mathrm{H}_{2} \mathrm{O}$ on $\mathrm{Au}$ is followed by spill over of $\mathrm{OH}$ species on the support [210,211]. The presence of $\mathrm{OH}$ species was also considered important in the promotion of the WGSR [212,213]. The $\mathrm{CO} / \mathrm{H}_{2} \mathrm{O} / \mathrm{Au}$ system was also studied by FIM [204] to try to shed some light on this system. For this, water was adsorbed at the surface of a gold catalyst (as presented in Figure 13a) leading to the formation of bright spots, and then $\mathrm{CO}$ was introduced in the chamber at $300 \mathrm{~K}$. When $\mathrm{CO}$ is present in the reaction chamber, bright waves ignite simultaneously on different regions of the tips and propagate. Water in the form of $\mathrm{H}_{2} \mathrm{O}^{+}$is supposed to be the imaging species. If the $\mathrm{CO}$ supply is stopped during the experiment, the wave stops and the brightness fades. If $\mathrm{CO}$ is removed after the experiment, new bright spots appear, associated with water adsorption: these facts suggest a reaction between $\mathrm{CO}$ and water. The wave front never starts from the same position and there is no preference for certain crystallographic orientations. Accordingly, the reaction is not "demanding", i.e., is not restricted to specific crystalline orientations. Analyses by PFDMS highlight the presence of surface hydroxyls, signs of water dissociation. When $\mathrm{CO}$ and $\mathrm{H}_{2} \mathrm{O}$ are present in the chamber, the intensity of the hydroxyl peak decreases, which is a strong argument in favour of a reaction between $\mathrm{CO}$ and $\mathrm{OH}$ species:

$$
\mathrm{CO}(\mathrm{ads})+\mathrm{OH}(\mathrm{ads}) \rightarrow \mathrm{CO}_{2}(\mathrm{~g})+\mathrm{H}(\mathrm{ads})+{ }^{*}
$$

where * stands for an empty site.

The absence of $\mathrm{CO}_{2}$ in the mass spectra is commonly explained by its formation as a neutral species, which escapes ionisation by field pulses. It has to be noted that a field of $1.1 \mathrm{~V} / \AA$ is necessary to activate the water dissociation on $\mathrm{Au}$ but not sufficient to ionise $\mathrm{CO}_{2}$. 
3.2.2. Processes on Au-Covered Tips: Determining $\mathrm{H}_{2} \mathrm{O}$ Adsorption/Desorption/Diffusion Energies by FEM

The previous section was dedicated to the investigation of reactive processes on Au tips by field ion microscopy. Here, we focus on the study of simple processes by field emission microscopy and the determination of parameters such as the activation energy of desorption and diffusion. Thanks to the FEM technique, these parameters can be obtained for a single grain of catalyst, rather than from a single crystal or from the collection of several particles. For this, Au-covered W tips were used. Au is deposited by evaporation and the Au coverage is estimated via measurements of the work function changes during the evaporation.

In a first set of experiments [214], water adsorption and desorption was studied on Au-covered W tips. Water is condensed on the sample at liquid nitrogen temperature, in field-free conditions to avoid any field-effects on the adsorption energy. To calculate the desorption energy, thermal desorption is applied to the system and corresponds to TPD measurements on a single nanoparticle. In the absence of field and from $78 \mathrm{~K}$, the sample is heated to a chosen temperature, then cooled down. At constant voltage, the presence of water induces a decrease in the emission current. Therefore, the authors monitored the voltage required to maintain a constant emission current (Fowler-Nordheim method). The voltage is measured at $78 \mathrm{~K}$. The first observation from these experiments is the presence of two adsorption states since desorption happens at two different temperature ranges: $150-160 \mathrm{~K}$ and $220-240 \mathrm{~K}$. All the water is completely desorbed at $240 \mathrm{~K}$, signs that there is no water dissociation in these conditions (in this case, $\Theta \geq 2$, where $\Theta$ corresponds to the surface coverage). For the first adsorption state, thermal desorption isotherms can be plotted, as presented in Figure 16a. An Arrhenius plot can be extracted from this graph and is represented in Figure 16b. The analysis indicates an activation energy for water desorption of $E_{\text {des }}=51.5 \pm 1.5 \mathrm{~kJ} / \mathrm{mol}$. The behaviour of water on gold-covered W tip can be compared to a pure W tip, or to a gold-covered tip with a monolayer or a sub-monolayer coverage. In the last case, water dissociation occurs because of the $\mathrm{W}$ influence.

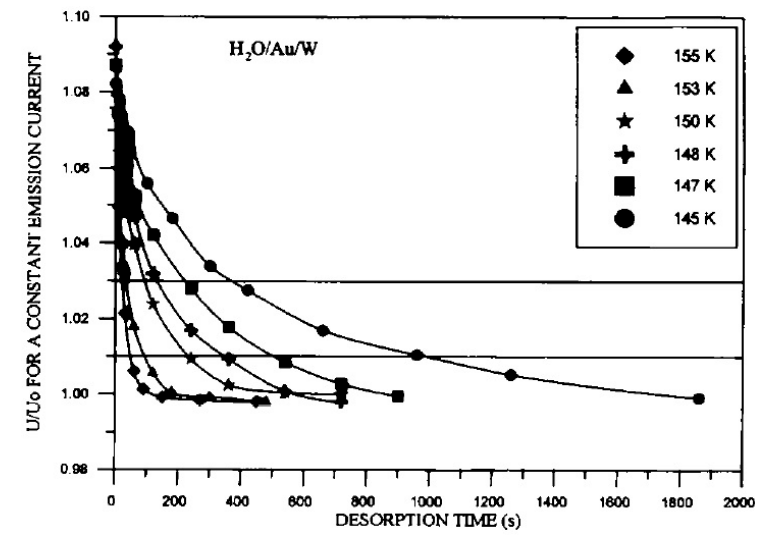

(a)

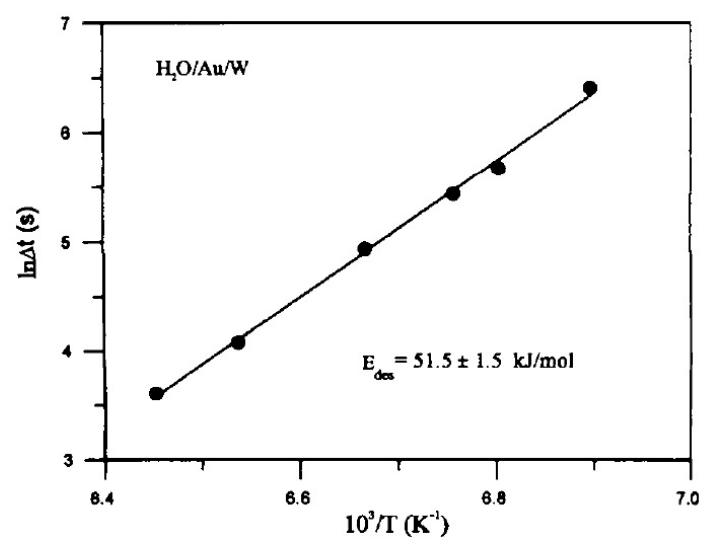

(b)

Figure 16. Extracting kinetic parameters from FEM analysis: (a) Thermal desorption isotherms of water from the Au-covered W tip in the temperature range 145-155 K to probe the desorption energy of the first water-adsorbed configuration; (b) Arrhenius plot obtained from (a). Reprinted from [137]. Copyright 1997, Elsevier.

Similar experiments were performed for $\mathrm{H}_{2} \mathrm{O}$ diffusion by plotting the isotherms in the temperature range 113-123 $\mathrm{K}$ and the corresponding Arrhenius plot, leading to an activation energy for diffusion $E_{\text {diff }}=27 \pm 2 \mathrm{~kJ} / \mathrm{mol}$ [214]. A more detailed analysis was performed by the same group [215] to study the influence of the Au-coverage and the crystallographic orientation of diffusion on the activation energy. The procedure is rather similar to the adsorption of water at low temperature, followed by sample heating to the temperature range of $118-127 \mathrm{~K}$ to let the water diffuse, all this 
in the absence of an external field. The sample is then imaged at a constant potential and the field emission pattern is processed (by background subtraction and stacking of images so as to increase the contrast and to highlight the low-brightness processes). Figure 17 represents a clean $\mathrm{W}$ tip (Figure 17a), a clean Au-covered W tip $\left(\Theta_{A u}=2.5\right)$ (Figure 17b), and a clean Au-covered W tip $\left(\Theta_{A u}=4\right)$ (Figure 17c). The remainder of the Figure $17 \mathrm{~d}-\mathrm{i}$ corresponds to snapshots of the water diffusion, presenting a sharp diffusion-boundary. The diffusing $\mathrm{H}_{2} \mathrm{O}$ is represented by the brighter areas of the field emission pattern, and the white lines in Figure 17g-i correspond to the crystallographic direction where the diffusion was measured. By heating the sample at the targeted temperature during specific time-lapses, it was shown that the square diffusion distance is linear to the diffusion time. Dependence on the $\mathrm{Au}$ coverage and crystallographic orientation with temperature shows an activation energy for surface diffusion from $28 \mathrm{~kJ} / \mathrm{mol}$ to $38 \mathrm{~kJ} / \mathrm{mol}$. The differences in energy suggest different roughnesses of the sample.
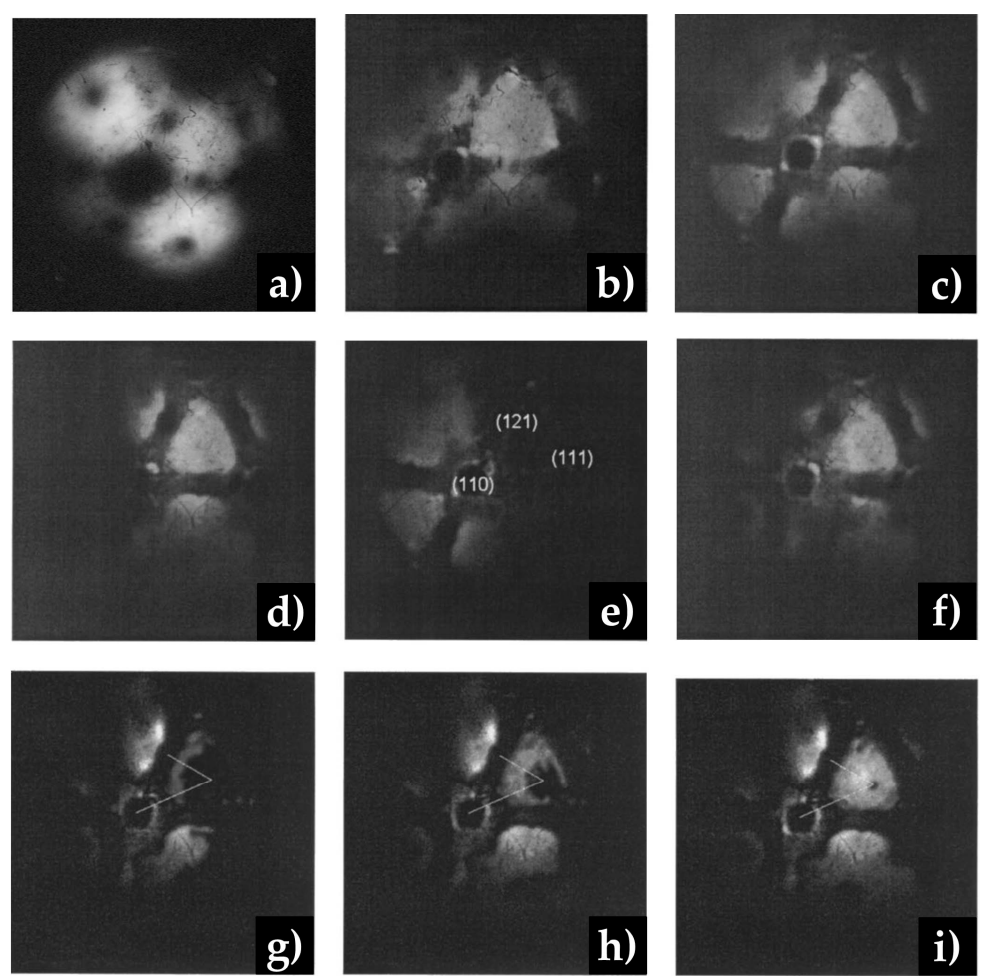

Figure 17. Imaging water diffusion by FEM: (a) Field emission pattern of a clean W tip. The magnification corresponds to $\sim 10^{6}$ on a detector screen of 3 inches diameter; (b) Field emission pattern of a clean $\mathrm{Au} / \mathrm{W}$ tip with a coverage of $\Theta_{A u}=2.5$; (c) Field emission pattern of a clean Au/W tip with a coverage of $\Theta_{A u}=4$; Diffusion of $\mathrm{H}_{2} \mathrm{O}$ (d) FE pattern after water condensation; (e) Processed FE pattern from (d) where the background has been removed and stacking of 2 identical images. The main crystallographic facets are represented by their Miller indexes: the bright parts correspond to regions where water is adsorbed; (f) FE pattern after $300 \mathrm{~s}$ of warming at $T=120 \mathrm{~K}$; (g) Processed FE pattern from (f) with background subtraction and stacking; (h) Processed FE pattern after $650 \mathrm{~s}$ of warming and; (i) after $1130 \mathrm{~s}$ of warming. Reprinted from [215]. Copyright 1999, Elsevier.

\subsubsection{Processes on Au-Based Alloys}

Oxygen Interaction with Au-Ag Alloys

Similarly to the previous system, the adsorption of oxygen was studied on Au-Ag alloys [139]. In this study, $\mathrm{Au}$ and $\mathrm{Ag}$ atomic layers (five to 10 atomic layers are sufficient since they have similar properties to the bulk [216]) were deposited by evaporation and further annealed to ensure a complete 
mixing of the alloy. Due to the inertness of $\mathrm{Au}$, a decrease of the $\mathrm{Ag} / \mathrm{Au}$ ratio within the alloy is accompanied by a drastic decrease of its ability to adsorb oxygen, subsequently affecting its catalytic properties. FEM was used to monitor the oxygen adsorption as a function of the alloy composition, and further data processing was applied to calculate the heat of adsorption. The conclusions of this work are: (1) an increase in Au content decreases the sticking probability of oxygen, (2) there is no oxygen detected on pure Au at $300 \mathrm{~K}$, and (3) there is a decrease of the heat of adsorption with added gold. It is interesting to note that 40 years after this study, Au-Ag systems are still studied to understand the behaviour of Ag within an Au backbone and its influence on the catalytic behaviour [217,218], and that relatively simple studies by FEM enable the nanoscale effect of $\mathrm{Au}-\mathrm{Ag}$ alloying on the energies of adsorption to be measured.

Towards deNOx Reactions on Au-Based Catalysts

Gold-based catalysts are frequently studied for deNOx reactions [219,220]. First, the adsorption of $\mathrm{NO}$ on Au nanoparticles at $300 \mathrm{~K}$ was studied [221] and induced, in addition to the expected $\mathrm{NO}^{+}$, the presence of dimer $(\mathrm{NO})_{2}{ }^{+}$, and of nitrous oxide $\mathrm{N}_{2} \mathrm{O}^{+}$species in the mass spectra. Previous works by kinetic analysis $[222,223]$ suggested the formation of nitrous oxide via the combination of two $\mathrm{NO}$ (ads) molecules rather than decomposition of $\mathrm{NO}$ (ads) and recombination. The absence of $\mathrm{N}^{+}$in the mass spectra suggests that indeed, this mechanism is plausible.

$$
(\mathrm{NO})_{2}(\text { ads }) \rightleftharpoons \mathrm{N}_{2} \mathrm{O}(\text { ads })+\mathrm{O}(\text { ads })
$$

The next level of complexity consists in investigating the adsorption of $\mathrm{NO}$ on an Au-based alloy, e.g., Au-Pd. Changes in structure and morphology of the catalyst may be present, but the sample can also undergo changes in the surface composition, i.e., surface segregation of one of the components. The presence of surface segregation in binary alloys plays an important role in catalysis because of the synergistic effects between the two metals that directly depends on their concentration ratio. Furthermore, the control of surface segregation is a crucial step in the design of catalysts with fine-tuned properties. Segregation behaviour in catalytic systems can be suitably studied by atom probe tomography, an extension of the FEM/FIM techniques [88].

The study of the adsorption of NO on Au-62 at\% Pd catalysts was performed by FIM, PFDMS and CAP (Catalytic Atom Probe [151]). Even though the presence of two different metals may induce an imperfect FIM image (as compared to pure metals), it is possible to image alloys and to discern different crystallographic facets with very good accuracy, as can be seen in Figure 18a. The adsorption of NO was studied by catalytic atom probe [138] and the main results obtained are as follows: there is no segregation when the sample is exposed to $\mathrm{NO}$ at $300 \mathrm{~K}$, and there is no segregation in absence of $\mathrm{NO}$ at $573 \mathrm{~K}$. However, exposing the sample to $\mathrm{NO}$ at $573 \mathrm{~K}$ induces the presence of Pd segregation at the surface, as can be observed in Figure $18 \mathrm{~b}$ representing the cumulative plots of total atoms $(\mathrm{Au}+\mathrm{Pd})$ as a function of the $\mathrm{Au}$ atoms. The slope of such plots corresponds to the composition of the analysed sample, and any change in this slope indicates segregation or depletion behaviour. In the case of NO adsorption, we can clearly observe a Pd-segregation: the initial sample composition of Au-62 at $\%$ Pd becomes Au- 80 at\% Pd after NO exposure. This behaviour is explained by the capacity of Pd to dissociate nitrogen monoxide, and the subsequent formation of a strong Pd-O bond. The segregation is thus thermodynamically driven. To prove the dissociation of NO, PFDMS measurements were performed and the mass spectra indicates the presence of $\mathrm{N}^{+}, \mathrm{O}^{+}, \mathrm{NO}^{+}$and $\mathrm{NO}_{2}{ }^{+}$species, proof of the NO dissociation and recombination on this alloy. This is in contrast to NO adsorption on pure $\mathrm{Au}$ where the formation of $\mathrm{N}_{2} \mathrm{O}$ was due to the dimerisation of $\mathrm{NO}$ rather than its dissociation [221].

Finally, FIM was used to image a catalytic reaction during the ongoing process [138]: a NO-precovered Au-62 at $\%$ Pd sample (NO exposure: $t=30 \mathrm{~s}, P_{N O}=3 \times 10^{-3} \mathrm{~Pa}, T=450 \mathrm{~K}$ ) was imaged in the presence of hydrogen. While $\mathrm{H}_{2}$ pressure is gradually increased, a 'titration-wave' can be observed and is reproduced in Figure $18 \mathrm{c}$ for different times of reaction, $t=0 \mathrm{~s}$ corresponding to 
the introduction of $\mathrm{H}_{2}$ in the reaction chamber. The changes in brightness pattern and the presence of this titration-wave prove that hydrogen species reacted with the adsorbate layer. The imaging field is such that $\mathrm{H}_{2}$ ionisation is impossible, but sufficient to ionise $\mathrm{H}_{2} \mathrm{O}$ which has the role of imaging gas. This observation combined with PFDMS studies suggests that NO dissociates on Pd, subsequent oxygen is more easily adsorbed on $\mathrm{Pd}$ than on $\mathrm{Au}$, and $\mathrm{O}(\mathrm{ads})$ is reacted off with the $\mathrm{H}(\mathrm{ads})$ species. The combined approach of FIM, PFDMS and CAP experiments allows a better fundamental understanding of the system, down to the nanometer-scale to be obtained.
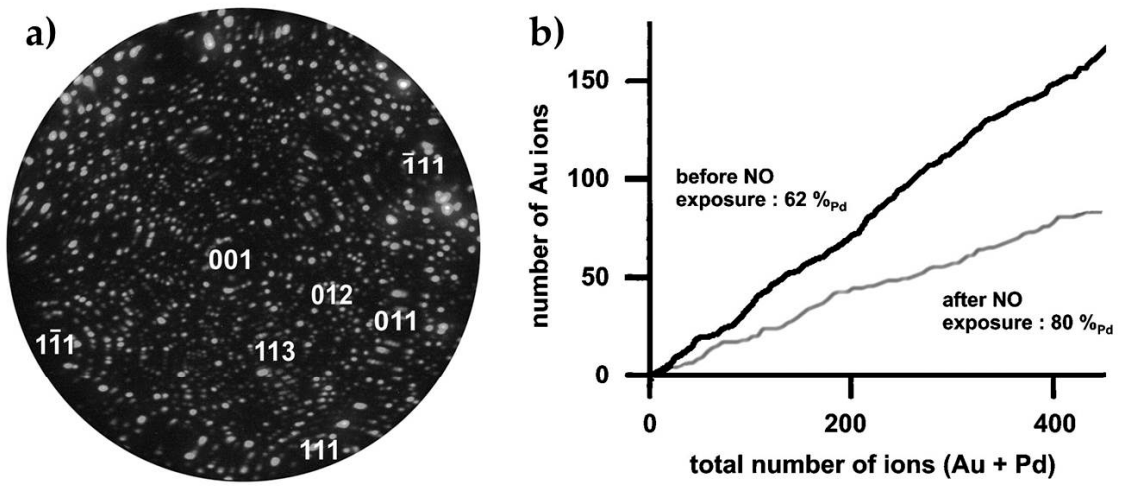

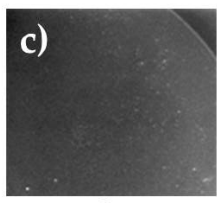

$\mathrm{t}=0 \mathrm{~ms}$

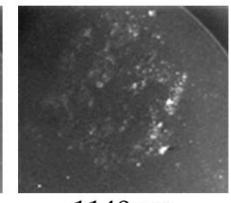

$1140 \mathrm{~ms}$

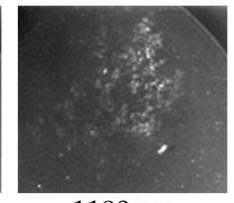

$1180 \mathrm{~ms}$

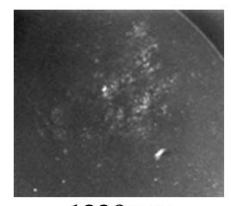

$1220 \mathrm{~ms}$

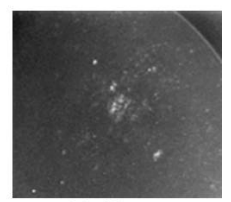

$1260 \mathrm{~ms}$

Figure 18. Study of Au-Pd alloy by field emission techniques: (a) FIM image of Au-Pd alloy (Au-62 at \% $\mathrm{Pd})$. The main discernable crystallographic orientations are represented by their Miller indexes. Conditions of acquisition: $T=45 \mathrm{~K}, P_{\mathrm{Ne}}=10^{-3} \mathrm{~Pa}, F=3.5 \mathrm{~V} / \AA$; (b) Cumulative plots of ions collected during atom probe experiments before any exposure and corresponding to a composition of $\mathrm{Au}-62 \mathrm{at} \%$ $\mathrm{Pd}$, and after exposure to NO corresponding to a composition of Au- 80 at $\% \mathrm{Pd}$, sign of the Pd surface segregation. Conditions of exposure: $T=573 \mathrm{~K}, P_{N O}=6 \times 10^{3} \mathrm{~Pa}, t=15 \mathrm{~min}$. Reprinted from [138]. Copyright 2009, Elsevier; Titration of a NO-precovered Au-62 at\% Pd sample by hydrogen, proving the formation of water, and therefore, the dissociation of NO on this catalyst. Panel (c) Courtesy of M. Moors.

\subsubsection{Perspectives}

In the past, Au-based systems were studied by FIM for various applications such as the study of long-range migration of self-interstitial atoms [224], phase transformation [225], precipitation in neutron-irradiated alloys [226], conductivity [227], or in the application of nano-tips to electron microscopy [228]. Even though these studies were not focused on catalysis, they proved the feasibility of imaging various Au-based alloys by FIM; alloys which are now used for catalysis applications: $\mathrm{Au}-\mathrm{Mo}$ [228] for the reverse water-gas shift reaction [229,230] or as $\mathrm{N}_{2}$ dissociation catalyst for the Haber-Bosch process [231], Au-Pt [224] for CO oxidation [49,232] and selective toluene oxidation [52], $\mathrm{Au}-\mathrm{Fe}$ [226] for $\mathrm{CO}$ oxidation [233] and $\mathrm{N}_{2}$ dissociation catalyst for the Haber-Bosch process [231], and $\mathrm{Au}-\mathrm{Cu}[225,234]$ for the water gas-shift reaction $[235,236]$ and $\mathrm{CO}$ oxidation [50].

Finally, three more applications are relevant for catalysis studies: the interaction of cyclohexane on Au tips [237], which finds its interest in the abatement of Volatile Organic Compounds (VOC); the behaviour of potassium-gold films [227], which could be used to study the influence of promoter in a catalytic reaction; and eventually, the imaging of Au nanoparticles by FIM after deposition on a field emitter tip [238,239], opening a way to study the catalytic process on a single Au nanoparticle rather than on a tip-model. 


\subsection{Study of Processes on Supported and Self-Supported Catalysts by E-TEM}

The selected examples presented in this section will describe the shrinking process of nanoparticles, the morphological changes of supported nanoparticles during exposure to different atmospheres and the support-dependence of these changes, and finally, the use of self-supported Au-based catalysts, i.e., nanoporous gold, for oxidation reactions. As a preliminary comment, we mention that imaging by TEM is based on the interaction of the sample with a high-energy electron-beam. It is known that the sample/e-beam interaction may induce undesired effects on the samples. In the specific case of gold, one example of this effect can be observed in Figure 19, which represents a maturation process of two Au nanoparticles [240]. The images are obtained by HR-TEM, and each image was acquired after a few minutes of illumination under the electron beam. We can observe that the small nanoparticle disappears layer by layer (Figure 19b-d), down to a single atomic layer.

This process is similar to the Ostwald ripening and the transport of atoms from the shrinking particle to the bigger particle may occur by surface diffusion along the $\mathrm{CeO}_{2}$ surface. Further studies highlight the structural changes of nanoparticles under e-beam radiation on different support $\left(\mathrm{TiO}_{2}, \mathrm{Fe}_{2} \mathrm{O}_{3} \ldots\right)$ [241,242]. Another study showed an increase in coordination of Au nanoparticles under e-beam irradiation [243]. Since the size, structure and the under-coordinated sites are known to affect the catalytic activity, one has to be careful in the interpretation of results obtained under e-beam.
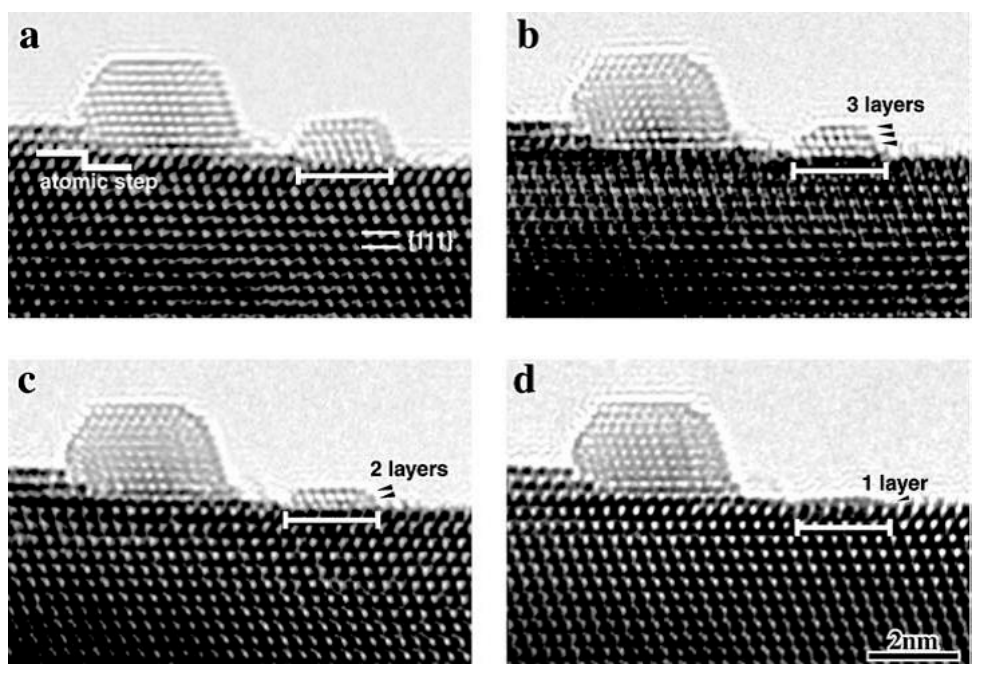

Figure 19. Series of high-resolution TEM revealing the shrinking process of an Au nanoparticle supported on $\mathrm{CeO}_{2}$ solely induced by e-beam illumination: (a) one large and one smaller $\mathrm{Au}$ nanoparticles can be observed; the smaller nanoparticle shrinks layer by layer (b) 3 remaining layers; (c) 2 remaining layers; (d) 1 remaining layer. Reprinted from [240]. Copyright 2005, Springer.

\subsubsection{Processes on Supported Au Nanoparticles}

\section{Coalescence of Au Particles}

One of the key parameters for the catalytic activity of gold is the size of the nanoparticles. It is then important to understand the factors affecting the sintering of nanoparticles, under reactive conditions, so as to control them. The mechanism of model Au nanoparticles sintering was studied on graphene support $[244,245]$ under vacuum and hydrogen flow at different temperatures. As depicted in Figure 20, Au nanoparticles present a size ranging from 1 to $5 \mathrm{~nm}$. The graphene support is stable at temperatures up to $673 \mathrm{~K}$. At room temperature, the nanoparticles are rather stable, meaning that they make irregular movements around a fixed site, both in vacuum and in the presence of hydrogen. Once the temperature is increased, nanoparticles become dynamic and coalescence of nanoparticles 
can be observed. Figure 20 represents such coalescence through surface mobility under hydrogen gas at a temperature of $373 \mathrm{~K}$.

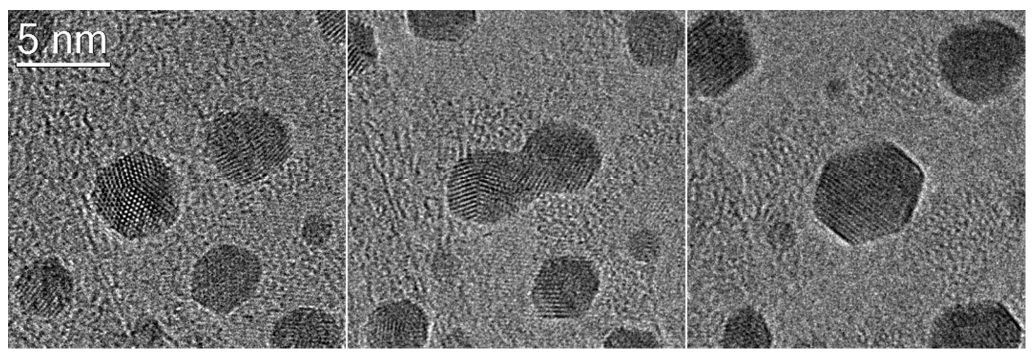

Figure 20. Coalescence of Au nanoparticles supported on graphene via migration of nanoparticles. The snapshots correspond to time $t=0 \mathrm{~s}, 56 \mathrm{~s}$ and $94 \mathrm{~s}$. Conditions of acquisition: $T=373 \mathrm{~K}, P_{\mathrm{H}_{2}}=200 \mathrm{~Pa}, 300 \mathrm{kV}$. Reprinted with permission from [245]. Copyright 2014, American Chemical Society.

We can observe that Au particles diffuse as crystalline entities on the graphene substrate until they make contact. At this point, the particles are linked together (Figure 20 middle) via the formation of a crystalline bridge, allowing the atoms to diffuse from one nanoparticle to eventually reach another. If the temperature is increased up to $673 \mathrm{~K}$ (and still under a pressure of $\mathrm{H}_{2}=200 \mathrm{~Pa}$ ), a different mechanism takes place, similar to the Ostwald ripening where bigger particles grow to the detriment of smaller ones via mass transfer. This proves that coarsening can follow multiple routes, particle migration and Ostwald ripening, which depends on the reactive conditions [244-246]. From a structural point of view, the choice of the support is thus crucial to avoid sintering and ensure the activity of gold catalyst.

Importance of the Support for the Stability

Catalysis by gold is most likely affected by the electronic state of the Au nanoparticles, which strongly depends on their interface with the support [247-250]. Metal-oxide supports such as $\mathrm{CeO}_{2}, \mathrm{TiO}_{2}$ and $\mathrm{Fe}_{2} \mathrm{O}_{3}$ are commonly used, their key function being the stabilisation of gold nanoparticles through the surface oxygen vacancies, which in turn depend on the size and shape of the support. On ceria support [251], it has been proved that the Au nanoparticles move reversibly, back and forth between equivalent sites by approximately $0.09 \mathrm{~nm}$ at room temperature and in presence of a reactive environment. This movement happens to a lesser extent in vacuum, but more frequently under $\mathrm{O}_{2}$ gas: this is explained by the compensation of oxygen vacancies by the $\mathrm{O}_{2}$ gas, decreasing the anchorage sites of the Au nanoparticles on the support. It was concluded that gold-based catalysts are relatively loosely bound to the support and may then diffuse on the surface with low activation energy. The authors also note that in the case of experiments by E-TEM, the low energy can be supplied by e-beam radiation. Using $\mathrm{CeO}_{2}$ nanorods rich in surface oxygen vacancies, Au nanoparticles are strongly anchored at the surface, active for CO oxidation and WGS reaction and stable under realistic reaction conditions. Indeed, no sintering was observed up to $573 \mathrm{~K}$ [252].

Another striking example of nanoparticle/support interaction is the structural reorganisation on the $\mathrm{Au} / \mathrm{TiO}_{2}$ system under beam irradiation [253]. The study was performed under vacuum, inert atmosphere $\left(\mathrm{N}_{2}-100 \mathrm{~Pa}\right)$, oxygen atmosphere $\left(\mathrm{O}_{2}-100 \mathrm{~Pa}\right)$ and reactive atmosphere $(1 \mathrm{vol} \% \mathrm{CO}$ in air-100 Pa).

The facetting of the Au nanoparticles, which will be described in the next section, can be summarised as follows: facetted morphology is observed under vacuum, inert and reactive environments; and round-shaped morphology is observed in only $\mathrm{O}_{2}$ atmosphere. By switching from one gas to another, a systematic change of the morphology can be observed in the majority of the nanoparticles [253-256]. Regarding the active phase/support interaction, it was observed 
that by increasing the electron dose $D$, the nanoparticles were increasingly decorated with material originating from the support. This can produce decorated, pillared or encapsulated particles, as can be observed in Figure 21A. The structural evolution diagram is presented in Figure 21b, where the regions of observation of different structures are plotted as a function of the electron dose $D$ and electron emission current $\phi$. For low $D$ and $\phi$, corresponding to the green region, no structural reorganisation can be observed. However, by increasing $D$ and $\phi$, the structural changes become an irreversible process. Finally, by extrapolating for $D=0$ and $\phi=0$, the intrinsic structure of the catalyst may be deduced and is located in the green region.

This study proves that the e-beam radiation must be accounted during E-TEM experiments, and that a careful control of the environment is required to avoid any artefacts. Indeed, earlier works explained the difference in catalytic reactivity of $\mathrm{Au} / \mathrm{TiO}_{2}$ as compared to $\mathrm{Au} / \mathrm{CeO}_{2}$ due to the presence of decorated/pillared/encapsulated nanoparticles. These structures are however present only in the presence of e-beam irradiation, and not in the applied formulation of catalysts.

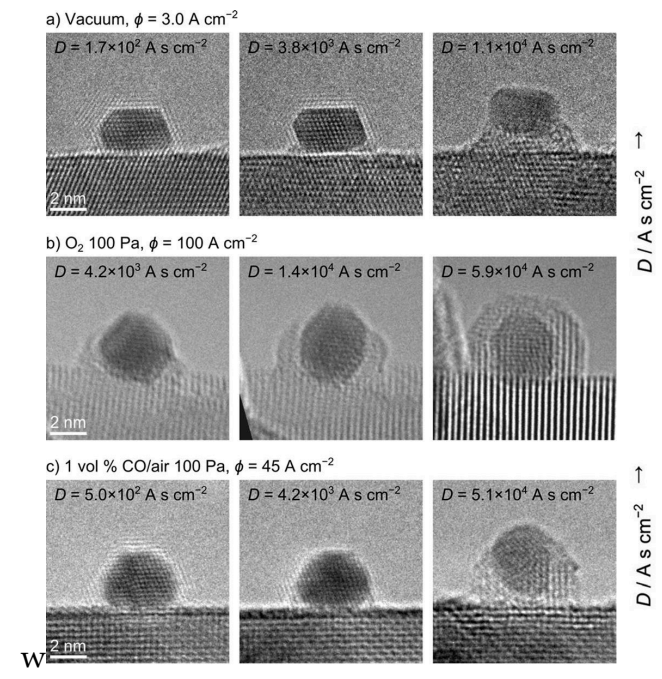

(A)
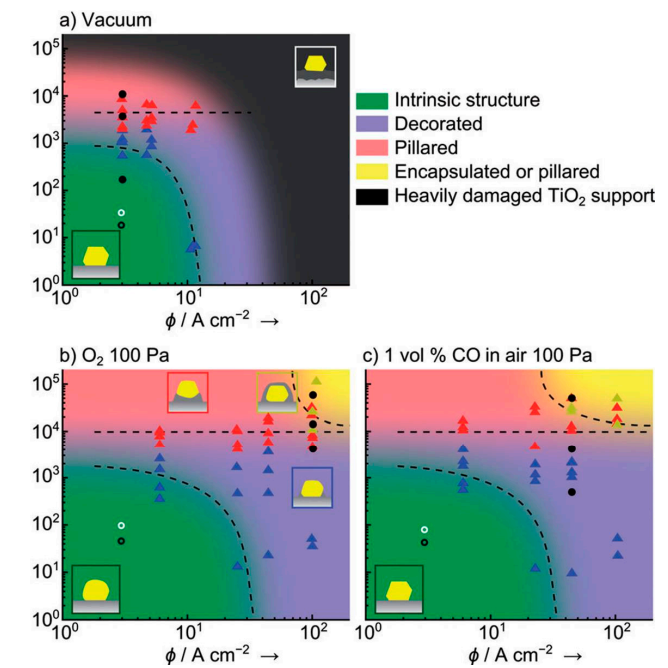

(B)

Figure 21. $\mathrm{Au} / \mathrm{TiO}_{2}$ nanoparticles changes under e-beam exposition: (A) Structural reorganisation of $\mathrm{Au} / \mathrm{TiO}_{2}$ nanoparticles under e-beam irradiation in vacuum, $\mathrm{O}_{2}$ environment (100 $\mathrm{Pa}$ ) and $\mathrm{CO}$ environment $(1 \mathrm{vol} \% \mathrm{CO}$ in air $100 \mathrm{~Pa})$. $D$ corresponds to the electron dose and $\phi$ to the electron current density; (B) Structure evolution diagram of $\mathrm{Au} / \mathrm{TiO}_{2}$ nanoparticles under e-beam showing the regions for the formation of decorated, pillared and encapsulated nanoparticles as a function of $D$ and phi. The intrinsic structure can be extrapolated for $D$ and $p h i=0$. Reproduced from [253]. Copyright 2012, Wiley-VCH Verlag GmbH \& Co. KGaA, Weinheim.

\section{Morphology of the Active Nanoparticles}

Previous sections focused on the behaviour of gold nanoparticles during coalescence, as well as the imaging of the behaviour of the substrate materials with nanoparticles. E-TEM can be applied to study the morphological changes of the gold catalyst during the reaction and to correlate the morphology to the catalytic activity. The behaviour of $\mathrm{Au} / \mathrm{CeO}_{2}$ and $\mathrm{Au} / \mathrm{TiO}_{2}$ under vacuum, inert, oxidising and reducing conditions has been extensively studied.

On $\mathrm{CeO}_{2}$ support, the $\mathrm{Au}$ nanoparticles present different morphologies as a function of the composition of the surrounding gas phase [257]. Under vacuum, inert gas atmosphere $\left(\mathrm{N}_{2}\right)$ and during $\mathrm{CO}$ oxidation (in a mixture $1 \mathrm{vol} \% \mathrm{CO} /$ air at $1 \mathrm{mbar}$, corresponding to the reactive environment), the nanoparticles appear in the form of a stable polyhedron enclosed by the major $\{111\}$ and $\{100\}$ facets. This morphology is represented in Figure 22A(a,b). The facetted morphology becomes "rounded" under $\mathrm{O}_{2}$ atmosphere, as shown on further TEM images in Figure 22 where the $\mathrm{CO} / \mathrm{O}_{2}$ pressure ratio is 
decreased, inducing a more oxidising environment. This change in morphology is however reversible. By applying a systematic change in the partial pressures of $\mathrm{CO}$ and $\mathrm{O}_{2}$, a morphology diagram can be plotted and is represented in Figure 22B. The statistically mixed region corresponds to a region where less than $70 \%$ of the particles present a well-defined shape. With this, it can be concluded that CO molecules stabilise the $\{111\}$ and $\{100\}$ facets. CO molecules are indeed adsorbed on the on-top sites of an $\mathrm{Au}\{100\}$-hex reconstructed surface under catalytic conditions (1 vol\% CO in air at $100 \mathrm{~Pa}$ and room temperature), and this structure is energetically favourable [258].

The origin of rounded morphology observed in $\mathrm{O}_{2}$ gas comes from fluctuating multi-facetted surfaces. Indeed, a careful examination of each frame of the E-TEM experiments showed that the minority $\{110\}$ facets emerged frequently in addition to the major $\{111\}$ and $\{100\}$. It is concluded that atomic oxygen from the dissociation of $\mathrm{O}_{2}$ causes the rounded shape of the nanoparticles. The authors also mentioned this because of the residual gases in the E-TEM, oxygen-related species may be formed and induce the rounded morphology. However, the studied nanoparticles present the same morphology as TEM experiments in vacuum after exposure to an environment at different gas pressures. The studies at low gas pressure are thus useful to understand the morphology of active nanoparticles under realistic catalytic conditions. Indeed, the morphology changes are in good correlation with the catalytic activity $[257,259]$. It has to be noted that even in the presence of strong interfacial bonding of $\mathrm{Au}$ with $\mathrm{CeO}_{2}$ nanorods [252], the reshaping of the nanoparticles and the nanoparticle/support interface under reducing environment (42 vol $\% \mathrm{CO} / 6 \mathrm{vol} \% \mathrm{O}_{2} / \mathrm{N}_{2}$ ) can be observed and prove the dynamic nature of the $\mathrm{Au} /$ support interface.

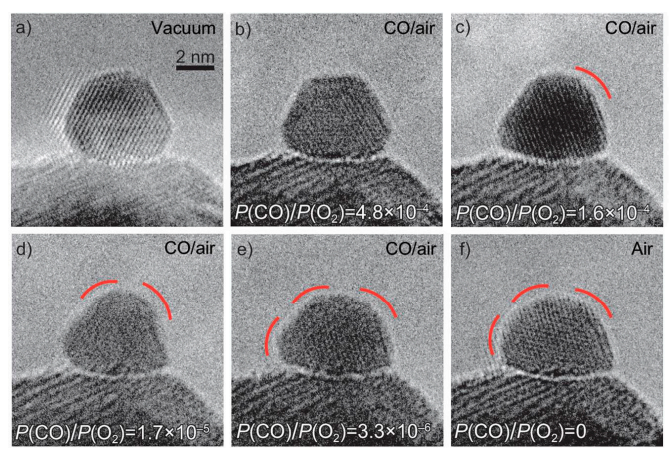

(A)

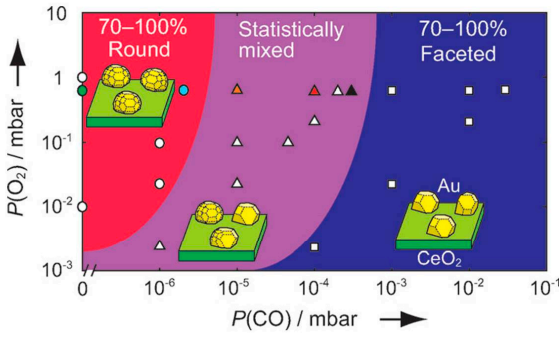

(B)

Figure 22. Study of the morphology of active Au nanoparticles: (A) Morphological change of an Au nanoparticle when the pressure ratio $\mathrm{CO} / \mathrm{O}_{2}$ is decreased; (B) Morphology diagram representing the dependence of the morphology of Au nanoparticles on the partial pressure of $\mathrm{CO}$ and $\mathrm{O}_{2}$, with mostly round-shaped particles in oxidising environment and facetted particles in reducing environment. Reproduced from [257]. Copyright 2011, Wiley-VCH Verlag GmbH \& Co. KGaA, Weinheim.

Importance of the Support for the Activity

As discussed above, $\mathrm{CeO}_{2}$ and $\mathrm{TiO}_{2}$ supports allow morphological changes of the $\mathrm{Au}$ nanoparticles to be observed. A comparative study was performed between two different $\mathrm{Au} / \mathrm{CeO}_{2}$ catalysts and less-active catalysts: $\mathrm{Au} / \mathrm{SiO}_{2}$ and $\mathrm{Au} / \mathrm{TiC}$ [260]. The nature of the support is different: reducible oxide for $\mathrm{CeO}_{2}$, non-reducible oxide for $\mathrm{SiO}_{2}$ and carbide for $\mathrm{TiC}$. By exposing the samples to $1 \mathrm{vol} \% \mathrm{CO} /$ air at $100 \mathrm{~Pa}$ and to $\mathrm{O}_{2}$ at $100 \mathrm{~Pa}$, both $\mathrm{Au} / \mathrm{CeO}_{2}$ catalysts switched from facetted to rounded morphology. In the case of $\mathrm{Au} / \mathrm{SiO}_{2}$ and $\mathrm{Au} / \mathrm{TiC}$, the nanoparticles mostly remained facetted in both reducing and oxidising environment, as depicted Figure 23.

In active catalysts, the rounded morphology is due to $\mathrm{O}_{2}$ gas in the reaction cell, and it is more likely that oxygen-species are generated at the periphery interface between the nanoparticles and the support. One of the hypotheses concerning the activation of oxygen on gold catalysts is the presence of surface oxygen vacancies on the support, contributing to a strong bond between the support and 
the Au nanoparticles. Therefore, electron transfer becomes possible and leads to negatively charged $\mathrm{Au}$ nanoparticles, enabling O-species adsorption on $\mathrm{Au}$. When the Au nanoparticle and the support are structurally coherent, the nanoparticle becomes a sphere. The resulting periphery interface is important, and thus the resulting catalytic activity becomes high. Whether it is because of a lack of surface oxygen vacancies or an amorphous structure, the $\mathrm{Au}$ /support interaction might not be the key feature to explain catalytic activity. Therefore, the latter may be related to the "morphology-changeable" character of the nanoparticles, which directly depends on the nature of the support and its synergy with the nanoparticle [260]. As can be seen in Figure 23, this morphology-changeable character correlates with the catalytic reactivity.

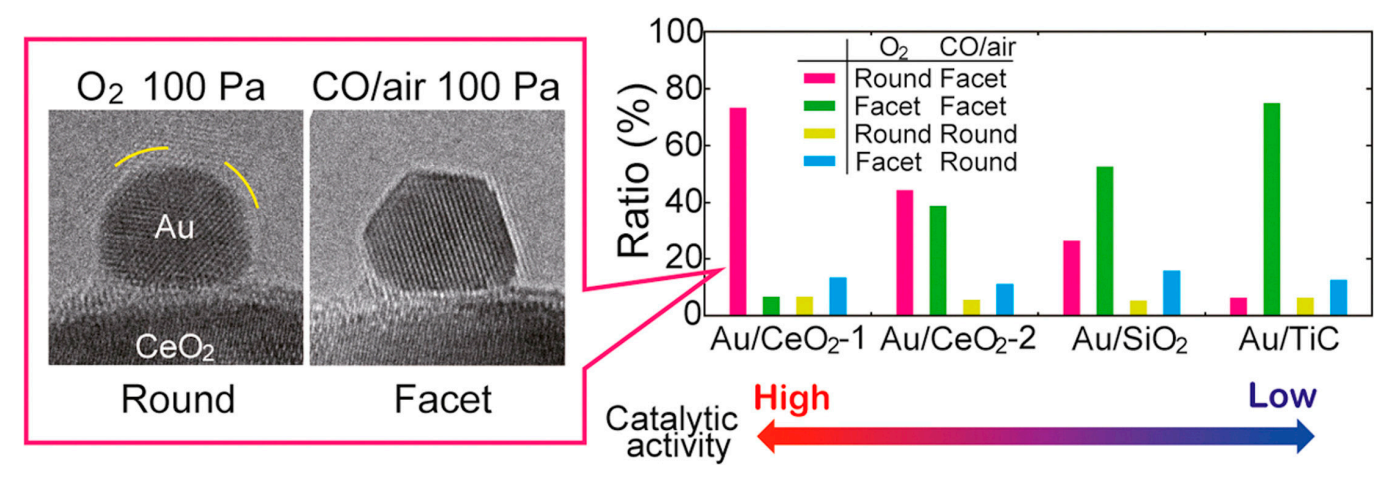

Figure 23. Correlation of the catalytic activity of supported Au catalysts with the "morphology-changeable" character of the nanoparticles, which is directly influenced by the nature of the support. Reproduced from [260]. Copyright 2017, Elsevier.

\subsubsection{Processes on Self-Supported Au}

The current research in gold catalysis consists of the study of catalytic reactions on nanoporous catalysts [261-265]. The nanoporous $\mathrm{Au}, \mathrm{npAu}$, consists of a 3D structure of interconnected pores and ligaments with a ligament size in the $20-100 \mathrm{~nm}$ range. The 3D network of ligaments and pores ensures the mechanical stability of the catalyst, as well as the mass transport of reactants and products through the catalyst [266]. These structures are prepared by free corrosion of a bulk Au-Ag alloy in an electrolyte [267], leading to the selective removal of the least noble metal, Ag in this case. As a function of the initial concentration, different ligament sizes can be obtained $[268,269]$, allowing the structure of the final catalyst to be fine-tuned. Residual Ag is present in the final structure with a concentration of few percent. This Ag is known to influence the catalytic activity [270-273] and thus its presence has to be considered.

It is known that the catalytic activity on gold nanoparticles depends on the size of the Au $[29,203]$ and that the support strongly influences the reactivity, as discussed in the previous section [260]. However, as is described below, significant activity can be observed in nanoporous systems, even though the characteristic length-scale is one order of magnitude higher (20-100 nm) and the catalyst is self-supported. In the same way that sintering decreases the activity of gold nanoparticles, coarsening decreases the activity of nanoporous gold. It has been proved that coarsening occurs during $\mathrm{CO}$ oxidation, and that planar defects can effectively prevent structure coarsening [274], and deformation mechanisms have to be accounted for [275]. Annealing and exposure to $\mathrm{O}_{2}$ gas can lead to coarsening, material loss and material migration [276].

Nanoporous $\mathrm{Au}$ as Catalyst for CO Oxidation

Nanoporous Au catalysts with a ligament size of $\approx 30 \mathrm{~nm}$ and a residual Ag content of 1.2 at $\%$ were studied under environmental conditions to understand their reactivity towards CO oxidation [277]. The reactivity of $\mathrm{npAu}$ is similar to the reactivity of Au nanoparticles. High-resolution imaging allows observing the presence of a high density of atomic steps and kinks on the curved surfaces of npAu 
(on both convex and concave surfaces), which is one of the features also present on Au nanoparticles. Under $\mathrm{CO}$ oxidation conditions at room temperature, the surface is catalytically active, and significant surface reconstruction is observed at a few $\mathrm{Pa}$, corresponding to $\{111\}$ facetting dynamics along the $\{011\}$ surface. The atoms in top-most surface are involved in $\mathrm{CO}$ oxidation. The facetting occurs while the e-beam is blanked, and is not observed under $\mathrm{N}_{2}, \mathrm{O}_{2}$ and $\mathrm{CO}$ atmosphere under the same imaging conditions: reconstructions are thus neither due to the e-beam irradiation, nor to the gas pressure. Residual silver may thus play a role. It is supposed that Ag segregates to step and kink positions on the surface so as to reduce the free energy for steps formation (as compared to pure $\mathrm{Au}$ ). To prove this, an npAu sample of similar pore size and similar internal surface but comprising $20 \mathrm{at} \%$ of residual $\mathrm{Ag}$ has been used for $\mathrm{CO}$ oxidation. With this catalyst, $\{111\}$ facetting dynamics are significantly suppressed during $\mathrm{CO}$ oxidation, leading to the conclusion that Ag significantly stabilises the surface steps and kinks. Therefore, the presence of a higher Ag concentration accelerates the catalytic oxidation by suppressing the surface reconstruction dynamics and providing more $\mathrm{Ag}$ active sites for $\mathrm{O}_{2}$ dissociation.

\section{Nanoporous Au as Catalyst for Selective Alcohol Oxidation}

The catalytic activity of nanoporous gold catalysts with a ligament size of $\approx 50 \mathrm{~nm}$ (Figure 24a) and a residual $\mathrm{Ag}$ content of $\approx 3$ at $\%$ were studied for the selective oxidation of methanol [217]. Both the ligament size and the $\mathrm{Ag}$ content are expected to influence the catalytic activity as compared to the previous example. In this work, the authors focused on influence of ozone activation on the catalyst to improve the selectivity towards alcohol oxidation reactions. One of the key steps towards this goal is the dissociation of oxygen species at the surface of the catalyst, and Ag provides active sites for oxygen dissociation [261-265].
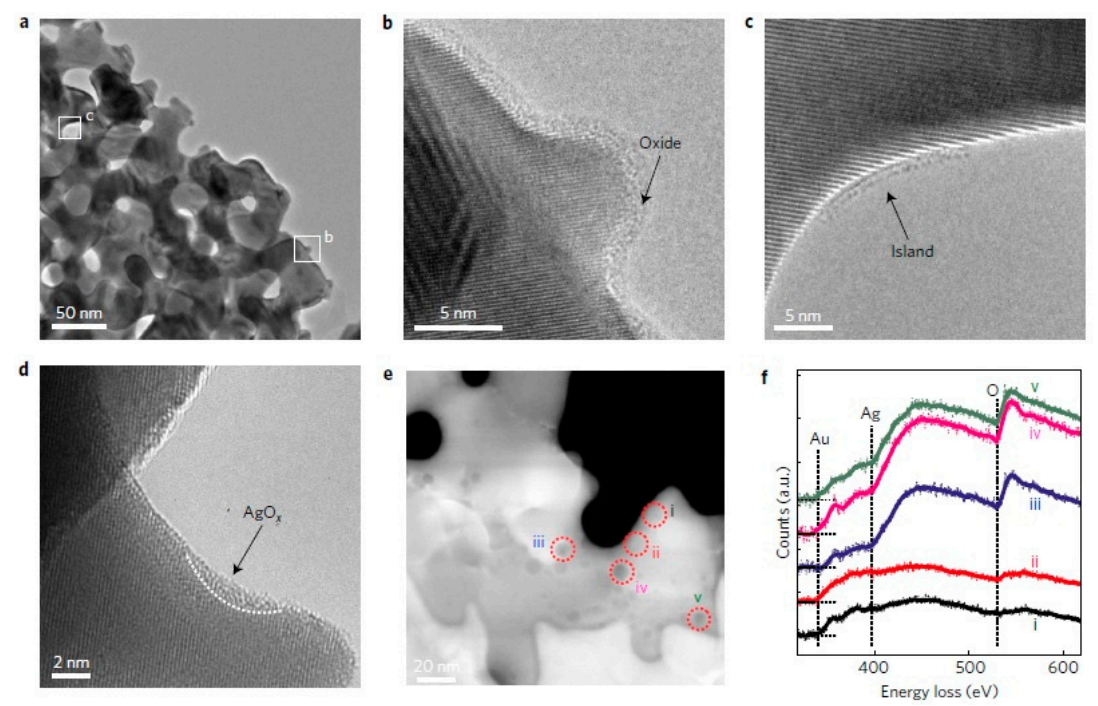

Figure 24. Nanoporous Au ad self-supported catalyst for selective alcohol oxidation: E-TEM analysis of nanoporous gold after ozone treatment showing (a) the porous and ligament structure of the sample; (b) the presence of an oxide layer due to ozone treatment; (c) the presence of crystalline islands; (d) TEM of amorphous oxide at the surface corresponding to silver-oxide species; (e) spots analysed by EELS; (f) EELS analysis showing the region of high Ag and O content. Reprinted by permission from [217]. Copyright 2016, Macmillan Publishers Ltd.

Experiments show that the ozone treatment creates a thin silver-rich layer $(1.1 \pm 0.1 \mathrm{~nm})$ (Figure 24b), as well as crystalline islands (Figure 24c) and amorphous oxides (Figure 24d). EELS analysis (Figure 24e,f) also prove the silver enrichment at the surface of the ligament. From a structural point of view, the oxide layer can be reduced by $\mathrm{CO}$, leading to the formation of small 
irregular nanoparticles on highly stepped regions of the catalyst. Further reduction in methanol results in the formation of 2-2.5 nm crystalline nanoparticles which may re-alloy into the bulk. From a catalysis point of view, the oxide layer is highly active for both $\mathrm{CO}$ and non-selective methanol oxidation. However, the reduction by $\mathrm{CO}$ leads to the formation of a distinct oxygen species stabilised by Au-Ag alloy sites. This distinct oxygen is inactive for $\mathrm{CO}$ oxidation, but active for selective methanol oxidation into formaldehyde. Ambient-pressure XPS and the temporal analysis of products (TAP) method corroborate these observations [217].

It can be concluded that the surface undergoes structural and compositional changes during activation by ozone and that the Ag segregation plays an important role in the formation of oxygen species for selective oxidation of methanol. The last two examples presented show that similar catalysts may behave completely differently as a function of the residual concentration of $\mathrm{Ag}$, but also as a function of the pretreatment/activation steps applied to that catalyst. The presence of $\mathrm{Ag}$, or any other metal, could be used to engineer catalysts for specific and selective reactions.

\subsubsection{Perspectives}

Currently, Au-based systems are studied by TEM and/or E-TEM for applications different to catalysis, but it may be of interest for heterogeneous catalysis applications to further study the role of the support and the synergy between the support and the catalyst. Such studies comprise the use of iron oxide and gold catalysts for the formation of carbon nanotubes [278], the analysis of unsupported $\mathrm{Au}$ particles deposited on $\mathrm{Si}$ [279], the $\mathrm{Au}$ assisted growth of $\mathrm{MgO}$ crystals [280], and $\mathrm{Au}$ assisted growth of Ge nanowires [281]. Different Au-based alloys were studied by TEM or E-TEM; these studies could be extended to their behaviour under catalytic conditions. These alloys are $\mathrm{Au}-\mathrm{Ni}$ [282], $\mathrm{Au}-\mathrm{Cu}$ alloys [283-285], Au-Pd, Au-Ag and Au-Pt nanorods [286].

As mentioned, e-beam irradiation may induce negative effects on the catalyst. However, in some cases, these effects are useful to produce Au-based alloys with specific structure. It has been proved that it was possible to grow Au layers on Pt particles by low-dose TEM [287,288], or to produce Au@Ag core-shell structures by exposing Au and Ag nanoparticles to a high dose of e-beam [242]. Finally, the e-beam irradiation has also been used in in situ liquid cell TEM to synthesise Au-Pd core-shell nanostructures [289]. The use of liquid cell for TEM [290] could thus be used to study the catalyst formation, as well as to follow liquid-phase reactions with $\mathrm{Au}$ as catalyst.

\section{Conclusions and Perspectives}

This review presents the main results that can be obtained from the analysis of gold and gold-based catalysts by environmental microscopies. By presenting case studies from three main families of techniques, it has been possible to cover the wide range of the catalytic complexity studied in fundamental research so as to get closer to the imaging of applied formulations of catalysts under industrial conditions. The PEEM/LEEM techniques address flat samples (single crystals, foils or composite surfaces); a model single nanoparticle of catalyst can be imaged by FIM/FEM techniques, whereas E-TEM can be used to study unsupported, supported and self-supported catalysts. Of course, these techniques present some limitations. PEEM experiments have a relatively low resolution, but allow global processes to be studied. FIM/FEM studies are, most of the time, performed with an imaging field, but allow Au catalysis in the complete absence of support to be studied; E-TEM imaging suffers from beam damages, but the technique can be used for a wide variety of catalysts.

PEEM was used to study how the presence of $\mathrm{Au}$, even at low coverage, on a Pt surface affects the dynamics by modification of the kinetic parameters, whereas LEEM was used to probe the mass transport of the catalytic material, due to the reaction. In the latter case, the initial structure is important: starting from an O-covered Rh surface or a clean Rh surface before the deposition of gold, the behaviour under reaction conditions differs from stationary waves to segregated phases. By further increasing the complexity and depositing $\mathrm{Au}$ and $\mathrm{Pd}$, the phase separation can be reversibly obtained by changing the control parameters. FIM experiments allowed wave propagation during the interaction of CO 
with $\mathrm{O}_{2}$ on a single nanoparticle of Au to be observed. A detailed analysis of this system proved that oxygen eventually had the role of imaging gas and that the $\mathrm{CO}$ oxidation did not occur on an unsupported $\mathrm{Au}$ nanoparticle. However, a mixture of $\mathrm{CO}$ and $\mathrm{H}_{2} \mathrm{O}$ seems to react via the water gas shift reaction. FEM was used to determine activation energies for water desorption and diffusion, to study the adsorption of oxygen on $\mathrm{Au}-\mathrm{Ag}$ alloy, and also to investigate the NO hydrogenation on Au-Pd nanoparticles. Finally, E-TEM is of great interest to move closer to real conditions, as was shown by the study of Au nanoparticles sintering and the influence of the support. The morphological changes during gas exposure is again correlated with the nature of the support and the nature of gas studied; and finally the study of nanoporous structures made of Au-Ag where the catalytic activity depends on the size of the ligaments, the Ag content and its distribution.

Environmental microscopies are thus crucial to get a better understanding of catalytic systems, but complimentary techniques have to be applied to obtain chemical information during imaging. Spectroscopy, spectrometry and/or diffraction methods are thus necessary to get a full picture of the catalytic process. To cite but a few, surface propagation during $\mathrm{CO}$ oxidation on $\mathrm{Pt}$ induces a surface transformation that cannot be observed by PEEM, but is probed by LEED; the brightness in the LEEM patterns is associated with different surface compositions via their comparison with micro-XPS measurements; mass spectrometry was extensively used to prove the presence or absence of dissociative processes observed by FIM, as well as the segregation of Pd in Au-Pd alloys; and EELS is used to highlight the Ag segregation on nanoporous gold catalysts.

The comparison of three different techniques allows us to draw a few conclusions regarding gold catalysis:

- The addition of a minor amount of surface species may severely affect the global reactivity of the catalyst, as it was demonstrated on Au-covered Pt in PEEM and Au-Ag alloys in nanoporous gold by E-TEM;

- $\quad$ Alloying induces synergistic effects, as shown on Au + Pd-covered Rh by LEEM and Au-Pd catalysts for NO hydrogenation by FEM, a reaction that was not possible on pure $\mathrm{Au}$;

- The size-effect in gold catalysis arises from the step and kinks density, as shown on nanoporous structures by E-TEM where the reactivity of the npAu depends on the size of the ligaments. These studies also prove the relevance of using a tip-sample of $20-50 \mathrm{~nm}$ by FIM to study fundamental processes;

- The presence of silver can be used to stabilise the structure, but also to guide the selectivity of the reaction, as it was studied by FEM and E-TEM;

- $\quad$ CO oxidation has been studied by PEEM, FIM and E-TEM; the water gas shift reaction by FIM and E-TEM, but current research focuses on more complex reactions over Au-based catalysts.

The emergence of environmental microscopies greatly improved the understanding of catalytic processes. The constant technological developments allow better imaging resolutions under reaction conditions to be obtained and more importantly, the developments towards correlative microscopy and spectroscopy/spectrometry under reaction conditions promise a golden future for the study of catalytic processes closer to conditions used in industrial applications.

Acknowledgments: C.B. and L.J. thank the Fonds de la Recherche Scientifique (F.R.S.-FNRS) for financial support (Postdoctoral fellowship from FNRS and Ph.D. grant from FRIA respectively). The authors thank Natalia Gilis for the realisation of Figures 2 and 3 and fruitful discussions.

Author Contributions: All the authors contributed equally.

Conflicts of Interest: The authors declare no conflict of interest. The founding sponsors had no role in the design of the study; in the collection, analyses, or interpretation of data; in the writing of the manuscript, and in the decision to publish the results. 


\section{References}

1. Liotta, L.F. Catalytic oxidation of volatile organic compounds on supported noble metals. Appl. Catal. B Environ. 2010, 100, 403-412. [CrossRef]

2. Wang, J.; Aguilar-Rios, G.; Wang, R. Inhibition of carbon monoxide on methanol oxidation over alumina supported Ag, Pd and Ag-Pd catalysts. Appl. Surf. Sci. 1999, 147, 44-51. [CrossRef]

3. Brunet, J.; Genty, E.; Landkocz, Y.; Al Zallouha, M.; Billet, S.; Courcot, D.; Siffert, S.; Thomas, D.; De Weireld, G.; Cousin, R. Identification of by-products issued from the catalytic oxidation of toluene by chemical and biological methods. Comptes Rendus Chim. 2015, 18, 1084-1093. [CrossRef]

4. Patterson, M.J.; Angove, D.E.; Cant, N.W. The effect of carbon monoxide on the oxidation of four $\mathrm{C}_{6}$ to $\mathrm{C}_{8}$ hydrocarbons over platinum, palladium and rhodium. Appl. Catal. B Environ. 2000, 26, 47-57. [CrossRef]

5. Patterson, M.J.; Angove, D.E.; Cant, N.W. The effect of metal order on the oxidation of a hydrocarbon mixture over alumina-supported combined platinum/rhodium catalysts. Appl. Catal. B Environ. 2001, 35, 53-58. [CrossRef]

6. Cant, N.W.; Angove, D.E.; Chambers, D.C. Nitrous oxide formation during the reaction of simulated exhaust streams over rhodium, platinum and palladium catalysts. Appl. Catal. B Environ. 1998, 17, 63-73. [CrossRef]

7. Al Zallouha, M.; Landkocz, Y.; Brunet, J.; Cousin, R.; Genty, E.; Courcot, D.; Siffert, S.; Shirali, P.; Billet, S. Usefulness of toxicology validation of VOCs catalytic degradation by air-liquid interface exposure system. Environ. Res. 2017, 152, 328-335. [CrossRef] [PubMed]

8. Tidahy, H.L.; Siffert, S.; Wyrwalski, F.; Lamonier, J.-F.; Aboukaïs, A. Catalytic activity of copper and palladium based catalysts for toluene total oxidation. Catal. Today 2007, 119, 317-320. [CrossRef]

9. Liotta, L.F.; Di Carlo, G.; Pantaleo, G.; Venezia, A.M.; Deganello, G. $\mathrm{Co}_{3} \mathrm{O}_{4} / \mathrm{CeO}_{2}$ composite oxides for methane emissions abatement: Relationship between $\mathrm{Co}_{3} \mathrm{O}_{4}-\mathrm{CeO}_{2}$ interaction and catalytic activity. Appl. Catal. B Environ. 2006, 66, 217-227. [CrossRef]

10. Genty, E.; Cousin, R.; Capelle, S.; Gennequin, C.; Siffert, S. Catalytic oxidation of toluene and CO over nanocatalysts derived from hydrotalcite-like compounds $\left(\mathrm{X}_{6}{ }^{2+} \mathrm{Al}_{2}{ }^{3+}\right)$ : Effect of the bivalent cation. Eur. J. Inorg. Chem. 2012, 2012, 2802-2811. [CrossRef]

11. Kim, S.C.; Shim, W.G. Catalytic combustion of VOCs over a series of manganese oxide catalysts. Appl. Catal. B Environ. 2010, 98, 180-185. [CrossRef]

12. Cook, K.M.; Poudyal, S.; Miller, J.T.; Bartholomew, C.H.; Hecker, W.C. Reducibility of alumina-supported cobalt Fischer-Tropsch catalysts: Effects of noble metal type, distribution, retention, chemical state, bonding, and influence on cobalt crystallite size. Appl. Catal. A Gen. 2012, 449, 69-80. [CrossRef]

13. Ataloglou, T.; Vakros, J.; Bourikas, K.; Fountzoula, C.; Kordulis, C.; Lycourghiotis, A. Influence of the preparation method on the structure-activity of cobalt oxide catalysts supported on alumina for complete benzene oxidation. Appl. Catal. B Environ. 2005, 57, 299-312. [CrossRef]

14. Genty, E.; Brunet, J.; Pequeux, R.; Capelle, S.; Siffert, S.; Cousin, R. Effect of Ce substituted hydrotalcite-derived mixed oxides on total catalytic oxidation of air pollutant. Mater. Today Proc. 2016, 3, 277-281. [CrossRef]

15. Fuentes, E.M.; da Costa Faro, A.; de Freitas Silva, T.; Assaf, J.M.; Rangel, M.D.C. A comparison between copper and nickel-based catalysts obtained from hydrotalcite-like precursors for WGSR. Catal. Today 2011, 171, 290-296. [CrossRef]

16. Palomares, A.E.; Uzcategui, A.; Corma, A. NOx storage/reduction catalysts based in cobalt/copper hydrotalcites. Catal. Today 2008, 137, 261-266. [CrossRef]

17. Casapu, M.; Bernhard, A.; Peitz, D.; Mehring, M.; Elsener, M.; Krocher, O. A Niobia-Ceria based multi-purpose catalyst for selective catalytic reduction of $\mathrm{NO}_{\mathrm{x}}$ urea hydrolysis and soot oxidation in diesel exhaust. Appl. Catal. B Environ. 2011, 103, 79-84. [CrossRef]

18. Brunet, J.; Genty, E.; Bugnon, L.; De Weireld, G.; Thomas, D.; Decroly, A.; Siffert, S.; Cousin, R. Co-Al-Ce mixed oxide materials prepared by hydrotalcite way for VOCs total oxidation in micro- and semi-pilot scale. Mater. Today Proc. 2016, 3, 188-193. [CrossRef]

19. Bera, P.; Hegde, M.S. Noble metal ions in $\mathrm{CeO}_{2}$ and $\mathrm{TiO}_{2}$ : Synthesis, structure and catalytic properties. RSC Adv. 2015, 5, 94949-94979. [CrossRef]

20. Zheng, T.; He, J.; Zhao, Y.; Xia, W.; He, J. Precious metal-support interaction in automotive exhaust catalysts. J. Rare Earths 2014, 32, 97-107. [CrossRef] 
21. Kinnunen, N.M.; Hirvi, J.T.; Kallinen, K.; Maunula, T.; Keenan, M.; Suvanto, M. Case study of a modern lean-burn methane combustion catalyst for automotive applications: What are the deactivation and regeneration mechanisms? Appl. Catal. B Environ. 2017, 207, 114-119. [CrossRef]

22. Ordóñez, S.; Bello, L.; Sastre, H.; Rosal, R.; Fernando, V.D. Kinetics of the deep oxidation of benzene, toluene, n-hexane and their binary mixtures over a platinum on $\gamma$-alumina catalyst. Appl. Catal. B Environ. 2002, 38, 139-149. [CrossRef]

23. Benard, S.; Ousmane, M.; Retailleau, L.; Boreave, A.; Vernoux, P.; Giroir-Fendler, A. Catalytic removal of propene and toluene in air over noble metal catalyst. Can. J. Civ. Eng. 2009, 36, 1935-1945. [CrossRef]

24. Mergler, Y.J.; van Aalst, A.; van Delft, J.; Nieuwenhuys, B.E. CO oxidation over promoted Pt catalysts. Appl. Catal. B Environ. 1996, 10, 245-261. [CrossRef]

25. Liotta, L.F.; Ousmane, M.; Di Carlo, G.; Pantaleo, G.; Deganello, G.; Boreave, A.; Giroir-Fendler, A. Catalytic removal of toluene over $\mathrm{Co}_{3} \mathrm{O}_{4}-\mathrm{CeO}_{2}$ mixed oxide catalysts: Comparison with $\mathrm{Pt} / \mathrm{Al}_{2} \mathrm{O}_{3}$. Catal. Lett. 2008, 127, 270-276. [CrossRef]

26. Haruta, M.; Kobayashi, T.; Sano, H.; Yamada, N. Novel gold catalysts for the oxidation of carbon monoxide at a temperature far below $0{ }^{\circ} \mathrm{C}$. Chem. Lett. 1987, 405-408. [CrossRef]

27. Haruta, M.; Yamada, N.; Kobayashi, T.; Iijima, S. Gold catalysts prepared by coprecipitation for low-temperature oxidation of hydrogen and of carbon monoxide. J. Catal. 1989, 115, 301-309. [CrossRef]

28. Haruta, M.; Tsubota, S.; Kobayashi, T.; Kageyama, H.; Genet, M.J.; Delmon, B. Low-temperature oxidation of $\mathrm{CO}$ over gold supported on $\mathrm{TiO}_{2}, \mathrm{Fe}_{2} \mathrm{O}_{3}$ and $\mathrm{Co}_{3} \mathrm{O}_{4}$. J. Catal. 1993, 144, 175-192. [CrossRef]

29. Haruta, M. Size- and support-dependency in the catalysis of gold. Catal. Today 1997, 36, 153-166. [CrossRef]

30. Hashmi, A.S.K.; Hutchings, G.J. Gold catalysis. Angew. Chem. Int. Ed. 2006, 45, 7896-7936. [CrossRef] [PubMed]

31. Hutchings, G.J.; Joffe, R. A novel process for the co-synthesis of vinyl chloride monomer and sodium carbonate using a gold catalyst. Appl. Catal. 1986, 20, 215-218. [CrossRef]

32. Nkosi, B.; Coville, N.J.; Hutchings, G.J. Vapour phase hydrochlorination of acetylene with group VIII and IB metal chloride catalysts. Appl. Catal. 1988, 43, 33-39. [CrossRef]

33. Andreeva, D.; Ivanov, I.; Ilieva, L.; Abrashev, M.V.; Zanella, R.; Sobczak, J.W.; Lisowski, W.; Kantcheva, M.; Avdeev, G.; Petrov, K. Gold catalysts supported on ceria doped by rare earth metals for water gas shift reaction: Influence of the preparation method. Appl. Catal. A Gen. 2009, 357, 159-169. [CrossRef]

34. Ivanova, S.; Petit, C.; Pitchon, V. Application of alumina supported gold-based catalysts in total oxidation of CO and light hydrocarbons mixture. Catal. Today 2006, 113, 182-186. [CrossRef]

35. Vargas, J.C.; Ivanova, S.; Thomas, S.; Roger, A.-C.; Pitchon, V. Influence of gold on Ce-Zr-Co fluorite-type mixed oxide catalysts for ethanol steam reforming. Catalysts 2012, 2, 121-138. [CrossRef]

36. Genty, E.; Cousin, R.; Gennequin, C.; Capelle, S.; Aboukaïs, A.; Siffert, S. Investigation of Au/hydrotalcite catalysts for toluene total oxidation. Catal. Today 2011, 176, 116-119. [CrossRef]

37. Ivanova, S.; Petit, C.; Pitchon, V. A new preparation method for the formation of gold nanoparticles on an oxide support. Appl. Catal. A Gen. 2004, 267, 191-201. [CrossRef]

38. Delannoy, L.; Fajerwerg, K.; Lakshmanan, P.; Potvin, C.; Méthivier, C.; Louis, C. Supported gold catalysts for the decomposition of VOC: Total oxidation of propene in low concentration as model reaction. Appl. Catal. B Environ. 2010, 94, 117-124. [CrossRef]

39. Zanella, R.; Louis, C.; Giorgio, S.; Touroude, R. Crotonaldehyde hydrogenation by gold supported on $\mathrm{TiO}_{2}$ : Structure sensitivity and mechanism. J. Catal. 2004, 223, 328-339. [CrossRef]

40. Zanella, R.; Giorgio, S.; Shin, C.-H.; Henry, C.R.; Louis, C. Characterization and reactivity in CO oxidation of gold nanoparticles supported on $\mathrm{TiO}_{2}$ prepared by deposition-precipitation with $\mathrm{NaOH}$ and urea. J. Catal. 2004, 222, 357-367. [CrossRef]

41. Zanella, R.; Delannoy, L.; Louis, C. Mechanism of deposition of gold precursors onto $\mathrm{TiO}_{2}$ during the preparation by cation adsorption and deposition-precipitation with $\mathrm{NaOH}$ and urea. Appl. Catal. A Gen. 2005, 291, 62-72. [CrossRef]

42. Park, E.D.; Lee, J.S. Effects of Pretreatment Conditions on CO oxidation over supported Au catalysts. J. Catal. 1999, 186, 1-11. [CrossRef]

43. Ueda, A.; Haruta, M. Nitric oxide reduction with hydrogen, carbon monoxide, and hydrocarbons over gold catalysts. Gold Bull. 1999, 32, 3-11. [CrossRef] 
44. Golunski, S.; Rajaram, R.; Hodge, N.; Hutchings, G.J.; Kiely, C.J. Low-temperature redox activity in co-precipitated catalysts: A comparison between gold and platinum-group metals. Catal. Today 2002, 72, 107-113. [CrossRef]

45. Barakat, T.; Rooke, J.C.; Genty, E.; Cousin, R.; Siffert, S.; Su, B.-L. Gold catalysts in environmental remediation and water-gas shift technologies. Energy Environ. Sci. 2013, 6, 371. [CrossRef]

46. Genty, E.; Cousin, R.; Capelle, S.; Siffert, S. Influence of gold on hydrotalcite-like compound catalysts for toluene and CO total oxidation. Catalysts 2013, 3, 966-977. [CrossRef]

47. Centeno, M.; Ramírez Reina, T.; Ivanova, S.; Laguna, O.; Odriozola, J. Au/CeO catalysts: Structure and CO oxidation activity. Catalysts 2016, 6, 158. [CrossRef]

48. Alshammari, A.; Kalevaru, V.N.; Martin, A. Bimetallic catalysts containing gold and palladium for environmentally important reactions. Catalysts 2016, 6, 1-24. [CrossRef]

49. Luo, Y.; Seo, H.O.; Kim, K.D.; Kim, M.J.; Tai, W.S.; Burkhart, M.; Kim, Y.D. CO oxidation of Au-Pt nanostructures: Enhancement of catalytic activity of Pt nanoparticles by Au. Catal. Lett. 2010, 134, 45-50. [CrossRef]

50. Destro, P.; Marras, S.; Manna, L.; Colombo, M.; Zanchet, D. AuCu alloy nanoparticles supported on $\mathrm{SiO}_{2}$ : Impact of redox pretreatments in the catalyst performance in CO oxidation. Catal. Today 2016, 282, 105-110. [CrossRef]

51. Hosseini, M.; Barakat, T.; Cousin, R.; Aboukaïs, A.; Su, B.-L.; De Weireld, G.; Siffert, S. Catalytic performance of core-shell and alloy $\mathrm{Pd}-\mathrm{Au}$ nanoparticles for total oxidation of VOC: The effect of metal deposition. Appl. Catal. B Environ. 2012, 111, 218-224. [CrossRef]

52. Peneau, V.; He, Q.; Shaw, G.; Kondrat, S.A.; Davies, T.E.; Miedziak, P.; Forde, M.; Dimitratos, N.; Kiely, C.J.; Hutchings, G.J. Selective catalytic oxidation using supported gold-platinum and palladium-platinum nanoalloys prepared by sol-immobilisation. Phys. Chem. Chem. Phys. 2013, 15, 10636-10644. [CrossRef] [PubMed]

53. Hosseini, M.; Siffert, S.; Cousin, R.; Aboukaïs, A.; Hadj-Sadok, Z.; Su, B.-L. Total oxidation of VOCs on $\mathrm{Pd}$ and/or Au supported on $\mathrm{TiO}_{2} / \mathrm{ZrO}_{2}$ followed by "operando" DRIFT. Comptes Rendus Chim. 2009, 12, 654-659. [CrossRef]

54. Qian, L.; Sha, Y.; Yang, X. Simple and convenient preparation of Au-Pt core-shell nanoparticles on surface via a seed growth method. Thin Solid Films 2006, 515, 1349-1353. [CrossRef]

55. Zhang, L.; Xie, Z.; Gong, J. Shape-controlled synthesis of Au-Pd bimetallic nanocrystals for catalytic applications. Chem. Soc. Rev. 2016, 45, 3916-3934. [CrossRef] [PubMed]

56. Huang, J.; Zhang, L.; Chen, B.; Ji, N.; Chen, F.; Zhang, Y.; Zhang, Z. Nanocomposites of size-controlled gold nanoparticles and graphene oxide: Formation and applications in SERS and catalysis. Nanoscale 2010, 2, 2733-2738. [CrossRef] [PubMed]

57. Silva, C.G.; Juárez, R.; Marino, T.; Molinari, R.; García, H. Influence of excitation wavelength (UV or visible light) on the photocatalytic activity of titania containing gold nanoparticles for the generation of hydrogen or oxygen from water. J. Am. Chem. Soc. 2011, 133, 595-602. [CrossRef] [PubMed]

58. Fenger, R.; Fertitta, E.; Kirmse, H.; Thünemann, A.F.; Rademann, K. Size dependent catalysis with CTAB-stabilized gold nanoparticles. Phys. Chem. Chem. Phys. 2012, 14, 9343-9349. [CrossRef] [PubMed]

59. Fang, X.; Ma, H.; Xiao, S.; Shen, M.; Guo, R.; Cao, X.; Shi, X. Facile immobilization of gold nanoparticles into electrospun polyethyleneimine/polyvinyl alcohol nanofibers for catalytic applications. J. Mater. Chem. 2011, 21, 4493-4501. [CrossRef]

60. Shang, C.; Liu, Z.P. Origin and activity of gold nanoparticles as aerobic oxidation catalysts in aqueous solution. J. Am. Chem. Soc. 2011, 133, 9938-9947. [CrossRef] [PubMed]

61. Matassa, R.; Familiari, G.; Battaglione, E.; Sibilia, C.; Leahu, G.; Belardini, A.; Venditti, I.; Fontana, L.; Fratoddi, I. Electron microscopy reveals a soluble hybrid network of individual nanocrystals self-anchored by bifunctional thiol fluorescent bridges. Nanoscale 2016, 8, 18161-18169. [CrossRef] [PubMed]

62. Lopez-Sanchez, J.A.; Dimitratos, N.; Hammond, C.; Brett, G.L.; Kesavan, L.; White, S.; Miedziak, P.; Tiruvalam, R.; Jenkins, R.L.; Carley, A.F.; et al. Facile removal of stabilizer-ligands from supported gold nanoparticles. Nat. Chem. 2011, 3, 551-556. [CrossRef] [PubMed]

63. Venditti, I.; Fontana, L.; Fratoddi, I.; Battocchio, C.; Cametti, C.; Sennato, S.; Mura, F.; Sciubba, F.; Delfini, M.; Russo, M.V. Direct interaction of hydrophilic gold nanoparticles with dexamethasone drug: Loading and release study. J. Colloid Interface Sci. 2014, 418, 52-60. [CrossRef] [PubMed] 
64. Venditti, I.; Palocci, C.; Chronopoulou, L.; Fratoddi, I.; Fontana, L.; Diociaiuti, M.; Russo, M.V. Candida rugosa lipase immobilization on hydrophilic charged gold nanoparticles as promising biocatalysts: Activity and stability investigations. Colloids Surf. B 2015, 131, 93-101. [CrossRef] [PubMed]

65. Porcaro, F.; Battocchio, C.; Antoccia, A.; Fratoddi, I.; Venditti, I.; Fracassi, A.; Luisetto, I.; Russo, M.V.; Polzonetti, G. Synthesis of functionalized gold nanoparticles capped with 3-mercapto-1-propansulfonate and 1-thioglucose mixed thiols and "in vitro" bioresponse. Colloids Surf. B 2016, 142, 408-416. [CrossRef] [PubMed]

66. Venditti, I.; Hassanein, T.F.; Fratoddi, I.; Fontana, L.; Battocchio, C.; Rinaldi, F.; Carafa, M.; Marianecci, C.; Diociaiuti, M.; Agostinelli, E.; et al. Bioconjugation of gold-polymer core-shell nanoparticles with bovine serum amine oxidase for biomedical applications. Colloids Surf. B 2015, 134, 314-321. [CrossRef] [PubMed]

67. Fontana, L.; Fratoddi, I.; Venditti, I.; Ksenzov, D.; Russo, M.V.; Grigorian, S. Structural studies on drop-cast film based on functionalized gold nanoparticles network: The effect of thermal treatment. Appl. Surf. Sci. 2016, 369, 115-119. [CrossRef]

68. Ertl, G.; Freund, H.-J. Catalysis and surface science. Phys. Today 1999, 32-38. [CrossRef]

69. Rotermund, H.H. Imaging pattern formation in surface reactions from ultra-high vacuum up to atmospheric pressures. Surf. Sci. 1997, 386, 10-23. [CrossRef]

70. Osterlund, L.; Rasmussen, P.B.; Thostrup, P.; Laegsgaard, E.; Stensgaard, I.; Besenbacher, F. Bridging the pressure gap in surface science at the atomic level: $\mathrm{H} / \mathrm{Cu}(110)$. Phys. Rev. Lett. 2001, 86, 460-463. [CrossRef] [PubMed]

71. Haas, G.; Pletcher, T.D.; Bonilla, G.; Jachimowski, T.A.; Rotermund, H.H.; Lauterbach, J. Ellipsomicroscopy for surface imaging: A novel tool to investigate surface dynamics. J. Vac. Sci. Technol. 1998, 16, 1117-1121. [CrossRef]

72. Besenbacher, F.; Lauritsen, J.V.; Wendt, S. STM studies of model catalysts. Nano Today 2007, 2, 30-39. [CrossRef]

73. Besenbacher, F.; Lauritsen, J.V.; Linderoth, T.R.; Lægsgaard, E.; Vang, R.T.; Wendt, S. Atomic-scale surface science phenomena studied by scanning tunneling microscopy. Surf. Sci. 2009, 603, 1315-1327. [CrossRef]

74. Chorkendorff, I.; Niemantsverdriet, J.W. Concepts of Modern Catalysis and Kinetics; WILEY-VCH Verlag GmbH \& Co. KGaA: Weinheim, Germany, 2003.

75. Imbihl, R.; Behm, R.J.; Schlogl, R. Bridging the pressure and material gap in heterogeneous catalysis. Phys. Chem. Chem. Phys. 2007, 9, 3459. [PubMed]

76. Genty, E.; Brunet, J.; Poupin, C.; Casale, S.; Capelle, S.; Massiani, P.; Siffert, S.; Cousin, R. Co-Al mixed oxides prepared via LDH route using microwaves or ultrasound: Application for catalytic toluene total oxidation. Catalysts 2015, 5, 851-867. [CrossRef]

77. Iablokov, V.; Xiang, Y.; Meffre, A.; Fazzini, P.F.; Chaudret, B.; Kruse, N. Size-dependent activity and selectivity of $\mathrm{Fe} / \mathrm{MCF}-17$ in the catalytic hydrogenation of carbon monoxide using $\mathrm{Fe}(0)$ nanoparticles as precursors. ACS Catal. 2016, 6, 2496-2500. [CrossRef]

78. De Decker, Y.; Bullara, D.; Barroo, C.; Visart de Bocarmé, T. Nonlinear dynamics of reactive nanosystems: Theory and experiments. In Bottom-Up Self-Organization in Supramolecular Soft Matter; Springer: Berlin/Heidelberg, Germany, 2015; pp. 127-150.

79. Vogel, D.; Spiel, C.; Schmid, M.; Stoger-Pollach, M.; Schlogl, R.; Suchorski, Y.; Rupprechter, G. The role of defects in the local reaction kinetics of CO oxidation on low-index Pd surfaces. J. Phys. Chem. C 2012, 117, 12054-12060. [CrossRef] [PubMed]

80. Hiebel, F.; Shong, B.; Chen, W.; Madix, R.J.; Kaxiras, E.; Friend, C.M. Self-assembly of acetate adsorbates drives atomic rearrangement on the $\mathrm{Au}(110)$ surface. Nat. Commun. 2016, 7, 1-8. [CrossRef] [PubMed]

81. Hawkes, P.W.; Spence, J.C.H. Science of Microscopy; Springer: Berlin/Heidelberg, Germany, 2007; Volume 53.

82. Gai, P.L. Environmental high resolution electron microscopy of gas-catalyst reactions. Top. Catal. 1999, 8, 97-113. [CrossRef]

83. Block, J.H.; Ehsasi, M.; Gorodetskii, V. Dynamic studies of surface reactions with microscopic techniques. Prog. Surf. Sci. 1993, 42, 143-168. [CrossRef]

84. Chenna, S.; Crozier, P.A. In situ environmental transmission electron microscopy to determine transformation pathways in supported Ni nanoparticles. Micron 2012, 43, 1188-1194. [CrossRef] [PubMed]

85. Bagot, P.A.J.; Kreuzer, H.J.; Cerezo, A.; Smith, G.D.W. A model for oxidation-driven surface segregation and transport on Pt-alloys studied by atom probe tomography. Surf. Sci. 2011, 605, 1541-1546. [CrossRef] 
86. Crozier, P.A.; Hansen, T.W. In situ and operando transmission electron microscopy of catalytic materials. MRS Bull. 2015, 40, 38-45. [CrossRef]

87. Miller, M.K.M.K.; Cerezo, A.; Hetherington, M.G.G.; Smith, G.D.W.D.W. Atom Probe Field Ion Microscopy; Clarendon Press: Wotton-under-Edge, UK, 1996.

88. Barroo, C.; Bagot, P.A.J.; Smith, G.D.W.; Visart, T. Investigating nano-structured catalysts at the atomic scale by field ion microscopy and atom probe tomography. In Atomically-Precise Methods for Synthesis of Solid Catalysts; Royal Society of Chemistry: London, UK, 2015; pp. 248-295.

89. Gorodetskii, V.; Lauterbach, J.; Rotermund, H.H.; Block, J.H.; Ertl, G. Coupling between adjacent crystal planes in heterogeneous catalysis by propagating reaction-diffusion waves. Nature 1994, 370, 276-279. [CrossRef]

90. Müller, E. Field Ion Microscopy Principles and Applications; American Elsevier Pub.: Amsterdam, The Netherlands, 1969.

91. Gorodetskii, V.V.; Elokhin, V.I.; Bakker, J.W.; Nieuwenhuys, B.E. Field electron and field ion microscopy studies of chemical wave propagation in oscillatory reactions on platinum group metals. Catal. Today 2005, 105, 183-205. [CrossRef]

92. Barroo, C.; De Decker, Y.; Visart de Bocarmé, T.; Kruse, N. Complex oscillation patterns during the catalytic hydrogenation of $\mathrm{NO}_{2}$ over platinum nanosized crystals. J. Phys. Chem. C 2014, 118, 6839-6846. [CrossRef]

93. Barroo, C.; De Decker, Y.; Visart de Bocarmé, T.; Kruse, N. Emergence of chemical oscillations from nanosized target patterns. Phys. Rev. Lett. 2016, 144501, 1-5. [CrossRef] [PubMed]

94. Suchorski, Y.; Imbihl, R.; Medvedev, V.K. Compatibility of field emitter studies of oscillating surface reactions with single crystal measurements: Catalytic CO oxidation on Pt. Surf. Sci. 1998, 401, 392-399. [CrossRef]

95. Suchorski, Y.; Beben, J.; James, E.; Evans, J.; Imbihl, R. Fluctuation-induced transitions in a bistable surface reaction: Catalytic CO oxidation on a Pt field emitter tip. Phys. Rev. Lett. 1999, 82, 1907-1910. [CrossRef]

96. Suchorski, Y.; Beben, J.; Imbihl, R. Spatiotemporal dynamics of fluctuations in a surface reaction by Karhunen-Loeve decomposition of field emission images. Surf. Sci. 2000, 454, 331-336. [CrossRef]

97. Cobden, P.D.; Gorodetskii, V.V.; Nieuwenhuys, B.E. Field emission microscope study of the initial behaviour of the palladium-hydrogen system at low temperatures. Surf. Sci. 1999, 432, 61-68. [CrossRef]

98. Barroo, C.; Lambeets, S.V.; Devred, F.; Chau, T.D.; Kruse, N.; De Decker, Y.; Visart de Bocarmé, T. Hydrogenation of $\mathrm{NO}$ and $\mathrm{NO}_{2}$ over palladium and platinum nanocrystallites: Case studies using field emission techniques. New J. Chem. 2014, 38, 2090-2097. [CrossRef]

99. Ertl, G.; Rotermund, H.-H. Spatiotemporal pattern formation in reactions at surfaces. Curr. Opin. Solid State Mater. Sci. 1996, 1, 617-621. [CrossRef]

100. Engel, W.; Kordesch, M.E.; Rotermund, H.H.; Kubala, S.; von Oertzen, A. A UHV-compatible photoelectron emission microscope for applications in surface science. Ultramicroscopy 1991, 36, 148-153. [CrossRef]

101. Rotermund, H.H.; Engel, W.; Jakubith, S.; von Oertzen, A.; Ertl, G. Methods and application of UV photoelectron in heterogeneous catalysis microscopy. Ultramicroscopy 1991, 36, 164-172. [CrossRef]

102. Bauer, E. A brief history of PEEM. J. Electron. Spectrosc. Relat. Phenom. 2012, 185, 314-322. [CrossRef]

103. Rotermund, H.H. Real time imaging of catalytic reactions on surfaces: Past, present and future. Surf. Sci. 2009, 603, 1662-1670. [CrossRef]

104. Cobden, P.D.; De Wolf, C.A.; Smirnov, M.Y.; Makeev, A.; Nieuwenhuys, B.E. Non-linear processes on Pt, $\mathrm{Rh}, \mathrm{Pd}$, Ir and Ru surfaces during the NO-hydrogen reactions. J. Mol. Catal. A Chem. 2000, 158, 115-128. [CrossRef]

105. Bauer, E. Low energy electron microscopy. Rep. Prog. Phys. 1994, 57, 895-938. [CrossRef]

106. Święch, W.; Rausenberger, B.; Engel, W.; Bradshaw, A.M.; Zeitler, E. In-situ studies of heterogeneous reactions using mirror electron microscopy. Surf. Sci. 1993, 294, 297-307. [CrossRef]

107. Rausenberger, B.; Swiech, W.; Rastomjee, C.S.; Mundschau, M.; Engel, W.; Zeitler, E.; Bradshaw, A.M. Imaging reaction-diffusion fronts with low-energy electron microscopy. Chem. Phys. Lett. 1993, 215, 109-113. [CrossRef]

108. Rausenberger, B.; Święch, W.; Engel, W.; Bradshaw, A.M.; Zeitler, E. LEEM and selected-area LEED studies of reaction front propagation. Surf. Sci. 1993, 287, 235-240. [CrossRef]

109. Tromp, R.M.; Hannon, J.B.; Ellis, A.W.; Wan, W.; Berghaus, A.; Schaff, O. A new aberration-corrected, energy-filtered LEEM/PEEM instrument. I. Principles and design. Ultramicroscopy 2010, 110, 852-861. [CrossRef] [PubMed] 
110. McCarty, K.F.; Bartelt, N.C. Spatially resolved dynamics of the $\mathrm{TiO}_{2}(110)$ surface reconstruction. Surf. Sci. 2003, 540, 157-171. [CrossRef]

111. Kodambaka, S.; Israeli, N.; Bareño, J.; Święch, W.; Ohmori, K.; Petrov, I.; Greene, J.E. Low-energy electron microscopy studies of interlayer mass transport kinetics on TiN(111). Surf. Sci. 2004, 560, 53-62. [CrossRef]

112. Donald, A.M. The use of environmental scanning electron microscopy for imaging wet and insulating materials. Nat. Mater. 2003, 2, 511-516. [CrossRef] [PubMed]

113. Zheng, H.; Meng, Y.S.; Zhu, Y. Frontiers of in situ electron microscopy. MRS Bull. 2015, 40, 12-18. [CrossRef]

114. Yuan, W.; Yu, J.; Li, H.; Zhang, Z.; Sun, C.; Wang, Y. In situ TEM observation of dissolution and regrowth dynamics of $\mathrm{MoO}_{2}$ nanowires under oxygen. Nano Res. 2017, 10, 397-404. [CrossRef]

115. Gai, P.L.; Boyes, E.D. In situ TEM measurement methods. In Characterization of Materials; John Wiley \& Sons, Inc.: Hoboken, NJ, USA, 2012; pp. 1-11.

116. Alayoglu, S.; Beaumont, S.K.; Zheng, F.; Pushkarev, V.V.; Zheng, H.; Iablokov, V.; Liu, Z.; Guo, J.; Kruse, N.; Somorjai, G.A. $\mathrm{CO}_{2}$ hydrogenation studies on $\mathrm{Co}$ and $\mathrm{CoPt}$ bimetallic nanoparticles under reaction conditions using TEM, XPS and NEXAFS. Top. Catal. 2011, 54, 778-785. [CrossRef]

117. Zhang, X.; Kamino, T. Imaging gas-solid interactions in an atomic resolution environmental TEM. Micros. Today 2006, 16-18.

118. Boyes, E.D.; Gai, P.L. Environmental high resolution electron microscopy and applications to chemical science. Ultramicroscopy 1997, 67, 219-232. [CrossRef]

119. Gai, P.L.; Boyes, E.D.; Yoshida, K.; Hansen, T.W. Development of the atomic-resolution environmental transmission electron microscope. In Controlled Atmosphere Transmission Electron Microscopy; Springer: Berlin/Heidelberg, Germany, 2016; pp. 45-62.

120. Xin, H.L.; Niu, K.; Alsem, D.H.; Zheng, H. In situ TEM study of catalytic nanoparticle reactions in atmospheric pressure gas environment. Microsc. Microanal. 2013, 19, 1558-1568. [CrossRef] [PubMed]

121. Rotermund, H.H. Imaging of dynamic processes on surfaces by light. Surf. Sci. Rep. 1997, 29, $265-364$. [CrossRef]

122. Punckt, C.; Rotermund, H.H. Optical imaging of pattern formation: Reflection anisotropy microscopy applied to globally coupled oscillatory CO-oxidation. Phys. Chem. Chem. Phys. 2007, 9, 3635-3640. [CrossRef] [PubMed]

123. Zambelli, T.; Wintterlin, J.; Trost, J.; Ertl, G. Identification of the "active sites" of a surface-catalyzed reaction. Science 1996, 273, 1688-1690. [CrossRef]

124. Wintterlin, J.; Trost, J.; Renisch, S.; Schuster, R.; Zambelli, T.; Ertl, G. Real-time STM observations of atomic equilibrium fluctuations in an adsorbate system: O/Ru(0001). Surf. Sci. 1997, 394, 159-169. [CrossRef]

125. Hendriksen, B.L.M.; Frenken, J.W.M. CO oxidation on $\mathrm{Pt}(110)$ : Scanning tunneling microscopy inside a high-pressure flow reactor. Phys. Rev. Lett. 2002, 89, 1-4. [CrossRef] [PubMed]

126. Helveg, S.; Lauritsen, J.; Laegsgaard, E.; Stensgaard, I.; Norskov, J.; Clausen, B.; Topsoe, H.; Besenbacher, F. Atomic-scale structure of single-layer $\mathrm{MoS}_{2}$ nanoclusters. Phys. Rev. Lett. 2000, 84, 951-954. [CrossRef] [PubMed]

127. Wintterlin, J. Scanning tunneling microscopy studies of catalytic reactions. Adv. Catal. 2000, 45, 131-206.

128. Zhu, Z.; Barroo, C.; Lichtenstein, L.; Eren, B.; Wu, C.H.; Mao, B.; Visart de Bocarmé, T.; Liu, Z.; Kruse, N.; Salmeron, M.; et al. Influence of step geometry on the reconstruction of stepped platinum surfaces under coadsorption of ethylene and CO. J. Phys. Chem. Lett. 2014, 5, 2626-2631. [CrossRef] [PubMed]

129. Barroo, C.; Gilis, N.; Lambeets, S.V.; Devred, F.; Visart de Bocarmé, T. Oxygen assisted reconstructions of rhodium and platinum nanocrystals and their effects on local catalytic activity of hydrogenation reactions. Appl. Surf. Sci. 2014, 304, 2-10. [CrossRef]

130. Ast, D.G.; Seidman, D.N. The field ion microscopy of gold. Appl. Phys. Lett. 1968, 13, 348-350. [CrossRef]

131. Schmid, T.E.; Balluffi, R.W. Formation and migration of artifact vacancies induced on gold surfaces by neon field ion microscopy. Surf. Sci. 1971, 28, 574-580. [CrossRef]

132. Nam, A.J.; Teren, A.; Lusby, T.A.; Melmed, A.J. Benign making of sharp tips for STM and FIM-Pt, Ir, Au, Pd, and Rh. J. Vac. Sci. Technol. B 1995, 13, 1556-1559. [CrossRef]

133. Eisele, M.; Krger, M.; Schenk, M.; Ziegler, A.; Hommelhoff, P. Note: Production of sharp gold tips with high surface quality. Rev. Sci. Instrum. 2011, 82, 20-22. [CrossRef] [PubMed]

134. Sakata, T.; Fujioka, H.; Sakai, A. Confinement of surface state electrons on $\mathrm{Cu}$ and Au field emitters. Ultramicroscopy 2001, 89, 89-94. [CrossRef] 
135. Nomura, K.; Rokuta, E.; Itagaki, T.; Oshima, C.; Kuo, H.; Tsong, T.T. Electron emission characteristics of Au-covered tungsten $<111>$ nanotips. e-Journal Surf. Sci. Nanotechnol. 2008, 6, 25-28. [CrossRef]

136. Plsek, J. Field emission study of pulsed laser deposition of gold on clean and oxidized tungsten tip. Appl. Surf. Sci. 2014, 292, 717-725. [CrossRef]

137. Bryl, R.; Błaszczyszyn, R.; Galewska, E. Interaction of water with clean and gold-precovered tungsten field emitters: Adsorption and desorption. Vacuum 1997, 48, 329-332. [CrossRef]

138. Visart de Bocarmé, T.; Moors, M.; Kruse, N.; Atanasov, I.S.; Hou, M.; Cerezo, A.; Smith, G.D.W. Surface segregation of Au-Pd alloys in UHV and reactive environments: Quantification by a catalytic atom probe. Ultramicroscopy 2009, 109, 619-624. [CrossRef] [PubMed]

139. Sobyanin, V.; Gorodetskii, V.; Bulgakov, N. Oxygen adsorption on silver-gold alloy. React. Kinet. Catal. Lett. 1977, 7, 285-290. [CrossRef]

140. Moors, M.; Amara, H.; Visart de Bocarmé, T.; Bichara, C.; Ducastelle, F.; Kruse, N.; Charlier, J.C. Early stages in the nucleation process of carbon nanotubes. ACS Nano 2009, 3, 511-516. [CrossRef] [PubMed]

141. Van Tol, M.F.H.; Gielbert, A.; Nieuwenhuys, B.E. Oscillatory behaviour of the reduction of $\mathrm{NO}$ by $\mathrm{H}_{2}$ over Rh. Catal. Lett. 1992, 16, 297-309. [CrossRef]

142. Visart de Bocarmé, T.; Kruse, N. Kinetic instabilities during the NOx reduction with hydrogen on Pt crystals studied with field emission on the nanoscale. Chaos 2002, 12, 118-130. [CrossRef] [PubMed]

143. Imbihl, R.; Ertl, G. Oscillatory kinetics in heterogeneous catalysis. Chem. Rev. 1995, 95, 697-733. [CrossRef]

144. Mc Ewen, J.-S.; Gaspard, P.; De Decker, Y.; Barroo, C.; Visart de Bocarmé, T.; Kruse, N. Catalytic reduction of $\mathrm{NO}_{2}$ with hydrogen on Pt field emitter tips: Kinetic instabilities on the nanoscale. Langmuir 2010, 26, 16381-16391. [CrossRef] [PubMed]

145. Barroo, C.; De Decker, Y.; Visart de Bocarmé, T.; Gaspard, P. Fluctuating dynamics of nanoscale chemical oscillations: Theory and experiments. J. Phys. Chem. Lett. 2015, 6, 2189-2193. [CrossRef] [PubMed]

146. Barroo, C.; De Decker, Y.; Jacobs, L.; Visart de Bocarmé, T. Nonlinear behavior during NO2 hydrogenation on a nanosized Pt-Rh catalyst sample. Appl. Surf. Sci. 2017, 412, 564-570. [CrossRef]

147. Kruse, N.; Gaussmann, A. Changes in the morphology of Rh field emitter tips due to the reaction with carbon monoxide. Surf. Sci. 1992, 266, 51-55. [CrossRef]

148. Moors, M.; Visart de Bocarmé, T.; Kruse, N. Surface reaction kinetics studied with nanoscale lateral resolution. Catal. Today 2007, 124, 61-70. [CrossRef]

149. Miller, M.K. Development of atom probe field-ion microscopy. Mater. Charact. 2000, 44, 11-27. [CrossRef]

150. Moody, M.P.; Vella, A.; Gerstl, S.S.A.; Bagot, P.A.J. Advances in atom probe tomography instrumentation: Implications for materials research. MRS Bull. 2016, 41, 40-45. [CrossRef]

151. Bagot, P.A.J.; Visart de Bocarmé, T.; Cerezo, A.; Smith, G.D.W. 3D atom probe study of gas adsorption and reaction on alloy catalyst surfaces I: Instrumentation. Surf. Sci. 2006, 600, 3028-3035. [CrossRef]

152. Ernst, N.; Bozdech, G.; Block, J.H. Filed Ion appearance spectroscopy: Investigations on ion generating processes at fiels emitter surfaces. Surf. Sci. 1979, 80, 645-655. [CrossRef]

153. Locatelli, A.; Heun, S.; Kiskinova, M. Direct observation of reaction-induced lateral redistribution of sub-monolayers of Au deposited on a Rh(110) surface. Surf. Sci. 2004, 566, 1130-1136. [CrossRef]

154. Bauer, E. LEEM basics. Surf. Rev. Lett. 1998, 5, 1275-1286. [CrossRef]

155. Schmidt, T.; Heun, S.; Slezak, J.; Diaz, J.; Prince, K.C.; Lilienkamp, G.; Bauer, E. SPELEEM: Combining LEEM and spectroscopic imaging. Surf. Rev. Lett. 1998, 5, 1287-1296. [CrossRef]

156. Yamaguchi, Y.; Takakusagi, S.; Sakai, Y.; Kato, M.; Asakura, K.; Iwasawa, Y. X-ray photoemission electron microscopy (XPEEM) as a new promising tool for the real-time chemical imaging of active surfaces. J. Mol. Catal. A Chem. 1999, 141, 129-137. [CrossRef]

157. Bauer, E.; Mundschau, M.; Swiech, W.; Telieps, W. Surface studies by low-energy electron microscopy (LEEM) and conventional UV photoemission electron microscopy (PEEM). Ultramicroscopy 1989, 31, 49-57. [CrossRef]

158. Nettesheim, S.; von Oertzen, A.; Rotermund, H.H.; Ertl, G. Reaction diffusion patterns in the catalytic CO-oxidation on Pt(110): Front propagation and spiral waves. J. Chem. Phys. 1993, 98, 9977-9985. [CrossRef]

159. Günther, S.; Kolmakov, A.; Kovac, J.; Marsi, M.; Kiskinova, M. Au on Ag/Si(111)-(3 × 3)R30 : A spectromicroscopy study of a bimetal-silicon interface. Phys. Rev. B 1997, 56, 5003-5013. [CrossRef]

160. Suchorski, Y.; Spiel, C.; Vogel, D.; Drachsel, W.; Schlögl, R.; Rupprechter, G. Local reaction kinetics by imaging: CO oxidation on polycrystalline platinum. ChemPhysChem 2010, 11, 3231-3235. [CrossRef] [PubMed] 
161. Suchorski, Y.; Rupprechter, G. Local reaction kinetics by imaging. Surf. Sci. 2016, 643, 52-58. [CrossRef] [PubMed]

162. Locatelli, A.; Kiskinova, M. Imaging with chemical analysis: Adsorbed structures formed during surface chemical reactions. Chem. A Eur. J. 2006, 12, 8890-8896. [CrossRef] [PubMed]

163. Aballe, L.; Barinov, A.; Locatelli, A.; Heun, S.; Kiskinova, M. Tuning surface reactivity via electron quantum confinement. Phys. Rev. Lett. 2004, 93, 5-8. [CrossRef] [PubMed]

164. Locatelli, A.; Bauer, E. Recent advances in chemical and magnetic imaging of surfaces and interfaces by XPEEM. J. Phys. Condens. Matter 2008, 20, 1-22. [CrossRef]

165. Podor, R.; Ravaux, J.; Brau, H.-P. In situ experiments in the scanning electron microscope chamber. In Scanning Electron Microscopy; inTech: Rijeka, Croatia, 2012; pp. 31-35.

166. Kamino, T.; Yaguchi, T.; Watabe, A.; Saka, H.; Kishita, K. Environmental transmission electron microscopy using a conventional TEM and a gas injection-specimen heating holder. Microsc. Microanal. 2006, 12, 766-767. [CrossRef]

167. Saka, H.; Mima, T.; Takeuchi, Y.; Marukawa, T.; Arai, S.; Kuroda, K.; Kishita, K.; Kamino, T. Observation of gas-solid and gas-liquid Reactions by In-situ environmental holder in TEM. Microsc. Microanal. 2006, 12, 764-766. [CrossRef]

168. Sharma, R.; Crozier, P.A. Environmental transmission electron microscopy in nanotechnology. Handb. Microsc. Nanotechnol. 2005, 531-565.

169. Williams, D.B.; Barry Carter, C. Transmission Electron Microscopy. Diffraction, Imaging, Spectroscopy; Springer: Berlin/Heidelberg, Germany, 2009.

170. Crozier, P.A.; Chenna, S. In situ analysis of gas composition by electron energy-loss spectroscopy for environmental transmission electron microscopy. Ultramicroscopy 2011, 111, 177-185. [CrossRef] [PubMed]

171. Tao, F.; Crozier, P.A. Atomic-scale observations of catalyst structures under reaction conditions and during catalysis. Chem. Rev. 2016, 116, 3487-3539. [CrossRef] [PubMed]

172. Chenna, S.; Banerjee, R.; Crozier, P.A. Atomic-scale observation of the Ni activation process for partial oxidation of methane using in situ environmental TEM. ChemCatChem 2011, 3, 1051-1059. [CrossRef]

173. Hansen, P.L. Atom-resolved imaging of dynamic shape changes in supported copper nanocrystals. Science 2002, 295, 2053-2055. [CrossRef] [PubMed]

174. Rotermund, H.H.; Engel, W.; Kordesch, M.; Ertl, G. Imaging of spatio-temporal pattern evolution during carbon monoxide oxidation on platinum. Nature 1990, 343, 355-357. [CrossRef]

175. Rotermund, H.H.; Jakubith, S.; Von Oertzen, A.; Ertl, G. Solitons in a surface reaction. Phys. Rev. Lett. 1991, 66, 3083-3086. [CrossRef] [PubMed]

176. Rotermund, H.H. Imaging of dynamic patterns on surfaces. Curr. Opin. Solid State Mater. Sci. 1998, 3, 354-360. [CrossRef]

177. Ertl, G. Reactions at surfaces: From atoms to complexity. Angew. Chem. Int. Ed. 2008, 47, 3524-3535. [CrossRef] [PubMed]

178. Asakura, K.; Lauterbach, J.; Rotermund, H.H.; Ertl, G. Modification of spatiotemporal pattern formation in an excitable medium by continuous variation of its intrinsic parameters: CO oxidation on Pt(110). Phys. Rev. B 1994, 50, 8043-8046. [CrossRef]

179. Asakura, K.; Lauterbach, J.; Rotermund, H.H.; Ertl, G. Spatiotemporal concentration patterns associated with the catalytic oxidation of CO and Au covered Pt(110) surfaces. J. Chem. Phys. 1995, 102, 8175-8184. [CrossRef]

180. Ertl, G. Dynamics of catalytic processes on atomic and mesoscopic scale. Appl. Surf. Sci. 1997, 121, 20-25. [CrossRef]

181. Asakura, K.; Lauterbach, J.; Rotermund, H.H.; Ertl, G. Spatio-temporal pattern formation during catalytic CO oxidation on a Pt(100) surface modified with submonolayers of Au. Surf. Sci. 1997, 374, 125-141. [CrossRef]

182. Locatelli, A.; Sbraccia, C.; Heun, S.; Baroni, S.; Kiskinova, M. Energetically driven reorganization of a modified catalytic surface under reaction conditions. J. Am. Chem. Soc. 2005, 127, 2351-2357. [CrossRef] [PubMed]

183. Mertens, F.; Imbihl, R. Parameter-dependent anisotropy of front propagation in the $\mathrm{H}_{2}+\mathrm{O}_{2}$ reaction on Rh(110). Chem. Phys. Lett. 1995, 242, 221-227. [CrossRef]

184. Makeev, A.; Imbihl, R. Simulations of anisotropic front propagation in the $\mathrm{H}_{2}+\mathrm{O}_{2}$ reaction on a $\mathrm{Rh}(110)$ surface. J. Chem. Phys. 2000, 113, 3854-3863. [CrossRef] 
185. Locatelli, A.; Mentes, T.O.; Aballe, L.; Mikhailov, A.; Kiskinova, M. Formation of regular surface-supported mesostructures with periodicity controlled by chemical reaction rate. J. Phys. Chem. B 2006, 110, 19108-19111. [CrossRef] [PubMed]

186. Locatelli, A.; Aballe, L.; Mentes, T.O.; Guo, F.Z.; Kiskinova, M. A spectro-microscopic study of the reactive phase separation of $\mathrm{Au}+\mathrm{Pd}$ and $\mathrm{O}$ on $\mathrm{Rh}(110)$. Surf. Sci. 2007, 601, 4663-4668. [CrossRef]

187. Johannesson, G.H.; Bligaard, T.; Ruban, A.V.; Skriver, H.L.; Jacobsen, K.W.; Norskov, J.K. Combined electronic structure and evolutionary search approach to materials design. Phys. Rev. Lett. 2002, 88, 2555061-2555065. [CrossRef] [PubMed]

188. De Decker, Y.; Marbach, H.; Hinz, M.; Gunther, S.; Kiskinova, M.; Mikhailov, A.S.; Imbihl, R. Promoter-induced reactive phase separation in surface reactions. Phys. Rev. Lett. 2004, 92, 198305. [CrossRef] [PubMed]

189. De Decker, Y.; Mikhailov, A.S. Promoter-induced nonlinear pattern formation in surface chemical reactions. J. Phys. Chem. B 2004, 108, 14759-14765. [CrossRef]

190. Grinter, D.C.; Muryn, C.; Santos, B.; Shaw, B.J.; Menteş, T.O.; Locatelli, A.; Thornton, G. Spectromicroscopy of a model water-gas shift catalyst: Gold nanoparticles supported on ceria. J. Phys. Chem. C 2014, 118, 19194-19204. [CrossRef]

191. Lamallem, M.; El Ayadi, H.; Gennequin, C.; Cousin, R.; Siffert, S.; Aïssi, F.; Aboukaïs, A. Effect of the preparation method on Au/Ce-Ti-O catalysts activity for VOCs oxidation. Catal. Today 2008, 137, 367-372. [CrossRef]

192. Nolan, M.; Parker, S.C.; Watson, G.W. Reduction of $\mathrm{NO}_{2}$ on ceria surfaces. J. Phys. Chem. B 2006, 110, 2256-2262. [CrossRef] [PubMed]

193. Guzman, J.; Carrettin, S.; Fierro-Gonzalez, J.C.; Hao, Y.; Gates, B.C.; Corma, A. CO oxidation catalyzed by supported gold: Cooperation between gold and nanocrystalline rare-earth supports forms reactive surface superoxide and peroxide species. Angew. Chem. Int. Ed. 2005, 44, 4778-4781. [CrossRef] [PubMed]

194. Carrettin, S.; Guzman, J.; Corma, A. Supported gold catalyzes the homocoupling of phenylboronic acid with high conversion and selectivity. Angew. Chem. Int. Ed. 2005, 44, 2242-2245. [CrossRef] [PubMed]

195. Nishiyama, H.; Inoue, Y. PEEM study of work function changes in $\mathrm{Cu}, \mathrm{Au}$ and $\mathrm{Pd}$ metal surfaces with surface acoustic wave propagation. Surf. Sci. 2006, 600, 2644-2649. [CrossRef]

196. Visart de Bocarmé, T.; Chau, T.-D.; Kruse, N. The interaction of CO-O ${ }_{2}$ gas mixtures with Au tips: In situ imaging and local chemical probing. Surf. Interface Anal. 2007, 39, 166-171. [CrossRef]

197. Bär, T.; Visart de Bocarmé, T.; Nieuwenhuys, B.E.; Kruse, N. CO oxidation on gold surfaces studied on the atomic scale. Catal. Lett. 2001, 74, 127-131. [CrossRef]

198. Gorodetskii, V.; Drachsel, W.; Block, J.H. The surface specificity of the oscillating CO oxidation on platinum investigated by field ion microscopy. Appl. Surf. Sci. 1994, 76, 122-128. [CrossRef]

199. Chau, T.D.; Visart de Bocarmé, T.; Kruse, N.; Wang, R.L.C.; Kreuzer, H.J. Formation of neutral and charged gold carbonyls on highly facetted gold nanostructures. J. Chem. Phys. 2003, 119, 12605-12610. [CrossRef]

200. Visart de Bocarmé, T.; Chau, T.D.; Tielens, F.; Andrés, J.; Gaspard, P.; Wang, R.L.C.; Kreuzer, H.J.; Kruse, N. Oxygen adsorption on gold nanofacets and model clusters. J. Chem. Phys. 2006, 125, 1-7. [CrossRef] [PubMed]

201. Visart de Bocarmé, T.; Kruse, N.; Gaspard, P.; Kreuzer, H.J. Field-induced CO adsorption and formation of carbonyl waves on gold nanotips. J. Chem. Phys. 2006, 125, 1-7. [CrossRef] [PubMed]

202. Schmidt, W.A.; Suchorski, Y.; Block, J.H.; Kreuzer, H.J.; Wang, R.L.C. Field ion appearance energy spectroscopy of $\mathrm{CO}^{+}$originated from $\mathrm{Rh}(111)$ and $\mathrm{Au}(111)$ surface step sites. Surf. Sci. 1995, 326, $243-251$. [CrossRef]

203. Taketoshi, A.; Haruta, M. Size- and structure-specificity in catalysis by gold clusters. Chem. Lett. 2014, 43, 380-387. [CrossRef]

204. Visart de Bocarmé, T.; Chau, T.D.; Kruse, N. Dynamic interaction of $\mathrm{CO} / \mathrm{H}_{2} \mathrm{O}$ mixtures with gold nanocrystals: Real-time imaging and local chemical probing. Surf. Sci. 2006, 600, 4205-4210. [CrossRef]

205. Chesters, M.A.; Somorjai, G.A. The chemisorption of oxygen, water and selected hydrocarbons on the (111) and stepped gold surfaces. Surf. Sci. 1975, 52, 21-28. [CrossRef]

206. Schrader, M.E. Chemisorption of oxygen to gold: AES study of catalytic effect of calcium. Surf. Sci. 1978, 78, 227-232. [CrossRef] 
207. Pireaux, J.J.; Chtaib, M.; Delrue, J.P.; Thiry, P.A.; Liehr, M.; Caudano, R. Electron spectroscopic characterization of oxygen adsorption on gold surfaces. Surf. Sci. 1984, 141, 211-220. [CrossRef]

208. Tielens, F.; Andrés, J.; Chau, T.D.; Visart de Bocarmé, T.; Kruse, N.; Geerlings, P. Molecular oxygen adsorption on electropositive nano gold tips. Chem. Phys. Lett. 2006, 421, 433-438. [CrossRef]

209. McEwen, J.S.; Gaspard, P. CO oxidation on electrically charged gold nanotips. J. Chem. Phys. 2006, 125, 1-11. [CrossRef] [PubMed]

210. Andreev, A.; Andreeva, D.; Idakiev, V.; Tabakova, T. Low-temperature water-gas shift reaction over $\mathrm{Au} / \alpha-\mathrm{Fe}_{2} \mathrm{O}_{3}$. J. Catal. 1996, 158, 354-355. [CrossRef]

211. Andreeva, D. Low temperature water gas shift over gold catalysts. Gold Bull. 2002, 35, 82-88. [CrossRef]

212. Costello, C.K.; Yang, J.H.; Law, H.Y.; Wang, Y.; Lin, J.; Marks, L.D.; Kung, M.C.; Kung, H.H. On the potential role of hydroxyl groups in $\mathrm{CO}$ oxidation over $\mathrm{Au} / \mathrm{Al}_{2} \mathrm{O}_{3}$. Appl. Catal. A Gen. 2003, 243, 15-24. [CrossRef]

213. Daniells, S.; Overweg, A.; Makkee, M.; Moulijn, J. The mechanism of low-temperature CO oxidation with $\mathrm{Au} / \mathrm{Fe}_{2} \mathrm{O}_{3}$ catalysts: A combined Mössbauer, FT-IR, and TAP reactor study. J. Catal. 2005, 230, 52-65. [CrossRef]

214. Bryl, R. Diffusion of $\mathrm{H}_{2} \mathrm{O}$ on surfaces of clean and Au covered tungsten field emitters. Vacuum 1997, 48, 333-335. [CrossRef]

215. Bryl, R.; Błaszczyszyn, R. Surface diffusion of water on clean and Au-covered tungsten field emitter tips. Vacuum 1999, 54, 103-112. [CrossRef]

216. Cetronio, A.; Jones, J.P. A study by high field microscopy of the effect of substrate surface structure on the work function of layers of group $1 \mathrm{~b}$ metals adsorbed on tungsten. Surf. Sci. 1974, 44, 109-128. [CrossRef]

217. Zugic, B.; Wang, L.; Heine, C.; Zakharov, D.N.; Lechner, B.A.J.; Stach, E.A.; Biener, J.; Salmeron, M.; Madix, R.J.; Friend, C.M. Dynamic restructuring drives catalytic activity on nanoporous gold-silver alloy catalysts. Nat. Mater. 2016, 1. [CrossRef] [PubMed]

218. Barroo, C.; Montemore, M.M.; Janvelyan, N.; Zugic, B.; Akey, A.J.; Magyar, A.P.; Ye, J.; Kaxiras, E.; Biener, J.; Bell, D.C. Macroscopic 3D nanoporosity formation by dry oxidation of AgAu alloys. J. Phys. Chem. C 2017, 121, 5115-5122. [CrossRef]

219. Nga, N.L.T.; Potvin, C.; Djéga-Mariadassou, G.; Delannoy, L.; Louis, C. Catalytic reduction of nitrogen monoxide by propene in the presence of excess oxygen over gold based ceria catalyst. Top. Catal. 2007, 42-43, 91-94. [CrossRef]

220. More, P.M.; Nguyen, D.L.; Granger, P.; Dujardin, C.; Dongare, M.K.; Umbarkar, S.B. Activation by pretreatment of $\mathrm{Ag}-\mathrm{Au} / \mathrm{Al}_{2} \mathrm{O}_{3}$ bimetallic catalyst to improve low temperature HC-SCR of NOx for lean burn engine exhaust. Appl. Catal. B Environ. 2015, 174, 145-156. [CrossRef]

221. Chau, T.-D.; Visart de Bocarmé, T.; Kruse, N. Formation of $\mathrm{N}_{2} \mathrm{O}$ and $(\mathrm{NO})_{2}$ during $\mathrm{NO}$ adsorption on Au 3D crystals. Catal. Lett. 2004, 98, 85-87. [CrossRef]

222. Burch, R.; Shestov, A.A.; Sullivan, J.A. A steady-state isotopic transient kinetic analysis of the $\mathrm{NO} / \mathrm{O}_{2} / \mathrm{H}_{2}$ reaction over Pt $/ \mathrm{SiO}_{2}$ catalysts. J. Catal. 1999, 188, 69-82. [CrossRef]

223. Burch, R.; Shestov, A.A.; Sullivan, J.A. A steady-state isotopic transient kinetic analysis of the $\mathrm{NO} / \mathrm{O}_{2} / \mathrm{H}_{2}$ reaction over $\mathrm{Pt} / \mathrm{SiO}_{2}$ catalysts 1 . Isotopic transient kKinetics and temperature programmed analysis. J. Catal. 1999, 186, 353-361. [CrossRef]

224. Wei, C.; Seidman, D.N. The stage II recovery behavior of a series of ion-irradiated platinum (gold) alloys as studied by field-ion microscopy. Radiat. Eff. 1977, 32, 229-249. [CrossRef]

225. Ivchenko, V.A. Field ion microscopy of phase transformations in a $\mathrm{Cu}_{2} \mathrm{Au}(\mathrm{Pt}, \mathrm{Pd}, \mathrm{Ag})$ alloy. Surf. Sci. 1992, 276, 273-280. [CrossRef]

226. Miller, M.K.; Russell, K.F.; Jostsons, A.; Blake, R.G. Characterization of neutron-irradiated FeAu alloys. Appl. Surf. Sci. 1995, 87, 216-222. [CrossRef]

227. Bernatskii, D.P.; Pavlov, V.G. Field desorption of a potassium-gold film on tungsten. Phys. Solid State 2004, 46, 1538-1541. [CrossRef]

228. Nomura, K.; Nagao, T.; Cho, B.L.; Katsuda, H.; Matsumura, T.; Oshima, C. Thermodynamically stable nanotips of Au-Mo alloy. J. Vac. Sci. Technol. B Microelectron. Nanom. Struct. 2009, 27, 2432-2434. [CrossRef]

229. Carrasquillo-Flores, R.; Ro, I.; Kumbhalkar, M.D.; Burt, S.; Carrero, C.A.; Alba-Rubio, A.C.; Miller, J.T.; Hermans, I.; Huber, G.W.; Dumesic, J.A. Reverse water-gas shift on interfacial sites formed by deposition of oxidized molybdenum moieties onto gold nanoparticles. J. Am. Chem. Soc. 2015, 137, 10317-10325. [CrossRef] [PubMed] 
230. Ro, I.; Carrasquillo-Flores, R.; Dumesic, J.A.; Huber, G.W. Intrinsic kinetics of plasmon-enhanced reverse water gas shift on Au and Au-Mo interfacial sites supported on silica. Appl. Catal. A Gen. 2016, 521, 182-189. [CrossRef]

231. Martirez, J.M.P.; Carter, E.A. Thermodynamic constraints in using AuM (M = Fe, Co, Ni, and Mo) alloys as $\mathrm{N}_{2}$ dissociation catalysts: Functionalizing a plasmon-active metal. ACS Nano 2016, 10, 2940-2949. [CrossRef] [PubMed]

232. Jahn, S.; Lechner, S.J.; Freichels, H.; Möller, M.; Spatz, J.P. Precise $\mathrm{Au}_{\mathrm{x}} \mathrm{Pt}_{1-\mathrm{x}} \mathrm{Alloy}$ Nanoparticle Array of Tunable Composition for Catalytic Applications. Nature 2016, 6, 1-8.

233. Cui, H.-Z.; Guo, Y.; Wang, X.; Jia, C.-J.; Si, R. Gold-iron oxide catalyst for CO oxidation: Effect of support structure. Catalysts 2016, 6, 1-13. [CrossRef]

234. Son, U.T.; Hren, J.J. Field-ion microscopy of ordered Cu-Au alloy. J. Appl. Phys. 1971, 42, 5895-5896. [CrossRef]

235. Cao, Z.; Guo, L.; Liu, N. A theoretical study of the water-gas-shift reaction on $\mathrm{Cu}_{6} \mathrm{TM}(\mathrm{TM}=\mathrm{Co}, \mathrm{Ni}, \mathrm{Cu}, \mathrm{Rh}$, Pd, Ag, Ir, Pt, Au) clusters. J. Clust. Sci. 2016, 27, 523-535. [CrossRef]

236. Saqlain, M.A.; Hussain, A.; Siddiq, D.M.; Leenaerts, O.; Leitao, A.A. DFT study of synergistic catalysis of the water-gas-shift reaction on Cu-Au bimetallic surfaces. Chem CatChem 2016, 8, 1208-1217. [CrossRef]

237. Klesper, G.; Röllgen, F.W. Field ionization behavior of cyclohexane on Au tips. Int. J. Mass Spectrom. 1999, 185-187, 189-194. [CrossRef]

238. Castro, T. Studies of individual nanometer-sized metallic clusters using scanning tunneling microscopy, field emission, and field ion microscopy. J. Vac. Sci. Technol. A 1989, 7, 2845. [CrossRef]

239. Lovall, D.; Buss, M.; Andres, R.; Reifenberger, R. Resolving the atomic structure of supported nanometer-size Au clusters. Phys. Rev. B 1998, 58, 889-896. [CrossRef]

240. Akita, T.; Okumura, M.; Tanaka, K.; Kohyama, M.; Haruta, M. TEM observation of gold nanoparticles deposited on cerium oxide. J. Mater. Sci. 2005, 40, 3101-3106. [CrossRef]

241. Akita, T.; Kohyama, M.; Haruta, M. Electron microscopy study of gold nanoparticles deposited on transition metal oxides. Acc. Chem. Res. 2013, 46, 1773-1782. [CrossRef] [PubMed]

242. Liu, Y.; Sun, Y. Electron beam induced evolution in $\mathrm{Au}, \mathrm{Ag}$, and interfaced heterogeneous $\mathrm{Au} / \mathrm{Ag}$ nanoparticles. Nanoscale 2015, 7, 13687-13693. [CrossRef] [PubMed]

243. Walsh, M.J.; Yoshida, K.; Pay, M.L.; Gai, P.L.; Boyes, E.D. On the effect of atomic structure on the activity and deactivation of catalytic gold nanoparticles. ChemCatChem 2012, 4, 1638-1644. [CrossRef]

244. Hansen, T.W.; Wagner, J.B. Environmental transmission electron microscopy in an aberration-corrected environment. Microsc. Microanal. 2012, 18, 684-690. [CrossRef] [PubMed]

245. Hansen, T.W.; Wagner, J.B. Catalysts under controlled atmospheres in the transmission electron microscope. ACS Catal. 2014, 4, 1673-1685. [CrossRef]

246. Gai, P.L.; Yoshida, K.; Ward, M.R.; Walsh, M.; Baker, R.T.; van de Water, L.; Watson, M.J.; Boyes, E.D. Visualisation of single atom dynamics in water gas shift reaction for hydrogen generation. Catal. Sci. Technol. 2016, 6, 2214-2227. [CrossRef]

247. Chen, M.S.; Goodman, D.W. The structure of catalytically active Au on titania. Science 2004, 306, $252-255$. [CrossRef] [PubMed]

248. Landman, U.; Yoon, B.; Zhang, C.; Heiz, U.; Arenz, M. Factors in gold nanocatalysis: Oxidation of CO in the non-scalable size regime. Top. Catal. 2007, 44, 145-158. [CrossRef]

249. Aguilar-Guerrero, V.; Gates, B.C. Kinetics of $\mathrm{CO}$ oxidation catalyzed by highly dispersed $\mathrm{CeO}_{2}$-supported gold. J. Catal. 2008, 260, 351-357. [CrossRef]

250. Fujitani, T.; Nakamura, I. Mechanism and active sites of the oxidation of $\mathrm{CO}$ over $\mathrm{Au} / \mathrm{TiO}_{2}$. Angew. Chem. Int. Ed. 2011, 50, 10144-10147. [CrossRef] [PubMed]

251. Kuwauchi, Y.; Takeda, S.; Yoshida, H.; Sun, K.; Haruta, M.; Kohno, H. Stepwise displacement of catalytically active gold nanoparticles on cerium oxide. Nano Lett. 2013, 13, 3073-3077. [CrossRef] [PubMed]

252. Ta, N.; Liu, J.; Chenna, S.; Crozier, P.A.; Li, Y.; Chen, A.; Shen, W. Stabilized gold nanoparticles on ceria nanorods by strong interfacial anchoring. J. Am. Chem. Soc. 2012, 134, 20585-20588. [CrossRef] [PubMed]

253. Kuwauchi, Y.; Yoshida, H.; Akita, T.; Haruta, M.; Takeda, S. Intrinsic catalytic structure of gold nanoparticles supported on $\mathrm{TiO}_{2}$. Angew. Chem. Int. Ed. 2012, 51, 7729-7733. [CrossRef] [PubMed] 
254. Ueda, K.; Kawasaki, T.; Hasegawa, H.; Tanji, T.; Ichihashi, M. First observation of dynamic shape changes of a gold nanoparticle catalyst under reaction gas environment by transmission electron microscopy. Surf. Interface Anal. 2008, 40, 1725-1727. [CrossRef]

255. Giorgio, S.; Sao Joao, S.; Nitsche, S.; Chaudanson, D.; Sitja, G.; Henry, C.R. Environmental electron microscopy (ETEM) for catalysts with a closed E-cell with carbon windows. Ultramicroscopy 2006, 106, 503-507. [CrossRef] [PubMed]

256. Giorgio, S.; Cabié, M.; Henry, C.R. Dynamic observations of Au catalysts by environmental electron microscopy. Gold Bull. 2008, 41, 167-173. [CrossRef]

257. Uchiyama, T.; Yoshida, H.; Kuwauchi, Y.; Ichikawa, S.; Shimada, S.; Haruta, M.; Takeda, S. Systematic morphology changes of gold nanoparticles supported on $\mathrm{CeO}_{2}$ during $\mathrm{CO}$ oxidation. Angew. Chem. Int. Ed. 2011, 50, 10157-10160. [CrossRef] [PubMed]

258. Yoshida, H.; Kuwauchi, Y.; Jinschek, J.R.; Sun, K.; Tanaka, S.; Kohyama, M.; Shimada, S.; Haruta, M.; Takeda, S. Visualizing gas molecules interacting with supported nanoparticulate catalysts at reaction conditions. Science 2011, 628, 317-319. [CrossRef] [PubMed]

259. Takeda, S.; Yoshida, H.; Kuwauchi, Y.; Sun, K.; Kohyama, M. Operand structural study of supported gold nanoparticulate catalysts by quantitative environmental transmission electron microscopy. Microsc. Microanal. 2012, 18, 1112-1113. [CrossRef]

260. Uchiyama, T.; Yoshida, H.; Kamiuchi, N. Correlation of catalytic activity with the morphology change of supported Au nanoparticles in gas. Surf. Sci. 2017, 659, 16-19. [CrossRef]

261. Biener, J.; Wittstock, A.; Baumann, T.F.; Weissmüller, J.; Bäumer, M.; Hamza, A.V. Surface chemistry in nanoscale materials. Materials 2009, 2, 2404-2428. [CrossRef]

262. Biener, J.; Biener, M.M.; Madix, R.J.; Friend, C.M. Nanoporous gold: Understanding the origin of the reactivity of a 21st century catalyst made by pre-columbian technology. ACS Catal. 2015, 5, 6263-6270. [CrossRef]

263. Personick, M.L.; Zugic, B.; Biener, M.M.; Biener, J.; Madix, R.J.; Friend, C.M. Ozone-activated nanoporous gold: A stable and storable material for catalytic oxidation. ACS Catal. 2015, 5, 4237-4241. [CrossRef]

264. Stowers, K.J.; Madix, R.J.; Biener, M.M.; Biener, J.; Friend, C.M. Facile ester synthesis on Ag-modified nanoporous Au: Oxidative coupling of ethanol and 1-Butanol under UHV conditions. Catal. Lett. 2015, 145, 1217-1223. [CrossRef]

265. Wang, L.-C.; Personick, M.L.; Karakalos, S.; Fushimi, R.; Friend, C.M.; Madix, R.J. Active sites for methanol partial oxidation on nanoporous gold catalysts. J. Catal. 2016, 344, 778-783. [CrossRef]

266. Falcucci, G.; Succi, S.; Montessori, A.; Melchionna, S.; Prestininzi, P.; Barroo, C.; Bell, D.C.; Biener, M.M.; Biener, J.; Zugic, B.; Kaxiras, E. Mapping reactive flow patterns in monolithic nanoporous catalysts. Microfluid. Nanofluidics 2016, 20, 105. [CrossRef]

267. Erlebacher, J.; Aziz, M.J.; Karma, A.; Dimitrov, N.; Sieradzki, K. Evolution of nanoporosity in dealloying. Nature 2001, 410, 450-453. [CrossRef] [PubMed]

268. Ding, Y.; Erlebacher, J. Nanoporous metals with controlled multimodal pore size distribution. J. Am. Chem. Soc. 2003, 125, 7772-7773. [CrossRef] [PubMed]

269. Chapman, C.A.R.; Chen, H.; Stamou, M.; Biener, J.; Biener, M.M.; Lein, P.J.; Seker, E. Nanoporous gold as a neutral interface coating: Effects of topography, surface chemistry, and feature size. ACS Appl. Mater. Interfaces 2015, 7, 7093-7100. [CrossRef] [PubMed]

270. Xu, C.; Su, J.; Xu, X.; Liu, P.; Zhao, H.; Tian, F.; Ding, Y. Low temperature CO oxidation over unsupported nanoporous gold. J. Am. Chem. Soc. 2007, 129, 42-43. [CrossRef] [PubMed]

271. Wittstock, A.; Biener, J.; Bäumer, M. Nanoporous gold: A new material for catalytic and sensor applications. Phys. Chem. Chem. Phys. 2010, 12, 12919-12930. [CrossRef] [PubMed]

272. Wittstock, A.; Zielasek, V.; Biener, J.; Friend, C.M.; Baumer, M. Nanoporous gold catalysts for selective methanol at low temperature. Science 2010, 327, 319-322. [CrossRef] [PubMed]

273. Wittstock, A.; Bäumer, M. Catalysis by unsupported skeletal gold catalysts. Acc. Chem. Res. 2014, 47, 731-739. [CrossRef] [PubMed]

274. Fujita, T.; Tokunaga, T.; Zhang, L.; Li, D.; Chen, L.; Arai, S.; Yamamoto, Y.; Hirata, A.; Tanaka, N.; Ding, Y.; Chen, M. Atomic observation of catalysis-induced nanopore coarsening of nanoporous gold. Nano Lett. 2014, 14, 1172-1177. [CrossRef] [PubMed] 
275. Zhu, X.Q.; Feng, Q.; Liu, D.Z.; Nie, A.M.; Liu, J.B.; Zhang, X.B.; Geng, L.M. In situ high resolution transmission electron microscopy investigation of deformation mechanism in sub-10-nm Au crystals. Mater. Sci. Technol. 2014, 30, 774-781. [CrossRef]

276. Baier, S.; Wittstock, A.; Damsgaard, C.D.; Diaz, A.; Reinhardt, J.; Benzi, F.; Shi, J.; Scherer, T.; Wang, D.; Kübel, C.; et al. Influence of gas atmospheres and ceria on the stability of nanoporous gold studied by environmental electron microscopy and in situ ptychography. RSC Adv. 2016, 6, 83031-83043. [CrossRef]

277. Fujita, T.; Guan, P.; McKenna, K.; Lang, X.; Hirata, A.; Zhang, L.; Tokunaga, T.; Arai, S.; Yamamoto, Y.; Tanaka, N.; et al. Atomic origins of the high catalytic activity of nanoporous gold. Nat. Mater. 2012, 11, 775-780. [CrossRef] [PubMed]

278. Tang, D.-M.; Liu, C.; Yu, W.-J.; Zhang, L.-L.; Hou, P.-X.; Li, J.-C.; Li, F.; Bando, Y.; Golberg, D.; Cheng, H.-M. Structural changes in iron oxide and gold catalysts during nucleation of carbon nanotubes studied by in situ transmission electron microscopy. ACS Nano 2014, 8, 292-301. [CrossRef] [PubMed]

279. Rath, A.; Juluri, R.R.; Satyam, P.V. Real time nanoscale structural evaluation of gold structures on $\mathrm{Si}(100)$ surface using in-situ transmission electron microscopy. J. Appl. Phys. 2014, 115, 1-5. [CrossRef]

280. Duchstein, L.D.L.; Damsgaard, C.D.; Hansen, T.W.; Wagner, J.B. Low-pressure ETEM studies of Au assisted $\mathrm{MgO}$ nanorod growth. J. Phys. Conf. Ser. 2014, 522, 1-4. [CrossRef]

281. Gamalski, A.D.; Tersoff, J.; Sharma, R.; Ducati, C.; Hofmann, S. Metastable crystalline AuGe catalysts formed during isothermal germanium nanowire growth. Phys. Rev. Lett. 2012, 108, 255702. [CrossRef] [PubMed]

282. Sharma, R.; Chee, S.W.; Herzing, A.; Miranda, R.; Rez, P. Evaluation of the role of Au in improving catalytic activity of Ni nanoparticles for the formation of one-dimensional carbon nanostructures. Nano Lett. 2011, 11, 2464-2471. [CrossRef] [PubMed]

283. Luo, L.; Kang, Y.; Liu, Z.; Yang, J.C.; Zhou, G. Effect of oxygen pressure on the initial oxidation behavior of $\mathrm{Cu}$ and $\mathrm{Cu}$-Au alloys. Mater. Res. Soc. Symp. Proc. 2011, 1318, 31-36. [CrossRef]

284. Luo, L.; Kang, Y.; Yang, J.C.; Zhou, G. Effect of gold composition on the orientations of oxide nuclei during the early stage oxidation of Cu-Au alloys. J. Appl. Phys. 2012, 111, 1-9. [CrossRef]

285. Zhou, G.W.; Eastman, J.A.; Birtcher, R.C.; Baldo, P.M.; Pearson, J.E.; Thompson, L.J.; Wang, L.; Yang, J.C. Composition effects on the early-stage oxidation kinetics of (001) Cu-Au alloys. J. Appl. Phys. 2007, 101, 1-6. [CrossRef]

286. Albrecht, W.; Van der Hoeven, J.E.; Deng, T.-S.; de Jongh, P.E.; van Blaaderen, A. Fully alloyed metal nanorods with highly tunable properties. Nanoscale 2017, 9, 2845-2851. [CrossRef] [PubMed]

287. Wu, J.; Shan, H.; Chen, W.; Gu, X.; Tao, P.; Song, C.; Shang, W.; Deng, T. In situ environmental TEM in imaging gas and liquid phase chemical reactions for materials research. Adv. Mater. 2016, 28, 9686-9712. [CrossRef] [PubMed]

288. Wu, J.; Gao, W.; Wen, J.; Miller, D.J.; Lu, P.; Zuo, J.M.; Yang, H. Growth of Au on Pt icosahedral nanoparticles revealed by low-dose in situ TEM. Nano Lett. 2015, 15, 2711-2715. [CrossRef] [PubMed]

289. Jungjohann, K.L.; Bliznakov, S.; Sutter, P.W.; Stach, E.A.; Sutter, E.A. In situ liquid cell electron microscopy of the solution growth of Au-Pd core-shell nanostructures. Nano Lett. 2013, 13, 2964-2970. [CrossRef] [PubMed]

290. Ring, E.A.; de Jonge, N. Microfluidic system for transmission electron microscopy. Microsc. Microanal. 2010, 16, 622-629. [CrossRef] [PubMed]

(c) 2017 by the authors. Licensee MDPI, Basel, Switzerland. This article is an open access article distributed under the terms and conditions of the Creative Commons Attribution (CC BY) license (http://creativecommons.org/licenses/by/4.0/). 